\title{
Senegal: Poverty Reduction Strategy Paper
}

Poverty Reduction Strategy Papers are prepared by member countries in broad consultation with stakeholders and development partners, including the staffs of the World Bank and the IMF. Updated with annual progress reports, they describe the countries macroeconomic, structural, and social policies in support of growth and poverty reduction, as well as associated external financing needs and major sources of financing. This country document for Senegal is being made available on the IMF website by agreement of the member country as a service to users of the IMF website.

Copies of this report are available to the public from

International Monetary Fund • Publication Services

$70019^{\text {th }}$ Street, N.W. $\bullet$ Washington, D.C. 20431

Telephone: (202) 623-7430 • Telefax: (202) 623-7201

E-mail: publications@imf.org Internet: http://www.imf.org

\section{International Monetary Fund Washington, D.C.}




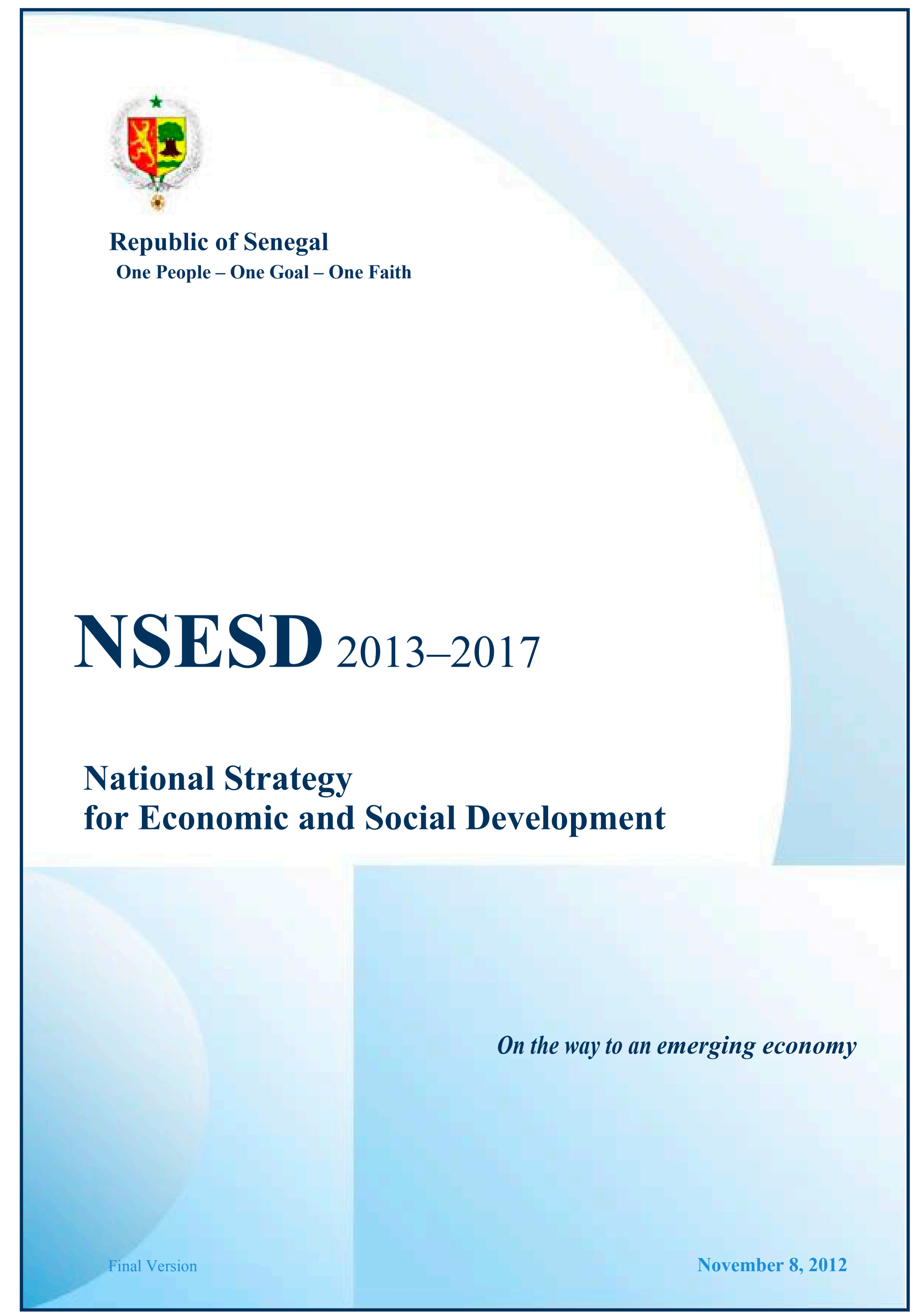




\section{Contents}

Introduction: General economic and social policy context ..........................................................

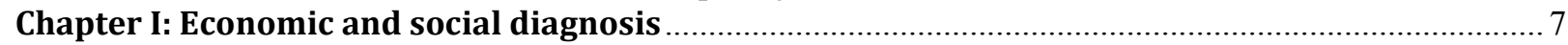

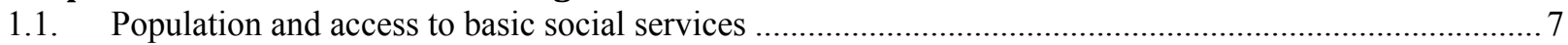

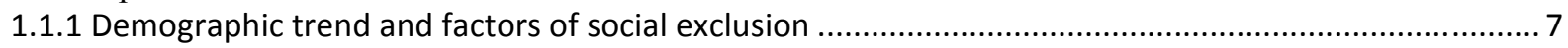

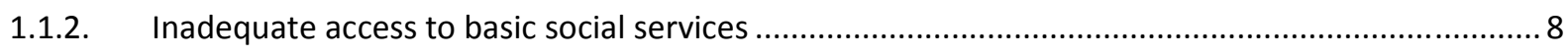

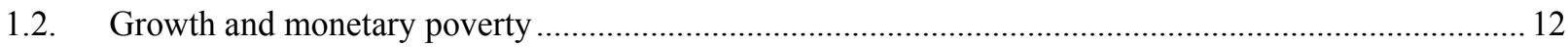

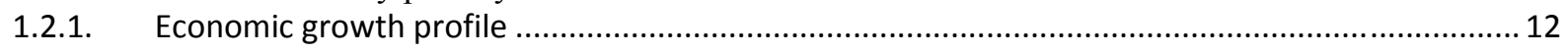

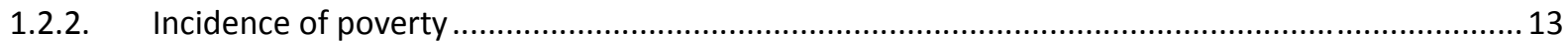

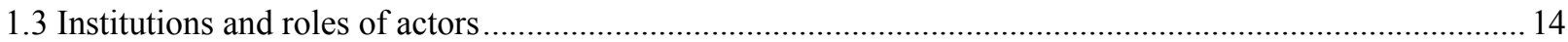

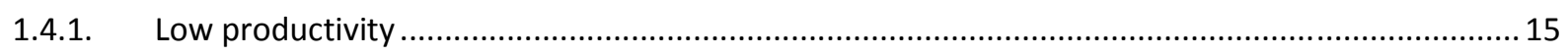

1.4.2. Underdeveloped human capital ...................................................................................... 17

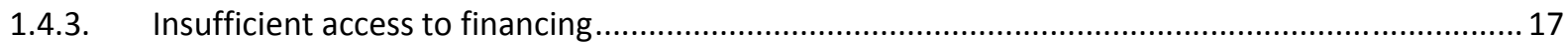

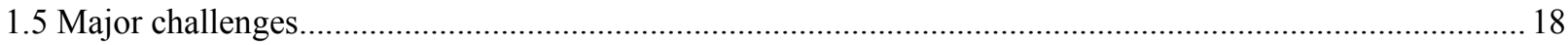

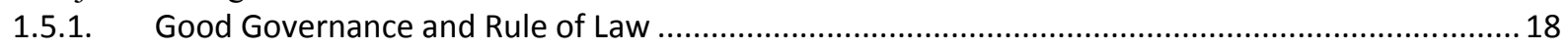

1.5.2. Preservation and restoration of natural resources ................................................................ 19

1.5.3. Profile of entrepreneurship and jobcreation.......................................................................... 19

Chapter II : Strategy for Economic and Social Development 2013-2017 .......................................2 21

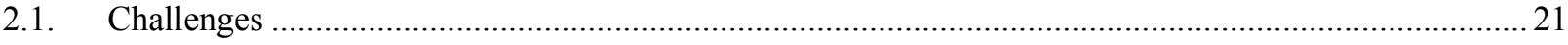

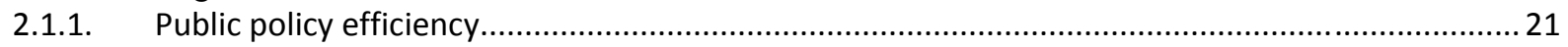

2.1.2. Viability of the macroeconomic framework .............................................................................. 21

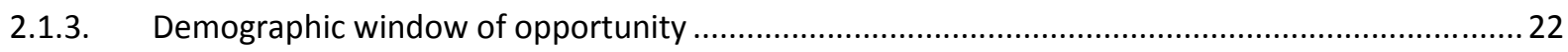

2.2 Vision and intervention strategy for the 2013-2017 period................................................................... 23

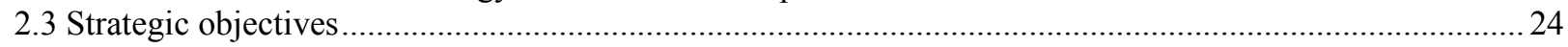

2.3.1. PILLAR 1 : Growth, productivity and wealth creation ............................................................ 24

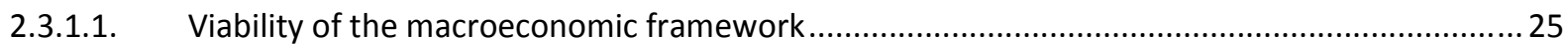

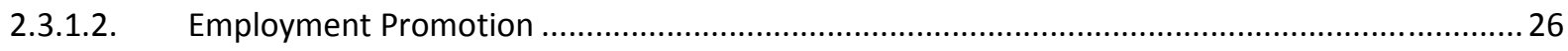

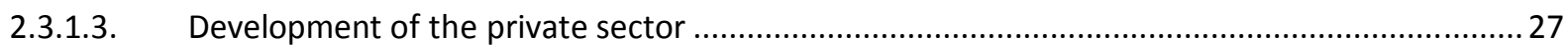

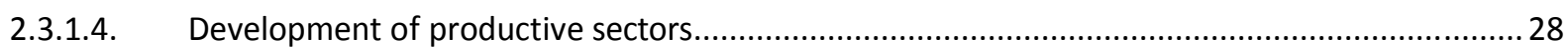

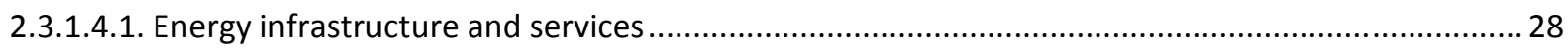

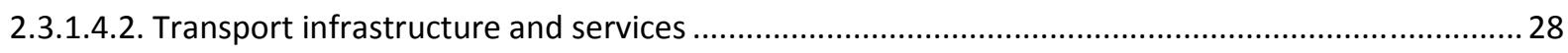

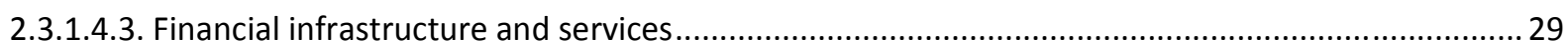

2.3.1.4.4.Communication, telecommunication infrastructure and services.................................................29

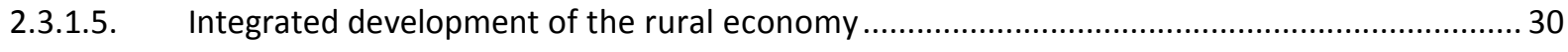

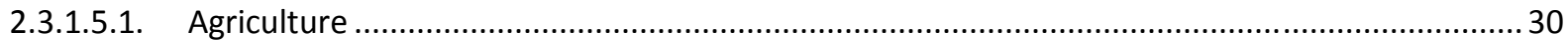

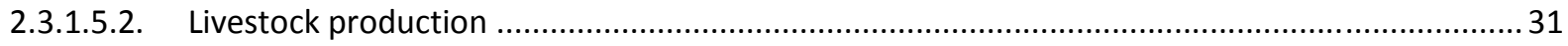

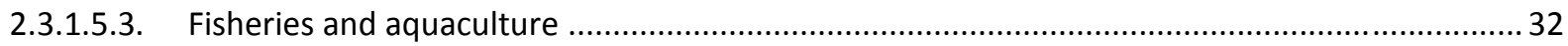

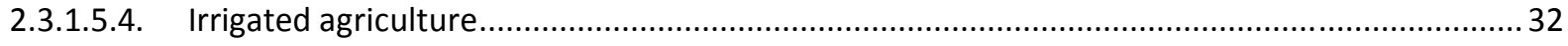

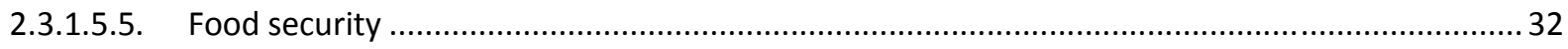

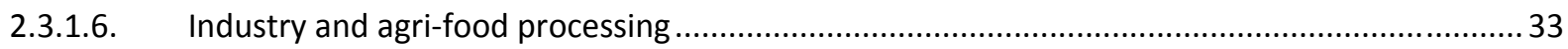




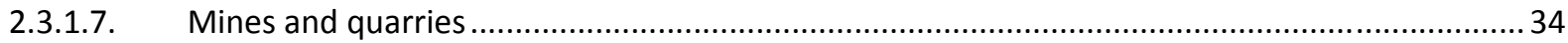

2.3.1.8. Promotion of other services and sectors of production ............................................................ 34

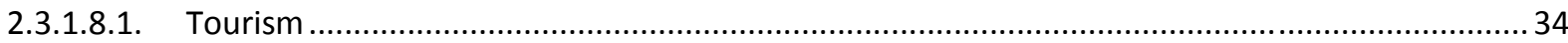

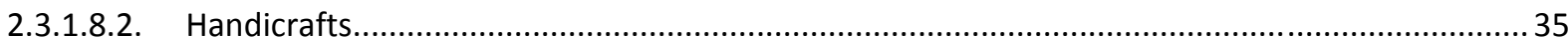

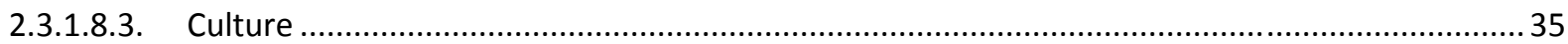

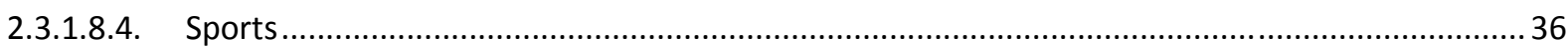

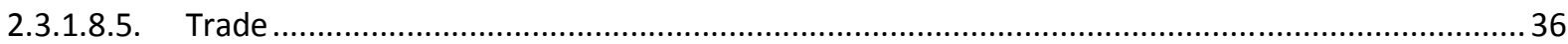

2.3.1.8.6. International cooperation, regional integration and Senegalese Abroad.............................36

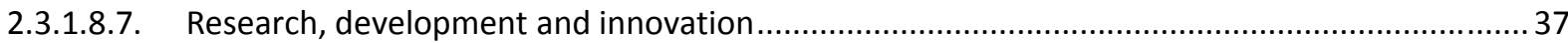

2.3.2. PILLAR 2: Human capital, social protection and sustainable development ....................................37

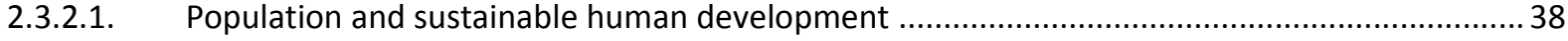

2.3.2.2. Universal education and skills development ........................................................................... 38

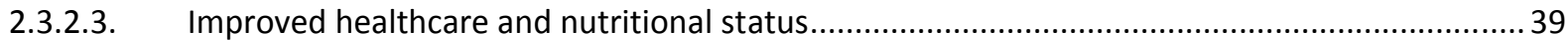

2.3.2.4. Increased access to safe drinking water and sanitation ............................................................. 40

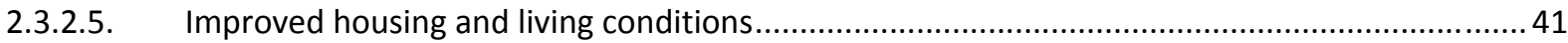

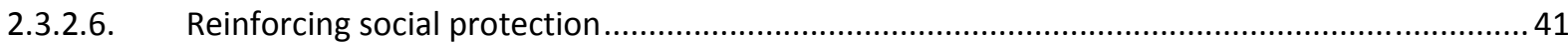

2.3.2.7. Risk and disaster prevention and management ................................................................... 42

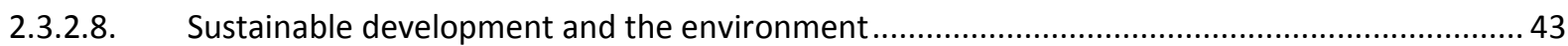

2.3.3. PILLAR 3: Governance, institutions, peace and security ............................................................... 44

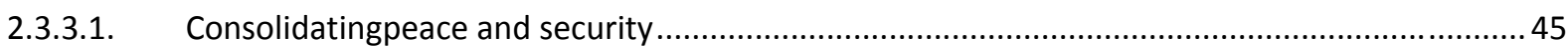

2.3.3.2. Promoting the rule of law, human rights and justice .............................................................. 45

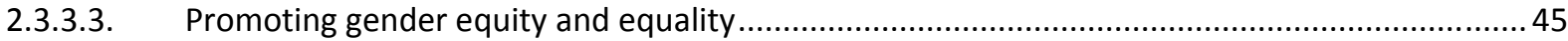

2.3.3.4. State Reformand strengthening public administration .......................................................... 46

2.3.3.5. Land-Use planning, local development and territorialization .................................................. 46

2.3.3.6. Strategic, economic and financial governance ......................................................................... 47

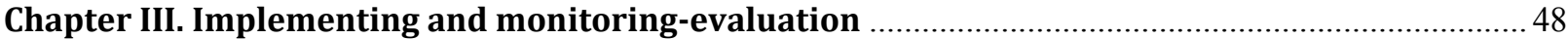

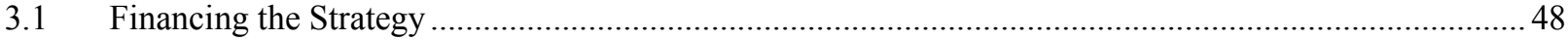

3.1.1. Financial planning and linkage with the national budget........................................................ 48

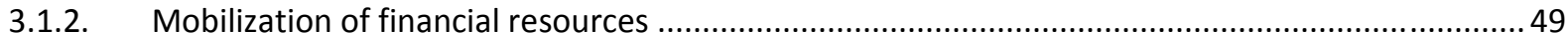

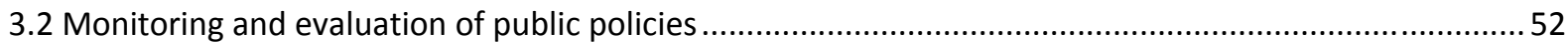

3.2.1 Mechanism to monitor and evaluate the Strategy ........................................................................ 52

3.2.2 Actors, appropriation and mutual responsibility .......................................................................... 53

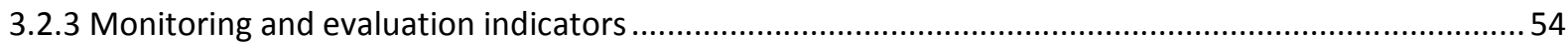

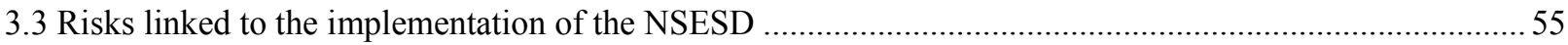




\section{List of Acronyms and Abbreviations}

AGS Accelerated Growth Strategy

AGVSAN Global Vulnerability, Food Security and Nutrition Analysis

ANDS National Statistics and Demography Agency

APIX Investment Promotion and Major Projects Agency

CAADP Comprehensive Africa Agriculture Development Programme

CTPS Technical Committee on Statistics Programmes

DAP Shared Agricultural Area

DCEF Economic and Financial Cooperation Directorate

DFS Decentralized Financial Systems

DGCPT Public Accounts and Treasury Directorate

DGF Finance Directorate

DHS Demographic and Health Survey

DIPE Integrated Early Childhood Development

DPEE Forecasting and Economic Studies Directorate

DPES Economic and Social Policy Document

ECOWAP Agricultural Policy of the Economic Community of West African States

ECOWAS Economic Community of West African States

EFA Education For All

ESPI Economic Policy Support Instrument

ESPS Poverty Monitoring Survey in Senegal

FDI Foreign Direct Investment

FONGIP Priority InvestmentsGuaranteeFund

FONSIS Sovereign Strategic Investment Fund

GDP Gross Domestic Product

FCF Gross fixed capital formation

HLI Highly Labour Intensive

HIPC Heavily-Indebted Poor Countries

IAS/IFRS International Accounting Standards/International Financial Reporting Standards

ICT Information and Communication Technologies

LOASP Agro-Sylvo-Pastoral Orientation Act

MDG Millennium development Goals

MDRI Multilateral Debt Relief Initiative

MICS Multiple Indicators Cluster Survey

MTEF Medium-Term Expenditure Framework

MTSEF Medium-Term Sectoral Expenditure Framework

NA National Assembly.

NFE Non-Formal Education

NPNE New National Employment Policy

NSESD National Strategy for Economic and Social Development

OECD Organization for Economic Cooperation and Development

PAP Priority Action Plan

PDU Urban Development Plans

PEFA Public Expenditure and Financial Accountability

PGAT General Land-Use Plan

PME Small and Medium-Sized Business

PMI Small and Medium-Sized Industry

PNG National Geomatics Plan

PNIA National Agricultural Investment Programme

PODES Orientation Plan for Economic and Social Development

POS Sectoral OperationsPlans

PRAESC Programme to Revive Economic and Social Activities in Casamance

PTIP Three-Year Public Investment Programme

RBM Results-based management

SDAU Development and Town Planning Master Plan

SENELEC National Electricity Company

SIE Energy Information System

SNAT National Land Use Planning Strategy

SNDS National Statistics Development Strategy

SNECRM National Strategy for the Extension of the Health RiskCoverage

SNPS National Social Protection Strategy

SPS Social Protection Floor

SRAT Regional Land-Use Planning Strategy

UCSPE Economic Policy Coordination and Monitoring Unit

WAEMU West African Economic and Monetary Union 


\section{Introduction: General economic and social policy context}

1. Since the country's eligibility for the Heavily-Indebted Poor Countries (HIPC) Initiative in 2000, Senegal has, through its Poverty Reduction Strategy (PRS), implemented integrated policies and programmes', using an all-inclusive approach. The objective is to provide the conditions for strong sustainable growth that would significantly reduce poverty and achieve the Millennium Development Goals (MDG).

2. The first Poverty Reduction Strategy Paper, PRSP-I, covering the 2003-2005 period, helped consolidate the economic performance of structural programmes. In addition to facilitating the correction of some shortcomings at both the social and political levels, it served as an effective instrument to mobilize resources and refocus development policies around clearly defined objectives combined with performance and impact indicators.

3. PRSP-II covering the 2006-2010 period, embarked on the implementation of the Growth and Poverty Reduction Strategy (PRS). It thus combined the Poverty Reduction Strategy and the Accelerated Growth Strategy (AGS) in order to better redirect the social and economic development objectives, taking into account the reduction of social inequalities, and accelerate the achievement of MDGs.

4. The preparation of the National Strategy for Economic and Social Development Strategy (NSESD/NSESD) for the 2013-2017 period is guided by the political will to move Senegal along the path to an emerging economy and the need to take account of the concerns of the population. It was formulated in a difficult international economic context, marked by the surge in the prices of food and energy products, combined with an uncertainty triggered by the likelihood that it might rapidly change.Besides, the persistence of the financial crisis illustrated by the turmoil in financial markets as well as the difficulties encountered by the advanced economies should, most probably, increase the risks of slow-down in world economic growth, but could on the other hand redirect part of the FDI flows.

5. The economic and social development of Senegal calls for the implementation of a strategy that takes into consideration public finance recovery, the development of domestic savings and its effective redirection through incentives; a sustainable improvement in the long term of the balance of trade and the balance of payments, expected to lead to an economic growth with strong positive impact on the living conditions of the population. In this respect, the major challenge basically concerns the reactivation of the economy, the path that Senegal should embark on more resolutely, in a context of righteous, effective and efficient governance.

6. The indicators for the 2005-2011 period show a relative decline of poverty which went along with an absolute increase in the number of poor during this period. This situation is partly due to the fact that the annual growth rate of the GDP per capita stood at about $0.5 \%$ during the said period. Poverty is higher in the rural areas than in the urban centres.It is worth noting that the 'rurality' of poverty has not been influenced by the policies implemented so far. These results highlight the fragility of the Senegalese economy and the urgent need to sustainably improve the population's living conditions. This situation should be rapidly reversed in order to usher Senegal into the path of poverty reduction and the achievement of the Millennium Development Goals (MDG), by 2015.

7. Besides, there is need to underscore the emergence of new challenges that Senegal needs to address. These include: economic emergence, optimizing the energy policy, adapting to climate change, food security, peace and security. These challenges call for the formulation and implementation of an Economic and Social Strategy likely to step up economic growth levels, smooth and absorb the external shocks while preserving future options and resilience 
and place Senegal in a context of sustainable development. This national strategy intended to be realistic and innovative, will serve as a framework for all development actors. It is in line with a long-term vision andcalls for an optimum implementation of public policies at the central and local levels, to facilitate the achievement of MDG and lay the foundations for emergence

Box 1: Updating methodology

In 2011, Senegal prepared the Economic and Social Policy Document (DPES), validated to serve as a frame of reference for the action conducted by the State and its development partners during the 2011-2015 period. However, in view of the recent changes that occurred, Senegal is confronted with new challenges at the political, institutional, economic and social levels. In the light of this, there is need to make the necessary adjustments in the Policy Paper in order to better adapt the Strategy to the new context, bring in fresh momentum and build a more ambitious partnership.

Furthermore, the availability of recent statistical data on the state of poverty and vulnerability, as well as the developments observed in some sectors and the decentralization issue make it even more urgent to update and finalize the draft DPES 2011-2015.

The new document which defines the economic and social priorities should take adequate account of the real aspirations of the populations and the urgent need to develop a competitive economy that provides opportunities for growth. To that end, the revised DPES, which became the National Economic and Social Development Strategy, 2013-2017, was prepared according to a participatory process, both at the central and decentralized level. Thanks to this approach, regional actors were involved, with the holding of local consultations and the sectoral constraints were reviewed with all technical ministries and the national armed forces.

Emphasis was laid on wealth creation, the strengthening of governance, the development of strategic sectors with significant impact on the improvement of the populations' well-being and the social demand. In a special context of demographic transition, it was deemed appropriate to address cross-cutting issues like employment, gender, social protection and sustainable development.

The formulation process was premised on synergy between economic and social policy tools such as AGS, the Social and Economic Development Orientation Plan (PODES), the Economic Policy Support Instrument (EPSI) and the citizens' initiatives, in line with the new orientations of the State of Senegal. In this respect, there is need to take advantage of all the national potentialities likely to improve the level of income and living conditions of the populations.

8. This document is organized as follows: the first chapter provides the growth, poverty and inequality profile and outlines the challenges it poses. The second chapter describes the Strategy through the long-term vision, the sectoral strategic orientations and the policies and programmes that make them operational. Finally, the third chapter outlines the mechanism identified for the implementation of the Strategy. It discusses the financing of the strategy, the roles and responsibilities of actors as well as the review mechanisms to be set up. This last chapter also defined the external monitoring and evaluation framework as well as the risk factor linked to the implementation of the strategy. 


\section{Chapter I: Economic and social diagnosis}

9. This chapter discusses the economic, social and environmental performance of policies, the political and institutional environment and the constraints weighing on its growth as well as the challenges to be addressed. Special attention is paid to regional disparities, gender equity and equality, as well as inequalities in the distribution of income and access to basic social services.

\subsection{Population and access to basic social services}

\subsubsection{Demographic trend and factors of social exclusion}

10. The Senegalese population grew from 3 million inhabitants in 1960 to about 12.5 million inhabitants in 2010. It increases by more than 260000 persons per annum, i.e. a demographic growth of $2.6 \%$. The sizeable population increase is due to the considerable decline in mortality and the high fertility level. According to the 2010 estimates, 55\% of the Senegalese population live in the rural areas, one out of two Senegalese is under 20 years old and about two out of three Senegalese are under 25 years old. This population increase did not come along with a substantial provision of basic social services.

11. With regard to human resources, the high rate of unemployment and under-employment are the most obvious signs. Actually, only one out of five people are working full time in Senegal. Such a situation appears to suggest a high dependency rate which, among other things, translates into constant pressure on working individuals who run the risk of falling into monetary poverty. The scattered location and multiplicity of employment support structures, the fact that there is no linkage between the labour market, vocational training and the selfemployment support policy, as well as lack of labour market transparency constitute factors that are not conducive for the decline in unemployment and under-employment.

12. The results of the 2011 poverty monitoring survey estimate unemployment rate a $10.2 \%$. It remained basically stable compared to 2005 when it was estimated at $10.0 \%$. Unemployment rate is estimated at $7.7 \%$ among men and $13.3 \%$ among women. Besides, it must be underscored that the majority of women are essentially engaged in unpaid activities. Depending on their level of education, unemployment is more frequent among those with secondary education level in the broader sense. It has reached more than $20 \%$ in the rural areas; the migration into towns, of youths and active women is an obvious sign of the shortage of productive employment. In the urban areas, the training offer often matches the needs of the labour market. The highest unemployment rate is especially found among young graduates. Globally, vocational training levels are low and limited. This partially leads to the expansion of the informal sector.In the rural areas, illiteracy and under-employment are widespread among the active population, largely agricultural, who are thus exposed to hazards. In case of climate shock like drought, the population is mostly left without jobs.

13. Moreover, the youthfulness of the population has significant social repercussions, notably tensions on the labour market. The majority of the population are women $52 \%$ of the total population) who represent $65 \%$ of the active population.

14. Depending on the economic sectors, employment presents geographical and gender disparities. In the rural areas, women are primarily engaged in agriculture, livestock production and fisheries. They carry out close to $82.6 \%$ of the work, often with rudimentary means, against $79.4 \%$ for men. In the urban areas, women consider the informal sector as an interesting alternative since it requires less skills and specialization, but is also more flexible 
and more adapted to their financial capacities and their schedule of activities. They are thus underrepresented in the formal sector.

15. Moreover, the informal sector contributes 55\% to GDP and is considered as a refuge sector which attracts all job creating initiatives. This makes it an attractive lever for most youths, struggling with the restricted absorption capacities of the formal sector. Informal employment which absorbs more than $60 \%$ of non-agricultural jobs is increasing with urbanization.

16. In addition to the extensive underemployment observed in the agricultural sector, the nonagricultural sector is also said to be affected by this phenomenon, but to a lesser degree. In 2011 , the underemployment rate was estimated at $32 \%$ for the entire active population, with a slight disparity for active women (37\%).

17. Besides, the gender inequality index, which was 0.566 in 2011, reflects the persistence of major social and gender disparities in Senegal. The disparities between regions concern access to basic infrastructure: safe safe drinking water and sanitation, transportation infrastructure, infrastructure for the storage, conservation and processing of local products, electricity and large-scale irrigation activities. These elements are perceived as major sources of inequality and inefficiency with regard to contribution to economic growth.

\subsubsection{Inadequate access to basic social services}

18. Notable progress was registered with regard to access to primary education, safe drinking water and health. However, concerning the Millennium Development Goals (MDG), the progress registered for access to maternal, infant and child health care was quite shy and relatively limited in the field of sanitation and primary school completion.

19. With regard to education, sizeable efforts have been made to step up the populations' level of education and develop their skills. Thus, the gross pre-school enrolment rate increased from $8.0 \%$ in 2006 to $10.7 \%$ in 2011 . The gross grade 1 admission rate gained about 10 points (103.2\% in 2006 against $113.0 \%$ in 2011$)$. The gross primary school enrolment rate 1 was $79.7 \%$ in 2011 , against $75.8 \%$ in 2005 , with significant regional disparities. The highest levels are registered in Dakar (102.6\%) and Ziguinchor (115.6\%) while Kaffrine (44.2\%) and Diourbel (47\%) show a less favourable performance. However, Education for All (EFA) has not yet been attained because the net primary school enrolment rate, in 2011, is around $59.6 \% 2$ while it was $54.6 \%$, in 2005 . This is reflected by the educational delay for a significant number of children who have exceeded the normal primary enrolment age. The primary cycle completion rate is not yet satisfactory even though it registered a positive trend, since 2006, rising from $49.7 \%$ to $66.9 \%$, in 2011 . Thus, about $1 / 3$ of school-age children do not complete the primary cycle. The unmet demand for schooling, on the one hand, and the high number of drop-outs (about 8\% in 2010), on the other hand, constrain progress. Thus, the pupil-teacher ratios remained high in primary schools: 51 pupils per teacher, in 2000, and about 40, in 2011. These ratios represent more than twice the results registered in most emerging countries where they are currently estimated at between 15 and 25 pupils per teacher.

20. In the area of vocational and technical training and that of literacy and non-formal education,3 further efforts need to be made. The results of vocational and technical training show serious regional disparities; the majority of pupils enrolled $(62.5 \%)$ and an essential

\footnotetext{
${ }^{1}$ ESPS-II, 2011. Edstats (World Bank) shows a rate that increased from $82.6 \%$ in 2005 to $86.8 \%$ in 2010

${ }^{2}$ ESPS-II, 2011. Edstats (World Bank) shows a rate that increased from $72.2 \%$ in 2005 to $75.5 \%$ in 2010

${ }^{3}$ The number of learners' objective was not attained in 2011. 
component of those attending private schools are still concentrated in the region of Dakar. The regions of Louga, Matam and Fatick have the lowest student population.

21. Higher education is marked by the rapidly growing student population. The number of new baccalaureate holders rose from 29,908 in 2010, to 30,564 in 2011. Girls account for $40.9 \%$ of these students. The admission of this large inflow of students in public universities is still a serious problem, despite the contribution of the private sector for the beneficiaries' access to higher education. Notwithstanding the creation of the Regional University Centres (CUR), l'Université Cheikh Anta Diop is still congested. The public offer has not developed sufficiently to meet the demand.

22. In general, the main problem of education is its low internal efficiency, reflected in the poor quality of education, the inadequate teaching and learning materials, insufficient enrolment capacities due to a deficit in volume and the delay in the classrooms construction programmes, teachers' lack of qualification, with the massive recruitment of volunteer and contract teachers and the negative impacts of the recurrent school disturbances on the school calendar and the individual schedules.

23. In the field of health, Senegal has not yet reached the recommended WHO standards, in terms of health facility cover and skilled staff; these indicators are still unevenly distributed throughout the country, at the detriment of the rural areas. The same applies to the provision of drugs. In terms of demand, the poorest populations did not systematically benefit from the free health care programmes that have been instituted, and this reduces their capacity to have access to the health care they are entitled to.

24. The population's state of health varies in degree. Malaria is still the leading cause of morbidity in Senegal and accounts for $42.6 \%$ of causes of diseases. Efforts to fight against malaria have led to a dramatic fall 4 in the proportional malaria morbidity which plunged from $39.7 \%$, in 2000 , to $3 \%$, in 2009 . However, cardiovascular diseases have become a real health problem due to the increase in their incidence in all countries. Neglected for far too long because of the scale of transmissible diseases, they have become the second cause of mortality, after malaria, in Dakar health facilities. They are chronic diseases that are costly with a great burden of morbidity and mortality The risk factors associated with cardiovascular diseases include high blood pressure (50\%), smoking (47\%), obesity (23\%), cholesterol (12.5\%) and diabetes (11.6\%). Among these cardiovascular diseases, heart failure is a major cause of concern since it is the principal cause of hospitalization in cardiology services of the various hospitals, with a rate of between 37 and $40 \%$.

25. With regard to AIDS, $0.7 \%$ of Senegalese adults in the 15-49 years age bracket were HIVpositive in 2010-11. The rate remained stable compared to 2005. The HIV-positive rate is highest among women in the regions of Kédougou (2.5\%) and Kolda (2.4\%), and those having attained primary level education $(1.2 \%)$. Among men, the highest seroprevalence rate is found in the region of Kolda (2.4\%) and, to a lesser extent, in Tambacounda (1.2\%) and Ziguinchor (0.9\%). Anti-Retrovirals are free.

26. The rate of mortality among children, regardless of the cause, has declined considerably. During the 2007-2011 period, 47 out of 1000 live births died before their first birthday, 29 of whom died between 0 and 1 month exactly (i.e. a contribution of $61.7 \%$ to child mortality) and $18 \%$ between 1 and 1 months old. It is worth noting that $26 \%$ of children having reached a year did not celebrate their fifth anniversary. Subsequently, attaining the objective ${ }^{5}$ of reducing the level of child mortality by two-thirds require substantial efforts in terms of the global management of the health of the newborn, at the risk of missing the target, in 2015.

\footnotetext{
${ }^{4}$ With the introduction of the Rapid Diagnostic Test.

${ }^{5}$ As compared to the level of infant mortality in 1992 (DHS 2): 68\%. National Economic and Social Development Strategy
} 
27. In the same vein, infant and child mortality is still high, despite the $45 \%$ decline registered between 1992 (DHS 2) and 2010-11 (DHS-MICS), when72 deaths per 1000 live births were registered. This decline is partly due to improved immunization coverage, at national level, which rose from59\%to 63\%of children aged 12-23 months. Thus, the objective of reducing infant-child mortality to 44 deaths per 1000 live births by 2015, may not be achieved.

28. With regard to maternal mortality, 392 maternal deaths for100 000live births were registered in 2010-11, i.e. a 2\% decline in 6 years. Its reduction pace is too slow to reach the MDG target of 127 deaths for 100000 live births by 2015 . However, efforts were made in the area of maternal health with a proportion of births assisted by skilled attendants increasing from $49 \%$ in 1999 , to $65.1 \%$, in $2010-11$ (DHS-MICS). The rate of prenatal checkups 6 increased to $93.3 \%$, in $2010-11$, against $74 \%$, in 2007 . The causes of maternal mortality include direct obstetrical pathologies such as hemorrhages, high blood pressure and its complications, obstructed labour and infections but also indirect obstetrical causes dominated by anaemiaand malaria.

29. However, there is need to improve the offer in reproductive health services by accelerating the reduction of maternal mortality as well as maternal and neonatal morbidity. This signals the repositioning of family planning in order to cover the unmet needs estimated 7 at $29.4 \%$. The coverage of these needs helps reduce maternal deaths ${ }^{8}$ from 20 à $30 \%$ and infant mortality ${ }^{9}$ from 12 to $20 \%$.

30. Moreover,chronic malnutrition rate among children under 5 declined by half, dwindling from $30 \%$, in 2000 , to $16 \%$, in 2011 . By contrast, about one out of six children $(18 \%)$ in 2011 , against $17 \%$, in 2005 , are underweight while $\%$ suffer from severe underweight against3 \%, in 2005. In the rural areas, $21 \%$ of children are affected by this form of malnutrition compared to $12 \%$, in the urban areas. The prevalence of severe underweight is high in the regions of Sédhiou (27\%), Kolda (26\%), Saint-Louis (25\%), Matam (25\%), Kaffrine (24\%), Louga (23\%), Tambacounda (22\%) and Kédougou (21\%) where more than one out of five children is affected by this phenomenon. Dakar is the region with the lowest prevalence of underweight children (9\%).

31. The main constraints to the decline in maternal and infant-child mortality are: i) difficult access to health care and medication, ii) the time spent to access a health care facility and the average price paid for consultation that can also be a deterrent to their seeking health care; iii) disruptions in the stock of vaccines in health posts and centres; iv) the very limited capacity to mobilize resources for health care andv) inadequate sensitization and communication between the different actors of the sector leading to an unnecessary doubling of efforts and an inconsistency in the implementation of actions.

32. Besides, notable progress was registered in access to safe drinking water while the results for access to sanitation were insignificant. This implies that if the actual trend is maintained, the objective of ensuring access to water for $100 \%$ of the urban population and $82 \%$ of the rural populations could be attained. In fact, for the urban populations, the rate rose from $93 \%$, in 2006 to $98.797 \%$, in 2011. In the rural areas, the rate increased from 69.5\%, in 2006 to $80.1 \%$, in 2011 . Beyond the progress registered in the provision of infrastructure, the major challenge is still the regular supply of safe drinking water in all regions.

33. However, while satisfactory progress was registered in access to water, this was not the case for access to sanitation. Sizeable efforts still need to be made to improve the rural

\footnotetext{
${ }^{6}$ Coverage in prenatal care, with at least one prenatal visit.

${ }^{7}$ DHS-MICS, 2010-2011

${ }^{8}$ State of the World Population, UNFPA, 2005

${ }^{9}$ Demographic and political population growth in Sub-Saharan Africa, World Bank, December 1986. 
populations'access to an improved sanitation system. The rate of access to sanitation in the urban areas stepped up from $62.0 \%$, in 2005 , to $63.3 \%$, in 2011 , while the access rate increased from $26.2 \%$, in 2006, to $34.3 \%$, in 2011 in the rural areas.

34. The shortage of basic infrastructure, especially in the rural areas, is due to elevated costs and low investments. This is compounded by the high cost of individual sanitation infrastructure, the poverty of households and the limited resources of local communities. Finally, the recurrence of flooding, in 2012, reflects lack of consistency between the management of the occupation of housing areas and the water evacuation systems, in general, and rain water, in particular.

35. With regard to housing and living conditions, Senegal is striving to deal with the physical deterioration, essentially due to the rapid urbanization caused by the rural-urban drift.In most cities, the unsanitary zone unfit for human habitation represents 30 to $40 \%$ of occupied space and concentrates a sizeable proportion of the population. Thus, the uncontrolled occupation of space, the "slumification »of housing, problems of hygiene and public health caused by flooding which has become recurrent, insecurity linked to ill-planned urbanization are a set of factors that increased the vulnerability of the populations and led to the deterioration of the living environment in working class areas.

36. To improve the housing and living environment, some constraints need to be lifted: weak land regularization which creates difficulties to access land; inadequate participation of concessionary companies in the primary servicing of planned human settlements; lack of public financing for roads and other networks; lack of guarantee fund to subsidize the banks' interest rates and accelerate the funding of social housing; taxation and high charges that add up to the cost of social housing.

37. Moreover, the environmental policy has always been based on the rational management of natural resources in a sustainable development perspective. Despite the efforts and the progress made in biodiversity conservation, the situation is still characterized by an advanced degradation of natural resources. However, significant efforts were made through the activities of reconstitution, reforestation, conservation and protection of forestry resources, of the fauna and its habitat. The actions impacted on the natural regeneration of ecosystems. However, adapting to climate change is a new major challenge with the development of phenomena such as flooding, coastal erosion and land salinization. Sustainable solutions should be found to enable the populations to develop a culture of prevention and adaptation to climate change.

38. With regard to social protection, Senegal has a low coverage level. The social safety net is incapable of reacting rapidly and is even less capable of increasing the scale and scope of responses to crises. The formal health insurance systems provide health risk cover only to Senegalese families whose head is employed in the modern sector. Only $20 \%$ of the population is catered for by this system while the majority of Senegalese $(80 \%)$ employed in the rural and informal sectors are left behind. This situation led the State to initiate the National Strategy for the Extension of Health Risk Coverage (SNECRM) which promotes the development of mutual health insurance. Thus, the number of functional health insurance increased from 80, in 2003, to 237 including 217 community-based mutual health insurance and 20 nation-wide mutual insurance, in 2011. Today, the number of beneficiaries is estimated at 609182. The low level of social protection, the insufficient targeting and the lack of coordination of interventions and inadequate resource allocation still constitute the major constraints to social protection. 
39. The implementation of free health care and safety nets programmes helped improve the access of vulnerable groups to basic social services. However, difficulties are still being experienced in the implementation of certain programmes for the caring of vulnerable persons. These difficulties relate to the targeting of beneficiaries, inadequate mobilized resources, malfunctioning of the information systems and the coordination of interventions.

\subsection{Growth and monetary poverty}

\subsubsection{Economic growth profile}

40. The 2000-2011 period is marked by the fact that economic performance is insufficient for poverty reduction. The GDP growth rate stood at an annual average of $3.9 \%$, a ratio that is slightly higher than demographic growth $(2.6 \%)$. This mixed performance, which is less than the average of 5\% registered between 1995 and 2005, is partly due to external shocks and a slow pace of business climate reforms. However, internal and external deficits have intensified. The evolution of the general price level, during the period, was curbed with the exception of 2008 when inflation called for strong safeguard measures. Senegal's development prospects were particularly marred by the 2008-2009 financial and economic crisis, lack of effectiveness of public expenditure, low investment rate and rainfall deficit.

41. The upward trend of the final consumption has weakened the savings effort. During the period, it increased by more than 3.9\% among women and 3.8\% in the Public Administration. At the same time, the budget deficit reached relatively high levels. Its increase attests to the need to improve the quality of credit allocation and public expenditure implementation. In conjunction with this, both the domestic and foreign public debt outstanding increased considerably over the past four years, despite the debt cancellations registered within the framework of the HIPC and ADM initiatives. The overall foreign debt outstanding thus accounted for $39.7 \%$ of GDP in 2011, against $26.0 \%$, in 2008. The public debt-budget revenue ratios deteriorated. This new debt trend could jeopardize its viability, even though it is below the community ceiling.

42. The investment rate which sometimes reaches interesting levels remained constant at an average of around $22 \%$, in real terms. This trend is due to the positive externalities registered thanks to the improvement of public infrastructure. However, Direct Foreign Investments (DFI) were relatively low (58 million US dollars), before resuming growth between 2005 and 2009. They represent an average of $8 \%$ of the GFCF. This low level of investment is attributed an unattractive business environment. In this regard, the "Doing Business" report ranked Senegal 154th out of 183 countries in 2011, then $166^{\text {th }}$ out of 185 countries in 2012. Despite the reforms initiated since 2003, transactions relative to land ownership as well as access to credit and electricity are confronted with administrative red tape. In addition to its slow progression, investment is characterized by unequal spatial distributionas well as an unbalanced sectoral allocation. It did not significantly benefit the poor populations.

43. The 2000-2011 decade was marked by limited export performance, mitigated by the increase in the world prices of some exported products. The latter increased by $2.6 \%$ in volume per annum, during the period, i.e. a lot slower than GDP. Thus, Senegal's balance of trade is still in deficit. It declined, on average, by $15.3 \%$ between 1999 and 2008. This situation was combined with a loss of market shares, at world level. The structural deficit of the non-factor goods and services balance of trade to GDP ratio rose from $8 \%$, in 2000 , to about $12 \%$ per annum in 2010. Strong variations are observed, especially in 2007 and 2008, because of the increase in the price of imported products. By contrast, the Senegalese economy benefits from substantial transfers of private ${ }^{10}$ and public income (international aid) which contribute

${ }^{10}$ An average of 800 billion CFAF per annum linked to emigration $90 \%$ of which are used for consumption purposes. Stratégie Nationale de Développement Economique et Social Page 12 
to improving the current account deficit.

44. The low growth level of the Senegalese economy results from the following factors: i) the preponderance of the unproductive informal sector, in the creation of wealth and jobs ${ }^{11}$; ii) the external shocks which attests to the fragility of the productive bases of the Senegalese economy and iii) the relatively limited impact of public policies on economic growth. The Senegalese economy is still dominated by the production of low-value added goods and is underpinned by patterns of specialization based on stagnant products which made it difficult for it to take an active part in the global economy.

\subsubsection{Incidence of poverty}

45. The weak and erratic economic growth might compromise the chances of achieving the objective of halving the incidence of poverty (34\%). The approach adopted on the notion of « poverty » lays emphasis on the precariousness in several areas of human existence. An empirical approach to poverty is reflected by a basket of food and non-food commodities essential for every individual or group of individuals, to live in decent conditions.

Table 1: Evolution of poverty indicators in Senegal, 2001-2010.

\begin{tabular}{|l|l|l|l|l|}
\hline Indicators & Dakar & Other & Rural & Nation \\
\hline Year 2001 & \multicolumn{5}{|l|}{} \\
\hline Incidence of poverty & 38.1 & 45.2 & 65.2 & $\mathbf{5 5 . 2}$ \\
\cline { 1 - 5 } The depth of poverty & 10.2 & 13.4 & 21.2 & 17.3 \\
\cline { 2 - 6 } Severity of poverty & 3.8 & 5.5 & 9.2 & 7.3 \\
\hline Year 2005 & \multicolumn{5}{|l}{} \\
\hline Incidence of poverty & 28.1 & 41.4 & 59 & $\mathbf{4 8 . 3}$ \\
\hline Depth of poverty & 6.8 & 11.6 & 20.2 & 15.5 \\
\hline Severity of poverty & 2.4 & 4.8 & 9.5 & 7 \\
\hline Year 2011 & \multicolumn{5}{|l}{} \\
\hline Incidence of poverty & 26.2 & 41.3 & 57.3 & $\mathbf{4 6 . 7}$ \\
\hline Depth of poverty & 5.8 & 13.1 & 18.7 & 14.6 \\
\hline Severity of poverty & 2.1 & 5.9 & 8.7 & 6,6 \\
\hline
\end{tabular}

Source : Poverty Monitoring Survey in Senegal (ESPS-II), ANSD, Dakar, Senegal.

46. According to the provisional results of the second poverty monitoring survey in Senegal in 2010-11, poverty reduction showed a positive trend. In fact, the proportion of individuals living below the poverty line12 dropped from $55.2 \%$ in 2001 to $48.3 \%$ in 2005 , before reaching 46.7\% in 2011. Between 2005 and 2011, it slightly declined in Dakar and in the rural areas and stabilized in other urban centres. In fact, the proportion of individuals living below the poverty line ${ }^{12}$ dropped from $55.2 \%$ in 2001 to $48.3 \%$ in 2005, before reaching 46.7\% in 2011. Between 2005 and 2011, it slightly declined in Dakar and in the rural areas and stabilized in other urban centres.

47. In 2011, the highest poverty levels were found in the regions of Kolda (76.6\%), Kédougou (71.3\%), Sédhiou (68.3\%), Fatick (67.8\%) and Ziguinchor (66.8\%). Moreover, the incidence of monetary poverty is estimated at $34.7 \%$ among persons living in female-headed households against $50.6 \%$ among persons living in male-headed households. The civil status of the head of household makes a difference. The incidence of poverty is $36.3 \%$ among

\footnotetext{
${ }^{11}$ The formal public and private sector represent only $6 \%$ of total jobs.

${ }^{12}$ After adjustments of ESPS-II, 2010-11. 
persons living in households headed by single persons, $46.7 \%$ among monogamous households and $50.1 \%$ among polygamous households. The rate of poverty among persons living in households headed by single persons is $16.4 \%$ in Dakar, $39.0 \%$ in the other cities and $49.4 \%$ in the rural areas. Households headed by persons over 60 years old, often inactive or retired, are more affected by poverty; elders (over 60 ) represent $38.7 \%$ of the total poor at national level.

\subsection{Institutions and roles of actors}

48. The Republic of Senegal has two experiences of political power changeover, in 2000 and 2012 , which occurred in a climate of peace and stability. As a model of democracy, Senegal should put efforts into creating and consolidating a climate conducive to political, economic, cultural and social opening. Moreover, the Constitution confers to the Executive Power and, in particular, to President of the Republic, the central role of defining and implementing the economic policy of the country. Even though the executive, legislative and judiciary powers are separated in the Constitution, instances of malfunctioning are observed in practice. The requirement of balancing the powers is ill-adapted to the weaknesses and malfunctioning observed in the existing governance system.

49. To this end, there is need to ensure the separation of powers and the independence of the judiciary to reinforce democratic governance which is a keystone of sustainable human development. This system guarantees an equitable access of those to be tried to all services and contributes to the impartiality and efficiency of national human rights protection mechanisms, the establishment of an effective legislative framework and the consolidation of democratic institutions and citizen control.

50. Parliament, which was bicameral up to very recently, is henceforth embodied by the National Assembly alone with a renewable plural representation $43.3 \%$ of whom are women. After several legislatures, Parliament is still has limited capacities which makes it difficult for it to control the budget and monitor the populational impacts of public policies, despite the manifold assistance (capacity building, recruitment of parliamentary assistants...) provided to its members within the framework of the implementation of the National Good Governance Programme.

51. In its functioning, the Judiciary is characterized by its complex and lengthy procedures, which impairs its efficiency, despite recent reforms in the sector that took ample advantage of the strengths of the recent good governance programmes (PAPNBG, PRECABG).

52. Public Administration followed a process of rationalization and the quest for efficiency to improve the quality of public service. Even though the numerous strategic and institutional audits came up with measures, they were not followed by any significant reforms during the past decade, marked by institutional instability, which impacted on the economic environment.

53. The decentralization policy is still confronted by several obstacles. The constraints to the promotion of good local governance are institutional,organizational and financial. Actually, the difficulties lie in the inadequate operationalization of land-use planning in the management of local communities; poorly defined boundaries between local communities and the non existence of a rural land registry; the non application of planning mechanisms (for example, the plan contracts) provided for by law; the poor integration of space-related issues in public development policies, notably in the allocation of investment resources; the centralization of the economy which did not leave much latitude to regional and local initiatives. In addition to constraints to the promotion of good local governance, some local 
communities have no capacity building plan; poor synergy between local development actors; non-harmonized schedules, planning cycles and partners' interventions; poor connection between local community plans and sectoral planning; poor integration of the space aspect in local planning; the numerous consultation and harmonization frameworks; inadequate consideration of local communities in the contracting.

54. The Senegalese systems for the management of public finance and government contracts have, since 2002, undergone several performance evaluation exercises. This operation facilitated the implementation of the programme for improved practices.The last operations concerned the second public finance management performance evaluation based on the PEFA approach, conducted in March 2011, and the second evaluation of the national government procurement system based on OECD indicators (World Bank- CAD/OCDE) for 2010.

55. In the area of budgetary and accounting management, the adoption of theBudgetary and Financial Reforms in 2009, led to significant progress in the improvement of budget credibility, completeness and transparency as well as the preparation of the budget and its linkage to public policies with the introduction and gradual expansion of multi-annual public expenditure programmes. Such progress was also observed in the predictability and modulated control of budget execution as well as in the keeping of public accounts and accountability. They should be consolidated with the progressive application, with effect from 2012, of reforms and major innovations inspired by the new public management introduced by the new directives of the harmonized public finance framework, adopted by the UEMOA Commission in 2009.

56. With regard to public procurement management, despite the revisions made in 2010, in the provisions of the Government procurement Code, then corrected by the return to orthodoxy, the progress made in its consolidation is meant to ensure that the national system is in line with the best practices in the matter.

57. Besides, the State has opted for the involvement of key actors in the formulation and implementation of development policies. In this context, civil society and private sector organizations intend to consolidate their citizen participation role in the quest for economic and social development. However, they are still confronted with many constraints such as:(i) low assessment capacities, (ii) difficulties to access strategic information on public finance and the state of implementation of public projects and programmes and (iii) the non existence of a functional and sustainable consultation framework.

\subsection{Structural constraints}

58. The structure of growth sources is not sufficiently diversified and is therefore poorly adaptable and barely resilient to external shocks and options. The key constraints of economic sectors relate to the low productivity of production factors and their costs that are still high, the underdeveloped human capital and the difficulties for SMEs to access to financing. The economy suffers from a shortage in infrastructure in quantity and quality, the weakness of its industrial fabric and a low level of private investments in the productive sectors.

\subsubsection{Low productivity}

59. Since the devaluation of the CFA franc in 1994, growth has been driven by the building, telecommunications and industrial activities, tourism and trade sectors, to the detriment of agriculture, which still occupies more than half the population. This sectoral composition of growth, in the absence a recovery steering operation through rural micro- industrialization 
and a sub-sector for the local promotion of national agriculture, explains the persistence of poverty in the rural areas and in the outskirts of cities where labour is restricted to survival activities which characterize the informal sector. In general, the low overall productivity of the Senegalese economy with its resulting low rate of savings is due to the low agricultural productivity ${ }^{13}$ and the significant share of the informal sector.

60. The sub-sectors of the primary economy generally suffer from difficulties to access quality inputs and the non-existence of modern production facilities and infrastructure. The agricultural sub-sector is confronted with a certain number of difficulties including those concerning access to production factors; the low level of development of water works ; strong dependence on rain-fed crops, non availability of quality seeds;inappropriateness of the land policy; lack of integration and structuring of sub-sectors around value chains; insufficient integration of research results; difficulties to access markets and the low added value of exported products. With regard to the livestock production sub-sector, the constraints impeding its development are due, among others, to the low level of production of local breeds, insufficient basic physical infrastructure, the strong agriculture-animal breeding competition for the occupation of land and the non existence of modern systems for the processing and marketing of animal products.

61. Likewise, in the area of food security, Senegal is having difficulties with the populations' access to a sufficient amount of quality food products as well as uncertainty in meeting their food needs. In fact, the prevalence ${ }^{14}$ of food insecurity in households is estimated at $15.1 \%$, in the rural areas and 8.5\%, in the urban areas. In nutritional terms, the SMART survey conducted in June 2012 showed that 16 of the 45 Senegalese departments are in a distressing situation and 3 of them have already exceeded the nutritional crisis threshold.

62. For its part, the industry is confronted with insufficient production, inadequate competitiveness, lack of capacities of industrial firms, geographical and structural weakness of the industrial fabric. In operational terms, initiatives concerning partnership between the State and the private sector are still shy, particularly with regard to the promotion of entrepreneurial initiative, the development of innovation through research-application, the creation of integrated competitiveness poles and the training of future champions of the different sectors and the development of venture capital. The energy deficit and the weak infrastructural platforms cripple the performance and competitiveness of industries, causing substantial additional costs.

63. With regard to handicrafts, the fact that handicraft goods and services are not competitive is due to the craftsmen's lack of production and organizational capacities and the insufficient and unsuitable distribution channels, the inappropriate institutional, legal and organizational framework of the sector and the obsolescence of the actors' training, apprenticeship and reskilling system. Tourism is still characterized by lack of visibility of the destination Senegal, primarily due to the inadequate structuring and the poor quality of the supply, the nonexistence of a coherent and attractive framework for the competitiveness of the sector and lack of multi-sectoral spirit.

64. Moreover, the constraints to the growth of trade are reflected in the disruptions in the supply of the domestic market, combined with the high prices of consumer goods and services. They are linked to four major causes: qualitative and quantitative supply deficiency, insufficient means of intervention and supervision of markets and distribution channels, quantitative and qualitative deficiency in the supply of goods and services both for the domestic and foreign markets, lack of competition between private actors and congested distribution channels.

\footnotetext{
13 National Report on the Competitiveness of the Senegalese Economy- RNCS 2011

${ }^{14}$ Measured with the help of the food consumption score. Stratégie Nationale de Développement Economique et Social
} 
65. For its part, the energy sub-sector continues to weigh on the performance of all components of the national economy. This sub-sector is marked, among others, by the low volume of supply and the poor quality of electricity service in the urban and rural areas; recurrent power cuts which impede the performance of economic activities; lack of information and sensitization on the rational use of energy and technical failures of public and private operators. This situation is attributable to the quasi-exclusive dependence on oil imports and the non-existence of adequate mechanisms to cushion exogenous shocks. The poor refining capacity, the desuetude of the logistics at the Dakar port, the obsolescence of the production ad transport infrastructure as well as the delay in restructuring SENELEC and the operational recovery of ASER, in addition to the slowness in setting up the regulatory framework for the development of renewable energy are not conducive to an energy efficient policy for the diversification of energy sources.

66. The transport sub-sector is still confronted with the narrowness of the unevenly distributed road network, insufficient urban public transport offer and the run-down state of the vehicle fleet and rail (in particular, the Dakar-Bamako railway) and port infrastructure, among others. The limited access to the rural areas which is a constraint to the development of potentialities of these areas and the overloading, impede the enhancement of mobility androad security.

\subsubsection{Underdeveloped human capital}

67. Human capacities are skills, knowledge and aptitudes that enable a society to create capital and technology, sustainably process and develop natural resources for greater use and promote an environment conducive to the improvement of productivity. The inadequacy of human capital has, for a long time, contributed to the low level of productivity. It is measured by the level of training and acquisition of knowledge through professional experience, on the one hand, and health care expenditure, on the other hand. Well-trained and healthy men constitute sources of production of goods and services and contribute to competitiveness because of the existence of strong complementarities between factors of production, human capital and physical capital.

68. Studies conducted in some developing countries, revealed a significant impact of education and training on economic growth (a contribution to growth of $23.2 \%$ for Ghana, $16 \%$ for Nigeria, $15.9 \%$ for Korea). The development of human capital as the key objective for the improvement of competitiveness supposes a positive development of the education and health indicators.

69. However, in Senegal, the levels of education and skills are still relatively low and the areas covered are too limited. This results in low productivity due to poor proficiency and low degree of application of science and technology; thus the use of rudimentary production techniques are still observed. According to statistics provided by the last survey on poverty in Senegal (ESPS-2011), 72.4\% of heads of households have no education.

70. The low productivity is particularly accentuated by the fact that the low level of education is not compensated by continuing training, which is almost non-existent both on the side of the State and of private firms which hardly invest in the upgrading their staff's knowledge.

\subsubsection{Insufficient access to financing}

71. The role of the private sector is essentially limited by the low level of private investments, especially in the informal sector; the difficulties of access to funding and land; a business environment less conducive to private investment and a way of organizing businesses that 
does not foster their expansion.

72. The financing system ${ }^{15}$ hassubstantially grown in size during the $2000-2011$ period from $22.5 \%$ to $39.8 \%$. Besides, the extensive campaign to promote the use of banking services and non-cash means of payment led to an increase in the rate of access to banking services from $6.2 \%$, in 2009 , to close to $19 \%{ }^{16}$, at the end of 2010 . Domestic credit rose from 1122 billion, in 2006, to 2122 billion CFAF, in2011, with aprominent share representing credit to the economy.

73. Moreover, the financial system is marked by a high concentration of credit allocated by banks to major companies. With regard to the breakdown per business segment in percentage of the total loans between 2006 and 2010, services, transportation and communications increased from $30 \%$ to $34.5 \%$ while industry represents $28.9 \%$ and $21 \%$. The third activity sector comprising wholesale and retail trade recorded $18.9 \%$ in 2006 and 2010.

74. Besides, it is worth noting that the domestic credit granted to the private sector in percentage of GDP slightly exceeds the average for low-income African countries: it rose from $23 \%$ in 2006 to $29 \%$ in 2011 . However, there is need to strengthen in order to overcome difficulties of businesses to access financing. SMEs and SMIs have difficulty to access financing because of the high amount of bank guarantees required which can go up to $150 \%$ of the value of credit requested, depending on the sector. Moreover, they turn to costly alternative solutions like self-financing and supplier credit or to Decentralized Financing Systems (DFS), with low financing capacities and refinancing difficulties. Resorting to the sub-regional financial market is still very marginal because of the lack of promotion of stockmarket culture.The diversification and adaptation of products as well as the reform of required guarantees still constitute challenges for the expansionof the financial market.

75. With regard to microfinance, the obstacles facing the DFS are: insufficient supervision, deterioration in the credit portfolio and lack of credibility of information provided by some DFS. The latter also suffer from the non-existence of a deposit guarantee fund, lack of familiarity with the cycle and characteristics of existing agricultural sub-sectors and value chains that make them up, lack of savings culture and difficulties to formulate needs in the rural world. These constraints give rise to the average percentage rate of charge estimated at between $12 \%$ and $40 \%$ in 2010 , while the wear rate fixed at community level is $27 \%$.

\subsection{Major challenges}

\subsubsection{Good Governance and Rule of Law}

76. The political and economic variables like democracy, the rule of law, the existence of functional and efficient institutions, accountability, integrity and good governance constitute the elements that contribute to growth and competitiveness. The absence or weakness of these various factors has led to poor performance and distortions prejudicial to an optimum allocation of resources.

77. Public administration reforms were initiated within the framework of the different policies. However, they remained essentially focused on the quality of the macroeconomic framework, which was considered as the most important determinant of growth. The deficiencyof the method of organizationand incentive systems, i.e. the institutional framework that should underpin the relationships between the different actors of society, is a major constraint to

\footnotetext{
${ }_{16}^{15}$ Measured by the monetary mass M2 in percentage of GDP

${ }^{16}$ Opening of accounts in banks, micro-finance institutions and the postal network Stratégie Nationale de Développement Economique et Social
} 
emergence. The poor socio-economic performance can be explained by the distortions in the functioning of the institutions of the Republic. Difficulties to communicate and coordinate the roles of the different actors, namely the State, actors of decentralization, the civil society and the private sector have led to the inefficiency of institutions. The poor application of rules, the citizens' difficult access to information and public services, the slow procedures, lack of transparency, corruption, the use of public services and community facilities at the detriment of public interest encourage them in allocation of resources and lead to poor economic and social resources.

78. Moreover, administrative governance requires thephysical and operational modernization of structures, human resources development, the intelligent coordination of the different programmes,the promotionof the participatory process in public action and the simplification of procedures. It should also be exercised in a result-based management culture.

\subsubsection{Preservation and restoration of natural resources}

79. The abusive use of natural resources for consumption purposes is the main justification of the state of environmental degradation. With the options of creating opportunities for the populations, this challenge seems to be very important for the agriculture, forestry and fisheries sectors. Environmental threats have become real and are already reflected in the declining rainfall and biomass, among others, while the soils have at the same time become less and less fertile. Without an efficient management capable of reversing this trend, it will be impossible to attain a steady growth in production.

80. This requirement is more pronounced in the agricultural sector where natural capital is the primary means of production and the operating systems have a direct impact on the acceleration ofdegradation. With the development of organic inputs and the use of nondestructive means of production, thechances of increasing productivity and stepping up the income of actors are on the increase and compliance with the principle of intergenerational solidarity becomes easier. It will therefore entail being in line with the process of reversing the trend, notably by building incentive systems conducive to sustainable growth and the preservation of natural resources.

81. It will also be reflected in public policy options, ensure the preservation of biodiversity, job creation with a view to significantly reducing poverty and inequalities.

\subsubsection{Profile of entrepreneurship and job creation}

82. In view of its demographic profile, Senegal is confronted with the obligation of creating thousands of jobs this year even though the current configuration of the economic system does not produce enough job opportunities. The national supply is way below the demand. The State has multiplied the initiatives to fight against unemployment. Self-employment and the culture of entrepreneurship were promoted. Unfortunately, most Senegalese businesses operate on the basis of a model of entrepreneurship, which links them directly to public finances. 
Relying on entrepreneurshipto create jobs is, above all, distinguishing the different profiles of repreneurship, which are three in number. The first, called « Business to Government - B2G», concerns business activities linking private businesses to State services. Companies with this profile generally depend on public procurement. The second type, "Business to Consumer - B2C», refers to business transactions concerning individuals or final consumers. The last model referred to as "Business to Business-B2B», characterize exchanges between businesses.

83. Because of its weakness and profile, the national private sector recruits at an insufficient pace to absorb the national employment demand. Its concentration on the B2G model undermine the job creation potential because public treasury difficulties lead to the lethargy of the private sector. Besides, the traditional public service cannot be a source of massive job creation. With the promotion of ICT within the public administration and the concern to rationalize public spending, the massive recruitments or the systematic replacement of each retiree are no longer appropriate.

84. Thus, the major challenge to be addressed involves encouraging competitive entrepreneurship, under the formal B2B and B2C models, in growth areas and sectors, through economic structuring into value chains. 


\section{Chapter II : Strategy for Economic and Social Development}

2013-2017

\subsection{Challenges}

85. The economic and social policy was prepared in a difficult context, with a demographic transition which is putting a lot of strain on the labour market, health and education structures, urbanization, on the one hand, and a relatively low and erratic economic growth, on the other. The NSESD should provide relevant responses to replace the Senegalese economy on a higher and more sustainable growth path. It entails implementing reforms likely to trigger a resurgence of productivity essential for development and thus lay the foundations of a new model of economic growth.

\subsubsection{Public policy efficiency}

86. The preparation of appropriate public policies highlights the major role of sectoral planning units and is a precondition to the implementation of the NSESD. From the standpoint of efficiency and efficacy, adjustments should be made in the following areas: the quality of information systems such as the national statistical system, the selection of steering instruments, evaluation of public policy implementation mechanisms, strengthening capacities to analyze public policy and finally, evaluation of the impacts of the economic and social policy.

87. It will also involve maintaining a healthy macroeconomic framework in line with the new growth model and preparing relevant sectoral policies, underpinned by structural reforms. These reforms primarily concern the incentive systems in favour of effort and work, rational risk taking, the enterprise and profit, in exchange for rent and interest. Thus, the national economy, both the real sector and the financial sector, shall strive, through regulation and market incentives, to upgrade the populations' living standard and address the challenges of demographic transition.

88. The monetary policy shall contribute to the creation of an efficient financial infrastructure, while taking guarantee measures that promote risk-taking, in particular, by banks.

89. The organization and strategic and operational planning will complete these incentive schemes. All the organizations participating directly or indirectly in wealth creation and the improvement of the efficiency of collective action, should be concerned by the new incentive scheme. There is need to guarantee market efficiency, maintain competition and provide the backing of public resources to strengthen private sector competitiveness.

\subsubsection{Viability of the macroeconomic framework}

90. The State will ensure the stability of the macroeconomic framework by containing public deficit, reducing external imbalance with a view to significantly improving the living conditions of the populations.

91. In this regard, output growth should be built on a more solid foundation, through a revenue distribution policy which first promotes productive work, rewards private initiative and overcomes some forms of disparities, notably regional and gender-related. Resource distribution should be directed towards activities with the maximum added value and creating the greatest number of jobs. This calls for an effective targeting ofinterventions to 
ensure the optimum distribution of public resources.

92. The reduction of the balance of trade deficit through more dynamic exports and greater imports selectivity, a significant contribution of agricultural production to wealth creation, a business climate conducive to investments and risk-taking, improved competitiveness, should contribute to ushering the national economy into the path of prosperity.

93. Output growth should be based on more solid foundations and revenue distribution that is more focused on productive work and the reduction of social and spatial disparities. In an economy marked by resource shortage, there is need to provide as much clarification on budgetary trade-offs as possible, in order to guarantee the efficiency of public spending. At the same time, the debt policy should no longer be evaluated on the basis of viability criteria alone, but on the basis of considerations relative to the opportunity cost of capital and best alternative uses allowed by the borders of economic opportunities//the possibility of the economy.

94. The policy should be formulated after a large consultation, at national and regional level with the participation of all actors (State, private, civil societies and beneficiaries). Through this participatory process, each sector and each region should be able to evaluate the implementation of economic polices over the past years, define the guidelines, identify the potentialities, determine priorities and attendant measures necessary for the success of the new policy. The NSESD intends to mobilize all development actors around these strategic elements.

\subsubsection{Demographic window of opportunity}

95. The economic and social policy thus implemented should, in the final analysis, be beneficial to the populations. In fact, the interaction between demography and economy will be at the center of the economic and social development issue.

96. The Senegalese population is predominantly young. The economic support ratio which measures the capacity of the population to contribute to the current production, has been on the increase since 1998 and will be maintained at that level up to 2025, before declining. Senegal should therefore take advantage of the structure of its population per age between 2000 and 2025 during which it will have an enormous active population to contribute to national production.

97. Actually, with the expected decline in the demographic dependency ratio17, a «window of demographic opportunity » is opened (2000to2025). This phase corresponds to the period in which proactive policies should be implemented in order to benefit from the positive impact of demography on economic growth. In fact, if the appropriate economic and social policies are implemented, significant effects will be registered in the fight against poverty. Beyond this period, the fruits of economic growth might be offset by the increase in the active population.

98. While the youthfulness of the population is a major advantage for economic growth, it constitutes a core issue for basic social services. The quest for better health coverage, a quality education system, and access to water, sanitation and a decent living environment, are all areas that need investments. Moreover, there is need to ensure protection against social scourges, eradicate the exploitation of children and improve civic and citizen education services.

\footnotetext{
${ }^{17}$ Relationship between the inactive population of working age, likely to make social security contributions. 


\subsection{Vision and intervention strategy for the $2013-2017$ period}

99. The Senegalese society agreed on a long-term vision based on the finality of «emergence in intra and inter-generational solidarity ». " Emergence in solidarity » reconciles responsibility and freedom, efficiency and justice and finally, the economic and the social aspects.

100. Through this vision, Senegal relied on political values that govern relations between human beings as well as on the principles of rationality, control and efficiency. Thus, in2035, the Senegalese society should succeed in accumulating a huge quantity of tangible and intangible goods, reflectedby high standards of living .

101. The NSESD, drawing inspiration from this vision, charts the course up to 2017, with a view to delimiting the 2035 trajectory. However, the success of the economic and social policy depends on the establishment of solid structural foundations capable of boosting development. Actually, economic development and social progress can only be possible if sustainable peace is guaranteed both at national level and beyond the borders. The present globalization context is all the more real since it brings to mind the obligation to integrate the implications of geopolitics, regional integration and international commitments.

102. The future of Senegal is in the hands of its population which is increasing in terms of merit, ambition and commitment, regardless of the area of activity. These values are defended, applied and protected by citizens imbued with ethics, deontology and civic-mindedness. Ushering Senegal into the paths of development is a collective responsibility, which banishes all forms of corporatist or elitist exclusivity. Finally, the strong involvement of citizens will compel policy makers to ensure transparency and accountability in the management of public affairs and display technical skills and humility in strategic orientations, the consequences of which will be assumed by the entire nation.

103. Moreover, there is need to institute a legal environment conducive to development and ensure the deconcentration and decentralization of human and financial resources, in terms of transferred competence. The creation of a level of sustained and durable wealth, likely to reduce social inequalities, entails strict compliance with public finance management rules; thus the need to absorb the macroeconomic deficits and control the level and pace of indebtedness.

104. The huge productive investments and the economic diplomacy process help develop private initiatives and boost foreign capital flows. Moreover, the role of the banking and financial system in the supply of capital is refocused and expanded by facilitating the accessibility of SME/SMI to conventional bank credit, on the one hand, and promoting the possibility to resort to the financial market, on the other. In the same vein, the legal and regulatory business framework is readjusted, in collaboration with targeted actors. Restoring the economic fabric resulting from it will enable constituted businesses to reduce their dependence on public procurement and absorb the available workforce, alternating it with public service recruitments.

105. These growth support initiatives help step up national competitiveness because they are global productivity factors.Incidentally, the Strategy seeks to increase the production of goods and services, by developing the agricultural economy, reviving the industrial sector and increasing the supply of services. In this process, the regional growth poles are highlighted to trigger a fresh economic and social development impetus throughout the country .Thus, achieving food security and promoting exports will be all the more facilitated since national production will cover the needs expressed.

106. In view of its crucial role, the Strategy lays special emphasis on the promotion of human 
capital. In fact, the efficiency of the level ofproduction depends on the quality of employed labour. This entails the existence of an education and health system capable of providing human resources that fulfill the requirements of the labour market. Besides, the institution of a framework conducive to sustainable development, risk and disaster management and the reduction of vulnerabilities and gender inequalities, contributes to this effort.

\subsection{Strategic objectives}

107. On the whole, the NSESD seeks to accelerate economic growth and step up productivity. It strategically sets the orientations in the productive and production support sectors in the first pillar. The key component of this pillar is the Accelerated Growth Strategy (AGS). Through this strategy, the cluster approach encourages stakeholders to build fruitful partnerships around growth sub-sectors whose products can enjoy national or international visibility. This approach becomes operational through the structuring of the main productive sub-sectors into value chains, on the one hand, and the implementation of local cluster projects in sectors with high value creation potential, linked to incubators and networks ofbusiness incubators throughout the country. To this end, it has become imperative to identify each region (or territory), depending on its comparative advantages, as an exporter of specific products to the rest of the country, the sub-region and the world.

108. For this first pillar, the NSESD recommends the territorialization of productive activities, by initiating projects for special economic zones, scientific technological parks, incubators and creating other economic poles, in collaboration with local governments.Thus, the implementation of the AGS has become a key objective of the NSESD during the 20132017 period.

109. For sustainable development to succeed, there is need to develop the human capital, to which the objectives set in the second pillar will contribute. The third pillar controls the production and social development environment through governance, strengthening the institutions, constructing lasting peace, justice and human security.

110. In terms of strategic objectives, the NSESD is in line with the prospective study "Senegal 2035», of which it is a five-year illustration, on the one hand and on the other, with the government's policy guidelines, the AGS, international commitments (MDG and post-MDG), multi-sectoral policies (for example : SNPS National Social Protection Strategy ).

111. Thus, at the sectoral level, the strategic planning tools like Sectoral Policy Letters (SPL) and Medium-Term Sectoral Expenditure Framework (MTSEF), should take into account all the strategic objectives, lines of action and measures of the NSESD. The sectoral documents may include operational guidelines that contribute to achieving national economic and social development objective. Finally, the ultimate issue lies in the capacity to initiate, design and implement sectoral projects/programmes that contribute directly to fully achieving the NSESD, expressed in the lines of action and measures.

\subsubsection{PILLAR 1: Growth, productivity and wealth creation}

112. The consolidation of a healthy and stable macroeconomic framework in a business environment conducive to investments, helps promote global economic productivity. In this respect, the implementation of policies to develop productive sectors and support production guaranteeing competitiveness, calls for the prior strengthening of production sectors. It primarily involves energy and infrastructure, which are the key sectors for the integration of the economic fabric, and technological factors like Information and Communication Technologies (ICT) and telecommunications. Thus, in order to accelerate growth, the development of agriculture and rural economy should be combined with the promotion of 
SME/SMI and the support of the industrial sector and other market service activities. Besides, the productive sub-sector structuring process, already launched in connection with the growth cluster, should be maintained and strengthened in order to make the most of the potentials of these sectors and sub-sectors in terms of contribution to economic growth and the diversification of growth sources. In this context, an efficient integration of the external environment guarantees the chances of redeploying the national economy.

\subsubsection{Viability of the macroeconomic framework}

113. Maintaining a stable macroeconomic framework is the basis of strategies to be implemented in order to boost and maintain sizeable economic growth, with a wide sectoral and social basis. In fact macroeconomic stability is essential to contain inflation and interest rate volatility, reduce risks and uncertainties for investors and create conditions conducive to sustained revenue growth. The objective of ensuring the stability of the macroeconomic framework, expected of the NSESD, will be pursued by improving the business climate, stabilizing public finance and containing inflation.

114. Capitalizing on a healthy and stable macroeconomic framework calls for convergent policies for the development and diversification of growth source, to the credit of the private business and local communities initiative. In fact, one of the greatest challenges of national economic development lies in the fact that territorial and their linkage with sectoral policies are taken into consideration. From this standpoint, there is need to devise and implement a territorial approach to development which links land-use planning to decentralization, integrates the regionalization process and materializes the major regional development poles.

115. The objective of an average annual growth rate of $6.8 \%$ is achievable, judging by the interventions scheduled in the productive sector, the implementation of the plan for the revival of the electricity sub-sector and all NSESD priority measures. The economic governance actions will help improve the marginal efficiency of public investments, withthe development ofpublic-private partnership. In view of the poor performance registered since 2006, an alternative of the Senegalese economy consists in massive investments with high FBCF content, to substantially reduce poverty in the rural areas and hunger by 2017 .

116. In the bid to control public spending, the Strategy provides for a substantial increase in annual budget receipts expected to rise from 1569 billion CFAF in 2012 to 2206 billion CFAF in 2017. Tax receipts are expected to increase from 1492 billion CFAF in 2012 to 2152 billion CFAF in 2017, subject to the implementation of the new tax reform considered more attractive and more efficient. Total expenditure will rise from 2190 billion CFAF in 2012 to 2 912 billion CFAF in 2017. As a result, public finances should improve in 2017 with a global budget balance below $3.6 \%$ of GDP in 2017, against 5.9\% projected in 2012. The additional resources projected during the period is about 1493 billion CFAF, half of which should come from State resources. The rest will be mobilized through Technical and Financial Partners' funding in the form of grants and concessional loans. The marked deterioration of public deficit is due to the substantial increase in investment spending to support the effort made to catch up with the delay observed in the infrastructure sector.

117. Besides, the current account balance is expected to stand at 5.3\% of GDP at the end of the period. This performance would slightly improve the balance of trade, in particular. The global balance of payments is over target during the entire period, reflecting an increase in the net external assets for the period from 826.6 billion CFAF in 2013 to more than 2600 billion CFAF in 2017, a substantial increase in the average annual growth rates of domestic credit and of the monetary mass. To that end, the Strategy includes strengthening the export potential and inflows of foreign direct investments. 
118. In terms of GDP use, final consumption should improve slightly with an average of $5 \%$ during the 2013-2017 period. In real terms, it is expected to increase a bit slower than GDP (about 6.7\%) while the Gross Fixed Capital Formation (GFCF) could register an average growth rate of $9.5 \%$ attributable to the efforts to improve the GFCF public investment content and the new initiatives to boost private investment. Private GFCF is expected to increase by an average of 5.7\%. As a result, the investment rate measured by the GFCF could reach about $26 \%$ of GDP during the NSESD implementation period, notably with the continuation of works relative to the developmental infrastructure programmes for the densification of the economic fabric.

119. With regard to the net external demand, the exports of goods and services will register an average increase of $7.5 \%$ in real terms, while the importation of goods rose to $6.3 \%$ in real terms. The general price level, measured by the GDP deflator is projected below $1.3 \%$ during the period following an upsurge in inflation linked to the increase in the oil price noted over the past years. However, the conduct of a good monetary and budgetary policy would help maintain inflation below the community threshold of $3 \%$.

120. For the 2013-2017 period, Senegal undertook to: (i) step up the economic growth rate to an average of about7\%; (ii) reduce the public deficit to below 3.6\% of GDP, at the end of the period; (iii) improve the current account balance at (-) 4.5\% of GDP and (iv)stabilize the indebtedness ratio to less than $30 \%$ of GDP.

\subsubsection{Employment Promotion}

121. The New National Employment Policy is based on the relevant public policies on the promotion of employment. The average annual number of new potential job seekers ${ }^{18}$ is 202000. To ensure full employment and contain demographic growth, the economy should generate close to 150,000 jobs every year. There are plans to create at least 50,0000 jobs, during the 2013-2017 period. The jobs referred to concern the formal private sector and the public service with the progressive establishment of the local civil service. The said jobs also concern those required for the constant modernization of traditional businesses of the informal sector. For the next five years, the Strategy targets the following major strategic objectives:

i. promote massive job creation, through the promotion of public investments in highly labour-intensive activities and self-employment among youths by developing skills, implementing incentives to promote investments and job creation in the private sector, providing support for the integration of the military and paramilitary staff released from active service;

ii. improve the monitoring and management of the labour market, by organizing and upgrading the informal sector, installing a labour information system, regulating the labour market and rationalizing project funding structures, setting up a national system to evaluate technical and professional apprenticeship and validation of professional experience, setting up the national observatory of employment and professional qualifications and operationalizing the trades and occupations directory.

\footnotetext{
${ }^{18}$ Economic and social situation of Senegal, 2010, ANSD.
} 


\subsubsection{Development of the private sector}

122. The private sector is the driving force of wealth creation. In the perspective of its development, the promotion of new opportunities to develop economic activities, particularly job creating activities, should be strengthened by targeted programmes in support of the increased productivity and income of the populations. Special programmes will target groups like micro-businesses and small-scale businesses, youths of the countryside and suburbs and handicrafts. Specific programmestargeting women in production will also be encouraged, to ensure the supply of major urban centres and for export purposes. On another issue, independent producers as well as major businesses national or international- have an important role to play for the substantial increase in exports.

123. Such interventions should seek to create more skilled jobs in the rural areas and reduce the size of the informal sector. Thus, the regional development poles will be deployed in the process of conquering the domestic market, by exporting diversified and competitive products and services. Strengthening public-private dialogue will make it possible to identify other obstacles to be lifted, as a matter of priority, with a view to consolidating the viability and competitiveness of businesses.

124. The facilitation of access to financing gave rise to new initiatives for greater efficiency of guarantee funds and the development of factoring, the leasing agreement, venture capital and export credit. A decision was taken to rationalize the creation of credit lines and mutualize the costs of their management within a bank set up for SMEs. In turn, credit information offices will be set up next to the central balance sheet and risk offices, to facilitate access to information on businesses and borrowings. However, measures to be implemented to substantially improve competitiveness require a strong commitment of all segments of the public administration, the private sector and social partners.

125. The development and promotion of SMEs are based on the following strategic objectives:

i. improving the business environment by promoting youth entrepreneurship, encouraging the creation and development of businesses by women, the implementation of decisions taken by the Presidential Investors' Council and strengthening the share of national private capital in the economy ;

ii. facilitating access to financial and non-financial services, through the creation of the Priority Investments Guarantee Funds (FONGIP) and a Sovereign Strategic Investment Fund (FONSIS) , support to businesses in difficulty, finalization of the consultation on credit and stepping up funds earmarked for women entrepreneur ;

iii. consolidating the technical support and steering mechanism, by supporting the creation of service providing companies in each integrated economic pole, creating a "Small Businesses and SME-SMI Pact » integrating and strengthening business support mechanisms, reactivating industrial parks, setting up an SME Observatory, revising the Investors' Code and monitoring the " demography of companies ». 


\subsubsection{Development of productive sectors}

\subsection{Energy infrastructure and services}

126. The energy sub-sector plays a transversal role in the implementation of public policy. However, the low rate of access to modern energy services is a limiting factor for social and economic development. In its White Paper19 ECOWAS approves the targets - to which Senegal has adhered- for access to energy services. The sectoral vision is meant to ensure a more equitable geographical distribution of modern energy services covering the needs in terms of rural and urban electrification, driving force and domestic fuels to fight against poverty and preserve the environment, notably by promoting clean energy.

127. The following strategic objectives have been identified for the energy sub-sector:

i. promote access to energy services, by accelerating rural electrification, increasing the renewable energy supply, stepping up the capacity to produce electricity, improving access to hydrocarbons and domestic energy, integrating photovoltaic solar energy in structures and public buildings and securing the capacities and conditions of storage;

ii. promoting energy control and saving by promoting the use of energy-saving household appliances and promoting energy saving and substitution equipment ;

iii. improving the energy sub-sector management framework, b y improving the regulation, pursuing SENELEC's institutional reform and strengthening the Energy Information System (SIE).

\subsection{Transport infrastructure and services}

128. It is essential to develop the transport infrastructure and services to establish a competitive economy and strong growth. The construction of infrastructure is a priority because of its positive impact on the servicing of the country's major economic poles. Public investment spending is also expected to have a ripple effect on job creation, subject to the possibility to fabricate inputs locally. In this respect, public infrastructure makes private investments more efficient, lays the foundations for the creation of industries and paves the way for integration.

129. The transport infrastructure and services sub-sector has the following strategic objectives:

i. developing road, rail, airport and port infrastructure, through the construction, rehabilitation and maintenance of rural roads in production zones, the construction and rehabilitation of roads and structures as well as rail infrastructure, the modernization of bus stations and airport infrastructure, consolidating the portplatform facilities and conducting technical studies for all transport infrastructure project/programme;

ii. developing and modernizing transport services, by developing a modern public transport system in major cities, renewing and consolidating public transportation vehicle parks, improving and ensuring the security of inland waterways, strengthening the competitiveness of the Dakar Port and stepping up the prevention of risks linked to all forms of pollution;

iii. promoting good sectoral governance, with the reinforcement of road security, the strengthening of capacities of actors and the management of the sub-sector as

\footnotetext{
${ }^{19}$ White Paper for a regional policy, Decision A/DEC.24/01/06 of 12 January 2006.
} 
well as the preparation of a Ports Code.

\subsection{Financial infrastructure and services}

130. The global objective is to ensure the stability and solidity of the financial system, by consolidating the banking sector and ensuring the sustainability of the microfinance sector. The new regulation introduces provisions on the protection of depositors. In this regard, a project for the institution of a guarantee fund for bank deposits and DFS is being pursued and emphasis will be laid on enhancing transparency in the pricing of banking and financial services and on the increased competition between credit institutions, for the benefit of users of banking and financial services. With regard to the prospects of adapting to international standards, the revision of the Bank AccountingPlan that seeks to ensure its compliance with the IAS/IFRS standards in force, will be pursued.

131. With regard to the new programming cycle, the microfinance sub-sector intends to consolidate and sustain itself by progressively integrating the global financial sector. However, this movement should be done while respecting the identity of the sub-region and its specific contribution to the national economy. Two strategic objectives are being pursued:

i. diversify and adapt the supply of financial products and services, by facilitating access to credit for youths and women, the development of $\mathrm{new}$ means of payme $\mathrm{nt}$, strengthening the presence of microfinance institutions in the rural areas, promoting Islamic finance, promoting the savings culture and improving the access of DFS to non-financial services as technical support;

ii. improving the microfinance environment, by strengthening the regional, legal and regulatory microfinance framework, promoting appropriate guarantee mechanisms for DFS, improving DFS information and management systems and establishing a Risks Office for Decentralized Financial Systems (DFS).

\subsection{Communication, telecommunication infrastructure and services}

132. On the whole, significant progress has been noted thanks to the reforms and policies implemented in the ICT and telecommunications sub-sector. To play a major role in growth and production, the ICT and telecommunications sub-sector has the following strategic objectives:

i. developing the digital economy, by extending a global license to all operators, creating technological poles and consoliding ICT business incubators, supporting the emergenceof the ICT industry, preparing and implementing a national strategy for the development of the digital economy and implementing incentive measures provided for within the framework of the law on the information society;

ii. reducing the digital divide by installing facilities for access to ICT, promoting very high output Internet service, developing the universal telecommunications service and completing the passage from analogical to digital ;

iii. democratizing access to and use of ICT by training and sensitizing the population about the opportunities offered by the sector ; 
iv promoting good digital governance by improving the functioning of the administration with on-line services, preparing a National Geomatics Plan (PNG) and expanding and consolidating regulation and observatory missions;

v. promoting good audiovisual governance by adopting a new Press Code, adapted legislative and regulatory texts and instruments, upgrading the national radio broadcasting system to meet international standards and promoting educational, cultural, economic and medical contents in audiovisual production.

\subsubsection{Integrated development of the rural economy}

133. All things being equal, a $6 \%$ agricultural GDP growth will substantially contribute to bringing back the growth of the national economy to the trend observed in 1995-2005, thus reducing Senegal's dependence on food imports and lowering the balance of trade deficit. It will, at the same time, improve the food security level. The MDG- $1 \operatorname{target}^{20}$ would be virtually attained both at national level and in cities, but the relative poverty of the rural areas will persist. It will thus be necessary to reactivate agriculture and the rest of the rural economy to ensure that the rural populations benefit more equitably from the distribution of the fruits of growth. This will entail enhanced land-use planning through the redistribution of agricultural and rural investments and a greater participation of all the other rural areas in the development of a growth process.

134. The National Agricultural Investment Programme (PNIA) which is meant to address the challenges which the Common Agricultural Policy of theEconomic Community of West African States (ECOWAP), the sub-regional counterpart of the Comprehensive African Agricultural Development Program (CAADP),intends to meet this challenge. Thus, the objective of halving the incidence of acute poverty and hunger will be more achievable if the State is in keeping with the target of progressively devoting up to $10 \%$ of its domestic resources to the development of agriculture. The very strong interactions between the agricultural branches, as well as the equally substantial flows between the latter and the rest of the economy strengthen the effects of the complementarity between public and private investments and constitute an important determinant of global GDP growth.

135. Within the global context of growth acceleration, the reactivation of the rural economy and the development of agriculture, the food sub-sectors have maximum outlets and opportunities to reconcile the increase in the producers' income and the defense of the purchasing power of urban consumers through greater productivity. The integrated recoveryof the rural economy will materialize through policies meant to develop the primary or agricultural sectors in the wider sense.

136. Concerning the boosting the rural economy, the Strategy lays particular emphasis on the diversification of production, organizing the agro-sylvo-pastoral sub-sector, water control, agricultural development,reduction of the vulnerability of farming activities, modernization of producers' equipment,institution of production support facilities, access to quality inputs, the organization of productive sub-sectors, enhancing the marketing of products and the control of distribution channels

\subsection{Agriculture}

137. In view of the strong fluctuations and down trend of crop yields, more emphasis should be laid on irrigation, agricultural research and extension, in order to reverse this trend. The

${ }^{20}$ Halve, between 1990 and 2015, the proportion of the population with an income of less than a dollar a day. 
agro-sylvo-pastoral orientation law defines an integrated framework for the 2004-2024 period, conducive to the development of agriculture, livestock production and forestry and that of the rural populations. Many initiatives have been taken to provide pragmatic responses to the constraints thwarting the agricultural sub-sector.

138. Agriculture has some leeway for increased production, because of the arable and/or irrigable land reserve that has not yet been exploited, a rise in productivity that is still possible for the active rural population, notably women. Modern large-scale agriculture also has scope for improvement. Moreover, agriculture as a whole can strengthen its trade relations with the other sctors by developing value chains and processing activities. In turn, for the modernization and growth of agriculture and to develop prural SME and SMI, the levers on which to act are the roads and transport infrastructure, ICT, notably for access in real time to agricultural products markets, water resources, energy, agricultural and rural credit, mechanization, education and training of farmers, agro- industry and manufacturing activities.

139. The key objective of the LOASP is to turn agriculture into the driving force of a viable momentum for progress. In accordance with the LOASP guidelines, this Strategy seeks to step up the contribution of agriculture to economic and social development .To that end, the key specific objectives targeted in 2017 are as follows:

i. increase production and improve agricultural productivity, by modernizing the equipment used by agricultural workers, promoting the poles of emergence and Common Agricultural areas (DAP), creating and developing agricultural products, supporting the marketing of agricultural and market gardening products, improving the producers' access to agricultural loans adapted to their needs, the sustainable management of production, sustainable management ofland as well as the support and development of agricultural research;

ii. improving the agricultural sector management system, by strengthening dialogue between the State, professional organizations and the other actors; building the intervention capacities of support structures, setting up a harmonized gender sensitive monitoring-evaluation system, preparing and implementing a master plan of agricultural statistics and adopting a new land reform that takes into account the rural registry and the actors' equitable access to land ownership.

\subsection{Livestock production}

140. The livestock production sub-sector is of vital importance in both economic and social terms. In fact, its extensive scope for improvement should help increase the productivity, production and income of livestock producers substantially. However, this supposes a change of option and strategy, by securing pastoral stock farming and the emergence of a new type of exploitation well suited to the realities of our market. Thus, the overall orientation of the subsector is to meet the national demand in animal products and ensure the socio-economic promotion of actors.

141. The strategic objectives pursued by the animal production sub-sector are :

i. improving the production, productivity and competitiveness of livestock production by intensifying and developing poultry, improving the production of livestock, strengthening pastoral infrastructure and equipment, promoting modern animal production units, improving the conditions of marketing of animal byproducts and creating a pastoral insurance system;

ii. improving sectoral management, with the support to professional organizations, improving the monitoring-evaluation system of the sub-sector, improving the 
legislative and regulatory framework of the livestock production sub-sector and building the intervention capacities of competent technical services.

\subsection{Fisheries and aquaculture}

142. The overall objective is to turn fishing and aquaculture into a sub-sector that will continue to contribute substantially to economic growth, to the well being and feeding of the populations through a sustainable management of the proceeds from fisheries and the accelerated development of aquaculture production and continental fishing.

143. The following strategic objectives have been identified for the fisheries and aquaculture subsector:

i. sustainably manage fisheries resources by implementing the fisheries development plans, promote joint management in the small-scale fishing sector, promote a policy for the restoration and restocking of degraded ecosystems and regulate access to fisheries resources;

ii. improve the production and productivity of fisheries and aquaculture thanks to the promotion of sustainable fish farming for consumption and commercial purposes, facilitate access to credit for fisheries and aquaculture actors, establish basic infrastructure for the development of continental fisheries and aquaculture and promote applied research in fisheries and aquaculture ;

iii. Boost fisheries and fish farming production, by improving the conditions of access to the market and for the competitiveness of the industrial processing sub-sector, creating incubation platforms for the processing of fishery products, installing biotechnological laboratories in the fish farming zones and restructuring the fishery products processing industry.

\subsection{Irrigated agriculture}

144. In addition to the land potential, the country is endowed with substantial water resources, estimated at more than 35 billion cubic metres renewable, 31 billion of which comprise surface water (River Senegal, Rivers Gambia, Casamance and Kayanga) while 4billion is constituted by underground water. This evaluation does not take into account the uncontrolled runoffs; However, the level of mobilization of underground water resources (so far used essentially to satisfy the safe drinking water demand) is about $5.5 \%$. For better visibility in the diagnosis and planning of the strategy, the challenges to be addressed in the area of rural water services is attributable to the poor harnessing of water resources for agricultural production.

145. The agricultural water sector aims to make better use of surface and underground water for activities of the primary sector, by protecting fresh surface and underground water from marine salt and pollution, building hydro-agricultural infrastructure for developmental purposes, transferring excess water to dry areas, ensuring water control and developing hydro-agricultural facilities

\subsection{Food security}

146. To fight against food insecurity, there is need to target the eradication of extreme poverty and hunger in the medium term, through the promotion of self-sufficiency in rice, 
diversification of food products, economic and physical accessibility and the use of food products. Thus, the food security policy is linked to the modernization of agriculture and fits into a rural development process, which includes an important component consisting in the promotion of irrigation. The improvement of productivity in agriculture needs to be stimulated periodically through public investments in rural infrastructure, agricultural research and extension, irrigation and price incentives, so as to directly contribute to economic growth, the reduction of poverty and the improvement of the business environment, in the rural areas. Besides, do proper nutrition and health result from good health practices and adequate care, as well as the diversified consumption of healthy foods?

147. With the formulation of the Strategic and Incentive Framework to accelerate the implementation of MDG, the action plan linked to the initiatives on food security and nutrition will help accelerate the MDG achievement process by 2015. This framework will better guide the implementation of NSESD, by removing the bottlenecks in the productivity of the primary sector and the nutritional constraints. The Strategy includes the regional dimension of food security and the transborder cereal trade in order to better channel their quantity and the contribution of neighbouring countries in case of food crisis, through an effective coordination of interventions.

148. Besides, the importation of rice, despite the appropriate provisions reflected in the amount of irrigable land and high yields, is paradoxical. The rest depends on rain-fed agriculture with low productivity, rural infrastructure that needs to be strengthened, food stuffs marketing circuits that need to be improved, a rural economy that requires new technological gains and a monitoring and early warning system more effective in the detection and prevention of risks that hover over production and both the domestic and foreign markets. With a view to eradicating extreme poverty and hunger, interventions can be focussed on the quest for selfsufficiency in rice, andin foodstuffs. In the contributory sectors, emphasis will be placed on the improvement of production, the operation of foodstuffs markets and food aid quality management.

149. The following objectives are pursued during the implementation of the strategy:

i. strengthen the food crises prevention and management system, through enhanced food security, strengthening the early warning system and the agricultural market information system, including the use of the Improved Harmonized Framework.

ii. improve access to healthy and nutritious food by promoting food diversity and strengthening resilience among the vulnerable segments.

\subsubsection{Industry and agri-food processing}

150. The agri-food industry should actively participate in growth acceleration, because of the country's immense agricultural potential and its real and proven capacities in terms of diversification of processed products of agricultural, fishery and animal origin. Moreover, the textile and car industries are integrated into the targeted industrial deployment process.

151. Industrial deployment is therefore based on the following strategic objectives:

i. strengthen the competitiveness of industries, b y supporting access to SME funding and upgrading industries, setting up a technological monitoring system, strengthening standardization and the culture of performance and improving offer of services to investors; 
ii. fostering the development of endogenous industrial, through the spatial polarization of industrial development, the establishment of multipurpose community production workshops in both the rural and peri-urban areas, support for the creation of SME active in the fabrication of equipment and tools and the improvement of the industrial policy monitoring-evaluation mechanism.

iii. improve the competitiveness of agro-industry, by supporting the development of units and industries for the processing of primary sector production, promoting agribusiness in the processing of local products in order to create a sub-regional champion, supporting agro-industrial and agri-food research and strengthening the technical and managerial capacities of agri-food processing professionals.

\subsubsection{Mines and quarries}

152. The mining sector has experienced a recent renewal with the launching of gold production, in addition to phosphates and the prospects for the exploitation of iron deposits. To ensure returns on mining activities, there is need to act on the levers, namely the infrastructure for access to mining sites and markets, access to water, electricity, external outlets and strengthening pre-export processing capacities.

153. Significant achievements have been registered. But the sub-sector faced constraints linked to the inadequate human and physical means of the mining administration and the complexity of procedures for the formalization of the gold washers' profession, as a result of their unfamiliarity with the regulations.

154. The following strategic objectives have been identified for the energy sub-sector :

i. increase production and improve the productivity of mines and quarries, by reinforcing national private sector involvement in the exploitation of mines and quarries, simplifying mining rights and permit processing procedures, consolidating infrastructure in support of geological and mining activities and supporting quarry operators.

ii. promote the participatory and all-inclusive management of extractive activities, with the creation of clusters, in regionswith a strong mining orientation, with a view to polarizing mining activities, supervising the local populations involved in mining activities, reducing the effects of mining and quarry exploitation on the environment and health of the local populations, promoting mining exploration and improving transparency in the management of contracts.

iii. step up the competitiveness of the mining sector by strengthening actors of the mining sub-sector.

\subsubsection{Promotion of other services and sectors of production}

\subsection{Tourism}

155. Tourism is considered as one of the key sectors of the national economy. Its development requires the services and products of the agriculture, fisheries, handicrafts, cultural, building and civil engineering and transport sectors. The tourism activity also makes use of 
developmental public infrastructure that facilitate access to tourist sites, thanks to improved road networks, bus stations and ports and efforts to bring airports up to standard. This largely untapped multisectoral dynamics makes it necessary to rethink the development of tourism, following a global demand, with a cluster approach and within the framework of an efficient public-private partnership, involving local communities.

156. In view of the poor perception of the economic impact of the sub-sector, the global objective of tourism is to improve its visibility and the attractiveness of the destination, Senegal, with a view to stepping up its contribution to economic and social development.

157. To that end, the sub-sector has a strategic objective consisting in promoting an enhanced structuring and improving the tourism product quality, by diversifying the tourist offer through regional potentials and multisectoral initiatives for sustainable community development, the design and development of the Pointe Sarène, Mbodiène, Joal Finio, Grande Côte,Saloum Islands sites,the construction of developmental infrastructure and leisure facilities in tourist sites, the promotion of a communication and marketing system, the creation of conditions that are conducive to private investment and the regulation of the tourist offer.

\subsection{Handicrafts}

158. To ensure that handicrafts provide substantial income to actors, the policies are structured around the following strategic objective : modernize handicrafts and make its products competitive, by strengthening the productive base and the inputs and craftsmen's equipment supply system, facilitating access to the funding of handicraft projects, repositioning handicrafts on the production niches with high added value and developing a "brand » strategy, controlling and consolidating the distribution circuits and strengthening craftsmen's capacities, including professionalization.

\subsection{Culture}

159. The diagnosis shows that this sub-sector is confronted with lack of visibility of the cultural activity, the informal nature of the activity, the deterioration of cultural production, the nonexistence of a coordination structure, inadequate allocated means and administrative delays in the mobilization of resources. The global purpose of the policy to be implemented is to amplify the promotion of the expression of cultural diversity for the enhanced readability of the economic and social importance of cultural activity in the development of the country.

160. The following strategic objectives have been identified for this sub-sector:

i. step up the volume and quality of cultural production, by building and rehabilitating growth-related cultural facilities, improving access to credit for proponents of cultural projects, bracing the involvement of private individuals in cultural promotion, promoting the film, audiovisual and publishing industry as well as intellectual property and artistic rights and fighting against piracy;

ii. make full use of the cultural potential and natura l assets, by creating a solidarity fund for retired artists;

iii. improve the management of the cultural sub-sector, by decentralizing cultural services, organizing and regularly updating the cultural statistics and professionalizing cultural actors. 


\subsection{Sports}

161. The global objective of this sub-sector is to increase the contribution of sports to development and make it accessible to all, in view of its social, economic, psychological and therapeutic functions. To this end, the policies and strategies of the sports sub-sector essentially seek to promote sports and related activities, by building modern sports complexes, sports facilities and rehabilitating regional stadiums, developing sports in schools and fosteing the sports culture, promoting sports companies and related activities and improving sports management mechanisms.

\subsection{Trade}

162. The declared ambition for trade lies in the development of exports and the proper supply of domestic markets, at reasonable prices to enable businessmen and businesses to carry out their activities, in a competitive and modern environment, open to the outside world and marked by the fluidity of trade that has become more secure.

163. Thus, actions and measures are reflected through the following strategic objectives:

i. strengthen the capacities to provide goods and services, through the control of imports, the promotion of exports and e-commerce, the construction of modern marketing facilities that are evenly distributed geographically and the promotion of access to local and international markets;

ii. strengthen the institutional framework and the implementation of sectoral policies, with the professionalization of actors and marketing businesses and the establishment of a sectoral steering mechanism.

\subsection{International cooperation, regional integration and Senegalese Abroad}

164. To reactivate economic cooperation, regional integration and the participation of Senegalese Abroad, the Strategy seeks to:

i. develop a proactive economic diplomacy, through the reform and rationalization of the diplomatic map and the improvement of the quality of services;

ii. further regional integration, by rehabilitating and developing the infrastructure network, encouraging specialization according to the comparative advantages of States for a coherent integration, pursuing the implementation of regional economic programmes, removing impediments to the free movement of persons, goods and services and developing and intensifying intra-community trade.

iii. develop a proactive sub-regional diplomacy,with the institution of community monitoring mechanisms, the strengthening of consultations between neighbouring countries and Europe on migration issues, joint negotiations at the WTO for more equitable trade rules and the participatory and all-inclusive preparation and implementation of development policies ; 
iv. involve Senegalese Abroad in national development efforts, by popularizing productive investment opportunities among Senegalese Abroad, improving the management of the migratory statistics of Senegalese Abroad and promoting the transfer of knowledge and know-how of Senegalese Abroad.

\subsection{Research, development and innovation}

165. Access to technology is developed through continuous research \& development activities. Senegal needs to deploy sizeable efforts with regard to research and the capacity to absorb new technologies, notably in the coordination of research activities, scientific and technological production and the financing of research institutions. The main objective is to participate in accelerating the development process, through the application of science and technologies. This will entail promoting a better coordination of production and the dissemination of research results, a more efficient functioning of research institutions and refocusing and prioritizing research\& development activities.

166. Emphasis should be placed on research in strategic fields linked to the creation of farming systems adapted to the different agro-ecological zones. An operational partnership between research structures, the Agricultural and Rural Board and agricultural organizations and inter-trade bodies should significantly contribute to it. The specific objectives are:

i. promote Research \& Development, by progressively increasing the Research\& Development budget and strengthening South-South and North-North scientific cooperation in R\&D ;

ii. make full use of research results by transferring technology to the rural areas including the development of operational units, establishing a national scientific and technical information system and transferring knowledge and strengthening public-private partnership in R\&D.

\subsubsection{PILLAR 2: Human capital, social protection and sustainable development}

167. The satisfaction of basic social needs is an essential factor in the promotion of sustainable human development. Actually, access to basic social services has a direct impact on the quality of life. Moreover, it determines the economic opportunities offered to the populations. Without access to these goods and public or collective services, inequality in the face of opportunities will prevail at the geographical, community and individual levels.

168. Thus, the 2013-2017 Strategy includes the substantial increase in the offer of these infrastructure services financed through resources drawn from the acceleration of growth Improving and expanding social protection to the different segments of the population, achieving the MDG and pursuing the setting of pre-requisites for economic emergence require the State to have adequate budget room.

169. Besides, the initiatives, projects and programmes with high ecological, social and economic impact on sustainable development, on the one hand, and a greater consideration of the transversality of the environment, on the other, will receive outstanding support. Climate change whose effects are being increasingly felt, are factors of hydrological and thermal disturbances that can have an unfavourable impact on agricultural production, in the absence of the appropriate technologies. 
170. The new Strategy is intended to be a realistic framework federating all the actions that contribute to economic and social development, through access to basic social services, the protection of vulnerable groups and the promotion of green economy. More specifically, Senegal intends to give concrete expression to quality education for all, the management of mother and child health, access to a better living environment and the reduction of environmental degradation. There is also need to ensure that vocational training modules that match the needs of the labour market are accessible to the needy populations. Finally, there are plans to establish a global framework for social protection and disaster risks prevention and management mechanisms.

\subsubsection{Population and sustainable human development}

171. The demographic growth rate is estimated at $2.6 \%$ for the inter-censal period $188-2002$. About two out of three Senegalese are under 25 years old and life expectancy at birth is 59 . At this rate, the total populations will almost double every quarter of a century. As long as the annual efforts to satisfy basic needs are incapable of containing the average annual population growth, all forms of inequalities will tend to intensify.

172. Challenges to improve human capital have complex links with the demographic profile. In fact, the rapid increase and the youthfulness of the population constitute a major phenomenon of demographic transition. Despite the downtrend observed, the level of births and deaths that are still high place Senegal in the first phase of this transition. During this phase, the needs in terms of education, health, employment, sanitation and consumption of goods and services increase constantly. Moreover, while a rapidly growing customer base is a business opportunity, the increase in public users constitutes a heavy financial load for the State, especially when the latter's income is low.

173. There is no doubt that an increase in investments is likely to generate economic growth, but the latter can only be sustained through the marked promotion of human capital and the reduction of the number of dependents for an active individual. The demographic opportunity window, which has already been opened for Senegal, should lead to a «demographic bonus » whose conditions of achievement will be null and void ${ }^{21}$ in three to four decades. There is thus need to implement public policies integrating the demographic dimension into the development of human capital.

174. Thus, with regard to sustainable human development, the strategic objective is to strengthen the implementation and monitoring of population policies, through advocacy for the voluntary control of fertility, the modernization of the registration and the use of birth registration data, the development of technical tools and support to bodies in charge of coordinating and monitoring national population policy.

\subsubsection{Universal education and skills development}

175. Significant steps have been made in light of the results achieved in the education sector.

However, inadequacies persist and solutions are needed to improve the primary school completion rate and, in general, enhance the quality and performance of the education system, appease the school and university environment and accelerate the pace of classroom construction and delivery.

176. The aim is to provide equitable education and learning opportunities for all children, taking into consideration regional and gender disparities as well as issues relating to infrastructure

\footnotetext{
${ }^{21}$ Political inertia may lead to the occurrence of the opposite of bonus, ie « a demografic bomb »
} 
and the supervision of human resources. Likewise, the enhancement of skills in a growing economy necessitates the setting up of adapted and high-performance vocational training centres and the development of strategies to address imbalances in spatial distribution and tackle gender issues.

177. In this respect, the following strategic objectives have been identified for the education and training sub-sector:

i. Establish a 10-year cycle of basic education, through support to alternative DIPE facilities, training of elementary school teachers, careful targeting of education services, improving the school environment and that of Daaras 22 , consolidating basic knowledge in core subjects and supplying pupils with the required textbooks.

ii. Enhance the quality of teaching and learning through the construction/equipment and rehabilitation of middle and high schools, institutes and universities, improvement of the learning environment and reform of preservice and in-service teacher training programmes as well as curricula.

iii. Eradicate illiteracy and promote national languages by diversifying the provision of Non Formal Education (NFE), constructing and equipping NFE structures, promoting national languages in the basic education cycle and literacy programmes, codifying national languages and promoting terminology research.

iv Integrate apprenticeship in vocational and technical training programmes through apprenticeship training in Daaras, strengthening vocational training for women and training of instructors and apprentices.

v. Promote employment-oriented vocational training through the creation and decentralization of opportunities for vocational and in-service training, the diversification of training programmes, the construction, rehabilitation and equipment of high schools and vocational and technical training centres, better management of the demand and the provision of adapted vocational training programmes.

vi. Develop an effective, efficient and inclusive governance of the education system by improving the effectiveness of public spending, decentralizing and devolving the management of education programmes, constantly evaluating the quality of teaching at all levels, constructing and equipping school inspectorates and departmental education inspection offices in new regions and providing support to private institutions.

\subsubsection{Improved healthcare and nutritional status}

178. A population with poor health cannot contribute to creating economic growth. A sustained and comprehensive approach is required to meet healthcare needs and improve access to quality services.

179. Further efforts must be deployed to reach health-related MDGs.Actions will be strengthened to eliminate HIV/AIDS, malaria and other pandemic diseases. The healthcare system should therefore be more prevention-oriented. In addition, greater emphasis shall be placed on hygiene and the promotion of healthy eating habits. Opportunities to develop public-private partnerships for the construction and management of health facilities and the pooling of resources and risks shall be explored.

180. The following objectives are sought to ensure the provision of efficient public health services:

${ }^{22}$ Koranic schools. 
i. Improve the supply and quality of health services by developing a community approach to promoting healthcare, increasing evacuation means, constructing and rehabilitating health facilities, strengthening garrison medical centres, recruiting skilled health workers equitably stationed throughout the country and promoting generic drugs.

ii. Enhance performances in the area of disease prevention and control through prevention of HIV transmission and other communicable diseases, increased access to anti-retroviral drugs for people living with HIV, strengthening capacities of staff to diagnose and properly monitor $\mathrm{TB}$ cases and prevention and management of chronic illnesses.

iii. Improve maternal and child health by promoting deliveries in accredited health facilities and particularly skilled attendance at delivery, improving access to healthcare for women in rural areas, providing neonatal care, promoting family planning and improving immunization coverage for children.

iv. Improve the nutritional status of mothers and children by promoting dietary diversity, increasing the proportion of children that have access to nutrition programmes and promoting efforts to meet the nutritional needs of vulnerable groups (children under 5 years, pregnant women and nursing mothers).

v. Improve health system governance by enhancing the efficiency and effectiveness of public spending on healthcare and of the monitoring/evaluation system of sectoral policies as well as strengthening the health surveillance system.

\subsubsection{Increased access to safe drinking water and sanitation}

181. Analysis of the sub-sector reveals that further efforts are still to be deployed regarding the quality and distribution of water, despite the positive trend towards achieving MDG targets. The shortage in the distribution of drinking water should be gradually addressed. In the sanitation sub-sector, not only is additional funding required to achieve objectives, but the problem is particularly acute in rural areas. Besides, Senegal is not immune to problems caused by constantly increasing waste generation, whose primary effects include unhealthy and polluted environments as well as outbreaks of diarrhoeal, infectious and parasitic diseases that adversely affect public health.

182. The following objectives will be targeted in this sub-sector to create balanced access to safe drinking water and hygiene services between the rural and urban areas:

i. Increased access to safe drinking water for populations in urban and rural areas through the construction and rehabilitation of boreholes and water storage structures and supply systems in rural and periurban areas, water quality improvement particularly in the central regions of the country and widespread access to safe water supply in urban areas.

ii. Develop sanitation services in urban and rural areas by implementing reforms in the sub-sector, constructing and improving waste water treatment plants in large cities, extending rainwater drainage systems in urban centres, constructing and rehabilitating sewage systems in urban and periurban areas and constructing collective structures for excreta disposal in rural areas.

iii. Support the integrated and sustained management of water resources through the construction of collective structures for excreta disposal in rural areas, protection and conservation of strategic water supply sources and assessment of 
the water potential in the maastrichtian geological layer.

iv. Foster good governance in the safe-drinking water and sanitation sub-sector through the promotion of eco-citizenship at the community level, rationalization of water consumption, strengthening of logistical means and human resources of hygiene brigades and revision of the tariff system in urban areas.

\subsubsection{Improved housing and living conditions}

183. Housing and living conditions are largely influenced by the degradation of natural resources and the environment. The development of housing in both cities and rural areas is unregulated and hazardous. These types of housing account for approximately 30 to $40 \%$ of occupied space in urban areas and are located in areas characterised by the lack of privacy, the nonexistence or lack of infrastructure of any type and the absence of land occupancy titles. The quality of housing in rural areas has improved. Rural populations are moving increasingly from thatch/straw ${ }^{23}$ to tin sheets, concrete, tiles and slates. This trend thus advocates in favour of a better control over the safety of constructions.

184. The aim of the housing and living conditions sub-sector is to improve and uphold good living standards. Strategic objectives therefore include:

i. Ensure better spatial development and management in cities and towns by updating and generalizing SRATs, SDAUs, PDUs and POS, promoting social housing schemes and joint planning, systematically creating and maintaining green areas, parks and agricultural zones in urban areas, systemizing construction permits and increasing safety inspections in compliance with the provisions of the building code.

ii. Improve the quality of living conditions in urban and rural areas by landscaping outdoor, leisure and lake areas, improving the management of solid and liquid waste and ensuring the participation of military engineers in works of public interest.

iii. Flood control through flood prevention actions and the relocation of people living in lowlands and/or non-construction areas, banning of housing developments in non-habitable zones and gravity drainage of rainwater.

iv. Promote good governance and tools to monitor and evaluate the sector policy by building the capacities of technical services and other stakeholders and strengthening the monitoring, assistance and advisory mechanism for local governments to exercise their statutory duties in this area.

\subsubsection{Reinforcing social protection}

185. Social protection comprises a series of measures to protect populations from the occurrence of social risks. It includes both public social security schemes and private or communitybased schemes and is driven by three principles: assistance, insurance coverage for various services and empowerment of social groups. Non-contributory transfers through social

${ }^{23} 47.5 \%$ in 2005 compared to $35.6 \%$ in 2008 
assistance (regular and predictable transfers) and social safety nets ${ }^{24}$ make it possible for poor populations to have a minimum income, means of subsistence and healthcare. Insurance, as a risk-sharing mechanism and a contribution-based system, allows households to protect themselves against a variety of hardships and reduce the risk of debt.

186. Inclusive development is also based on respecting the differing needs of women, children and vulnerable groups through equitable access to opportunities. This means empowering them at the economic, social and political levels and strengthening mechanisms for the implementation of related texts and regulations. With the national master plan for the prevention and eradication of child labour, Senegal intends to successfully pursue political and social dialogue between the various stakeholders.

187. Besides, it is acknowledged that social protection directly contributes to economic growth. Senegal therefore intends to take ownership of the Social Protection Floor (SPF) ${ }^{25}$ initiative which aims to provide enhanced access to essential social services and transfers for the poorest and most vulnerable and dovetail this initiative with the national strategy on social protection (SNPS). In this respect, the 2013-2017 strategy promotes the protection of the rights of people with disabilities, gender parity in elective offices, gender equity and equality, and solidarity with vulnerable groups. Strategic objectives hence include:

i. Enhance social security for workers and retired persons through the reform of the institutional and legal framework of the social security system, increased income levels for certain categories of workers, improvement of social services and the fight against social contributions evasion.

ii. Improve the socio-economic conditions of vulnerable groups by facilitating access to resources and inputs for vulnerable groups, strengthening the social integration mechanism for vulnerable groups, improving access to devices for persons with disabilities, providing support to wards of the State and the military war-disabled and consolidating and extending social transfer mechanisms.

iii. Extend social protection to the informal sector and vulnerable groups by establishing universal health coverage through mutual health organizations, improving targeting mechanisms, setting up an information and monitoring and evaluation system, ensuring application of the social act for the protection of persons with disabilities, establishing an independent fund for universal social protection and extending free healthcare to vulnerable groups.

\subsubsection{Risk and disaster prevention and management}

188. Owing to its advanced geographic position into the Atlantic ocean, Senegal is exposed to the adverse effects of climate change coupled with the poor distribution of housing and industrial plants. A direct consequence is the increased vulnerability of populations to disasters. Furthermore, the production and storage methods of hazardous products and non-compliance with technical and environmental standards exacerbate the risk of industrial disasters.

189. Senegal plans to achieve the following strategic objectives:

\footnotetext{
${ }^{24}$ Pensions, disability allowance, family allowance, food coupons or stamps; canteens and school bursaries, labourintensive public works; price subsidies targeting poor households ; fee exemption for essential services.

${ }^{25}$ The African Union issued the Livingstone Call for Action in 2006 calling on all African countries to develop a basic set of social protection programmes 
i. Prevent and reduce major disaster risks by developing national and regional contingency plans, promoting a culture of disaster prevention and management, ensuring control over major industrial accidents, establishing an early warning system for natural disasters and improving the safe transport of hazardous materials.

ii. Improve the management of natural disasters with the establishment of a mechanism to assist and compensate disaster victims, the establishment of an emergency response fund and capacity-building of civil protection actors.

\subsubsection{Sustainable development and the environment}

190. The environment and natural resources management are transversal issues owing to their direct and indirect effects on other sectors. An analysis of the results indicates progress has been made in some areas such as the rehabilitation of natural resources and land, the development of protected areas for biodiversity, the management of transboundary resources and the fight against pollution and harmful effects. The various practices in these sectors must therefore be continued and improved as well as initiatives taken to, inter alia, promote sustainable production and consumption methods. Moreover, the development of instruments to measure the environmental impact of public policies should also be encouraged.

191. The excessive and increasing exploitation of natural resources in a context of environmental degradation have created new constraints on economic growth and on the prospects of job creation. Sixty per cent of the population depend on natural resources-related sectors such as agriculture, forestry, fisheries and tourism. Environmental risks and the lack of natural resources are serious threats (water deficit, decline in biomass, land degradation, reduced fish breeding areas...) to production and hence economic growth.

192. Promotion of an ecologically rational use of resources is an entry point for transitioning into a green economy that will contribute to reducing poverty in a direct and sustainable manner. The sound management of natural capital in the agricultural sector through the use of clean production methods contributes to maximizing the use of organic inputs, enhancing productivity and boosting the income of farmers, foresters, herders and fishermen.

193. A proper management of biodiversity and heightened awareness of its vital support functions can generate significant economic benefits and contribute to reducing poverty. Tourismrelated investments to support the sustainable development of forests and wildlife could therefore be profitable. And encouraging clean production could have major economic benefits for our industries, reduce environmental impacts and improve working conditions.

194. The 2013-2017 Strategy advocates sustainable development that incorporates natural resources management. The purpose is to preserve and maintain these resources while guaranteeing equitable access for populations. Increasing air and water pollution in cities is a sign that what is often perceived as progress can be a factor in the deterioration of the quality of life especially of vulnerable groups.

195. Integrating the sustainable development perspective will entail taking into account environmental impacts as a priority at all levels of the local and sectoral planning processes. To this end, the environment and natural resources sub-sector will implement its policies and 
strategies to reach the following strategic objectives:

i. Mitigate the effects of climate change on ecosystems through the preservation and management of natural resources by local government units, the management of community forests and the rational management of forest resources, the fight against bushfires, deforestation and land degradation, the ecological management of chemical products and waste, erosion control and the systematic introduction of environmental screening.

ii. Strengthen capacities in environmental and natural resources management through promotion of environmental education, production and broadcast of information on the state of the environment and natural resources and capacitybuilding of environmental stakeholders.

iii. Promote green economy and the creation of green jobs.

iv. Make rural ecosystems less vulnerable to the effects of climate change by developing agro-sylvo-pastoral activities, encouraging private investments and controlling air and water pollution.

\subsubsection{PILLAR 3: Governance, institutions, peace and security}

196. An inappropriate governance profile is a major constraint for development. The experience of the 1980-2010 period was valuable enough to build consensus on a number of elements that can be identified as rules governing the development process: (i) peace, democracy and human security; (ii) control of public finances for the timely conclusion of transactions with the government; (iii) alignment of the composition of public expenditures to development priorities; (iv) ethics, transparency and constant focus on accountability and the effectiveness of public spending; (v) the existence of functional frameworks for dialogue on public policies. Compliance with these five (5) rules calls for commitment to shared values so as to create and maintain mutual confidence among the various actors: Government and public administrations, local government units, private sector, civil society and technical and financial partners.

197. Local government units, civil society organizations and decentralized services are the primary implementation channels and providers of essential services. Hence, all elected officials in local government units and in the Parliament must be fully involved in the planning, implementation, monitoring and evaluation of core public services.

198. The 2013-2017 Strategy anticipates the setting up of a suitable budgetary, legal and institutional framework as well as a more efficient and effective implementation of programmes and initiatives supported and financed by the Government. In this regard, the participation of grassroots communities is necessary during both the design and implementation phases of government programmes.

199. This Strategy paper identifies economic and financial viability, the participation of local populations and the protection and promotion of the fundamental rights of men and women as areas that should back the development process. The efficiency and effectiveness of public spending should be ensured. Similarly, public administration reforms should eliminate excessive red tape so as to provide users with high quality services. Furthermore, spatial development and the implementation of the decentralization charter are indispensable in a dual 
planning process and for a greater involvement of grassroots communities.

\subsubsection{Consolidating peace and security}

200. Territorial integrity, peace and security of individuals, infrastructure, goods and services play a vital role in creating a positive economic and social climate. Social cohesion and maintaining public order are guaranteed by the civic behaviours expected of all segments of the population.

201. Strategic objectives in the area of peace and security therefore include:

i. Build sustainable peace and social cohesion by taking into consideration specificities of the southern part of the country when developing public policies, promoting a culture of peace, harmony and national solidarity, organizing national consultations on Casamance, combating gender-based violence and strengthening social dialogue.

ii. Provide greater resources to security forces through the fight against the proliferation and illicit circulation of small arms, the supply of additional equipment and intervention means to security forces, development of community policing, expansion of the national identification system, capacity-building for staff members and enhancement of in-service training programmes for the military and paramilitary.

\subsubsection{Promoting the rule of law, human rights and justice}

202. Judicial governance comprises the justice sub-sector, human rights promotion and protection and the application of related laws. The fight against corruption, though a transversal area, should be based on effective justice. Senegal reaffirms its determination to combat money laundering and the financing of terrorism.

203. Objectives identified to guarantee human rights rely on informing, raising the awareness of and advocating with the various stakeholders on enhancing freedom of action, capacity for decision-making and protection of the structural and specific rights of men and women. In doing so, attention should be paid to existing gaps in terms of participation, accountability, non-discrimination and empowerment.

204. Under the 2013-2017 development strategy, the objective is to improve access, quality and efficiency of the justice system through the reduction of the length of pre-trial detention, improvement of detention conditions of minors, stepping up of punishments for the infringement of the rights of women, children and minorities, improvement of prison conditions, increased access to community justice, strengthening of institutional and human capacities of courts as well as central and decentralized services.

\subsubsection{Promoting gender equity and equality}

205. Gender mainstreaming in public policies is adopted as a strategy to combat all forms of inequality and to level the playing field for a fair participation of both men and women in the development process. It is therefore a cross-cutting issue for all national development 
programmes.

206. Greater coordination should be ensured in the implementation of gender-related policies particularly the protection of human rights and the eradication of violence against women and children. The gender dimension is a cross-cutting issue for all national development programmes.

207. The 2013-2017 Strategy takes into account the needs, rights and contributions of women following an integrated approach. The strategic objective in this area is to empower and promote women by strengthening the capacities of institutions and local government units to integrate gender issues in public policies, enhancing the legal instrument for the protection of women and girls and strengthening the leadership and entrepreneurial skills of women.

\subsubsection{State Reform and strengthening public administration}

208. Public administration must remain a space for the regulation, steering, coordination and delivery of services, with the requirement of optimal efficiency.

209. The Strategy therefore focuses on improving the quality of public service by increasing access for users, streamlining the decentralization of government agencies, promoting a merit-based recruitment system, modernizing the management of human resources and strengthening capacities in the formulation, implementation, evaluation and overseeing of public policies.

\subsubsection{Land-Use planning, local development and territorialization}

210. The purpose of the planned reform regarding the decentralization and spatial development policy (Decentralization Act III) is to consolidate the authority of local government units by introducing the territorial approach as a performance lever for local public policies in all areas: land tenure, climate change, gender, emigration, management and conservation of natural resources and the environment, among others. Territorialization of public policies allows for their integration by local government units, in a coordinated and complementary manner, and ensures ownership by actors concerned.

211. The territorial approach to development and sectoral policies calls for the capacities of local actors to be strengthened and particularly those of local government units. Sustainable local development shall be based on the commitment of the central government and of local government units to reduce inter-regional and intra-regional disparities and on their capacity to lift populations out of their vulnerable situations.

212. The conflict that erupted in Casamance in the early 80s has had a negative impact on the economic and social development of the region and its communities. Following the peace agreement signed in 2001, PRAESC (Programme for the reactivation of economic activities in Casamance) began a coherent and comprehensive process to pacify the Casamance region. This programme progressively created the conditions for lasting peace and the reintegration of populations against the backdrop of an economic and social environment favourable to long-term development while respecting the specificities of the region. Under the present Strategy, implementation of PRAESC will be further accentuated using a participatory and inclusive approach. 
213. Land-Use management and decentralization areas share core principles such as proximity, inclusion and participation of all categories of stakeholders as well as the need for interaction and solidarity. In practice, these various principles require all actors to demonstrate ethical awareness and willingness, promote the interest of all and work for the common good. They will be held accountable and may be audited.

214. Policies and strategies to be implemented in these areas will focus on achieving the following strategic objectives:

i. Promote territorial viability and development hubs by developing integrated economic hubs, territorializing public policies, enhancing the potentials of ecogeographical areas, updating and implementing the PGAT (spatial development plan) and redesigning the territorial delineation plan in a participatory and consensual manner.

ii. Strengthen the capacities of local government units by promoting decentralized cooperation, transferring significant financial resources to local government units, improving the financial, economic and fiscal framework, advocating for gender responsive budgets and improving transparency and performances in the management of local matters.

\subsubsection{Strategic, economic and financial governance}

215. In general terms, the new public financial management system based on autonomy, performance, accountability and transparency will be progressively implemented by 2017 in accordance with the timetable laid down in the UEMOA directives. To this end, the following strategic objectives have been identified:

i. Improve the management of public finances by modernizing and streamlining the national tax system, reducing operating expenses of the civil service, controlling and "restructuring" public debt, complying with public spending procedures and improved monitoring of external aid management and exercising citizen control on the management of public affairs.

ii. Combat corruption and non-transparency by fighting money laundering, corruption and non-transparency, harmonizing national legislation with the United Nations Convention against corruption, developing and implementing a national strategy on the prevention of corruption and strengthening control organs.

iii. Improve economic governance by building capacities in planning, monitoring and evaluation of public policies and improving the quality of statistical outputs. 


\section{Chapter III. Implementing and monitoring-evaluation}

216. The dynamics of economic efficiency and efficacy calls for the selectivity of actions through the Priority Action Plan (PAP). The latter is the core of the strategy during the 2013-2017 period. As the key implementing lever, the PAP regroups the major actions that will help achieve the set objectives, through annual changes of the Fianance Act and the three-year programming of public investments.

217. In order to accelerate economic growth, the achievement of MDG by 2015 and greatly improve the populations' living conditions, the priorities will be focused on the densification of the economic fabric, the reduction of inequalities, good governance of public policies and the consolidation of peace and security.

218. The inclusion in the budget process of the funds mobilized within the framework of the implementation of the poverty reduction strategy, already launched, will be given preferential treatment in order to avoid duplication and create a spending synergy and speediness in the implementation. Integrating funds into the budget process would confirm NSESD in its role of consolidating the link between debt relief, poverty reduction and resource mobilization to achieve the MDG. Besides, the State will draw upon the interventions of local communities, NGOs and public-private partnership.

\subsection{Financing the Strategy}

\subsubsection{Financial planning and linkage with the national budget}

219. Phase 1: Development of implementation instruments. The public policies formulated in the Staregy are henceforth implemented in line with national budget instruments in order to move the key programmes forward, provide public services and support the competitive advantages of the economy. More specifically, within the framework of the multi-annual budget programing, it involves systematically monitoring the consistency between the PAP and NSESD, on the one hand and, the Finance Act and the Three-Year Public Investments Programme (PTIP), on the other.

220. Phase 2 : PAP Needs evaluation. The evaluation of PAP amounts is based on the costs of priority projects and programmes. For the sub-sectors comprising MDGs, the amounts were taken up again on the basis of consolidation objectives that have already been assessed and included in the various ongoing programmes. The amounts of the PTIP programmes served as reference for the reevaluation of needs. For other sub-sectors and areas for which no programmes have been evaluated or in which all projects were not formulated, information on targeted objectives, results indicators and unit costs are used to determine the funding needs.

221. A method was thus developed to ascertain whether the amounts proposed in these programmes would help achieve the MDG and economic growth objectives. This method is based on the principle of elasticity of indicators in relation to the allocated budget. Simulations were made on the basis of a methodology consisting in determining the evolution of the selected indicator and, as an indirect result, the volume of financing required 
to be included in the budget to attain the target by the set timeframe.

222. Phase 3: Scheduling.Funding needs for priority actions, identified in the PAP, are then compared to the resources available in the existing programmes or in the PTIP. The difference between the total amount required- NSESD amount- and the acquired and consolidated financing express the additional need - financing gap - for the achievement of the priority objectives.

223. In the light of these considerations, it seems necessary to integrate the resources mobilized in this connection in the State's planning and programming process and thus ensure traceability, transparency and the sense of responsibility required for the management of contributions to finance activities identified inthe NSESD.

224. In this regard, the implementation of the Strategy is expected to help strengthen partnership with bilateral and multilateral donors who are specifically urged to coordinate their contribution in terms of mobilized volumes, procedures and monitoring-evaluation. On the basis of this new partnership, donors are expected to strengthen the synergy between the various terms and conditions of official development aid, in accordance with the principles of the Paris Declaration (2005) and the Accra Programmeof Action (2008) on the effectiveness of Official Development Aid. They will be encouraged to give preference to budget support, integrate the funds earmarked for projects in a global approach and /or sectoral programme or within the common resource basket mechanism, at least for the funding of priority activities.

\subsubsection{Mobilization of financial resources}

225. All actions selected by actors during the participatory process and expected to have a significant impact on economic and social development were listed in a matrix of measures. The priority objectives and corresponding actions were identified within the framework of a priority action plan (PAP) covering the 2013-2017 period. To determine priority actions, the lines of actions were assessed ${ }^{26}$ on the basis of their possible contribution to economic growth, in particular, and the improvement of the living conditions of households.

226. For the sustainable financing of the NSESD, the resource mobilization approach is based on the following elements: domestic public resources and the different forms of support by technical and financial partners, namely budget support, grants and concessional loans. Moreover, the State intends to diversify the funding sources of priority investments: the national private sector and Foreign Direct Investments (FDI) have a key role to play.

227. In connection with the implementation of the Strategy, three scenarios were considered, in order to align the choice of public investments with the resource mobilization capacity. These are the trend scenario, the optimistic scenario and the pessimistic scenario. These scenarios were developed thanks to a prioritization methodology which was used to classify the global action plan according to priorityactions and measures, of average and low importance in relation to their contribution to economic growth, the reduction of inequalities and the improvement of the populations' living conditions. Thus, all the actions set forth are ranked in order of priority, andin accordance with the global expectations of the NSESD.

\footnotetext{
${ }^{26}$ It is the dynamic cloud method, by the principle of optimizing intra and inter group variances
} 
228. The trend scenario - or baseline scenario - adopted ${ }^{27}$ with IMF has an average annual growth rate of $4.9 \%$ and a deficit of $4.1 \%$, with total capital expenditure standingat 5276 billion CFAF for the 2013-2017 period It corresponds to the trend of the entire PTIP expenditure: all the projects and programmes being implemented and new agreements that are almost completed. In this scenario, the NSESD action plan totals 3646 billion CFAF of capital expenditure in this scenario.

Table 2: Formation of the base scenario, 2013-2017.

\begin{tabular}{|c|c|c|c|c|c|c|c|}
\hline \multirow{2}{*}{\begin{tabular}{|r} 
Baseline \\
scenario \\
Years
\end{tabular}} & \multirow[t]{2}{*}{$\begin{array}{r}\text { Growth } \\
\%\end{array}$} & \multirow{2}{*}{$\begin{array}{c}\text { Public } \\
\text { Deficit } \\
\% \text { of } G D P\end{array}$} & \multirow{2}{*}{$\begin{array}{c}\text { Current } \\
\text { Expenditure } \\
\text { Billions of } \\
\text { CFAF }\end{array}$} & \multicolumn{3}{|c|}{$\begin{array}{r}\text { Capital expenditure } \\
\text { Billions of } C F A F\end{array}$} & \multirow{2}{*}{$\begin{array}{r}\text { Total } \\
\text { Expenditure } \\
\text { Billions of } \\
C F A F\end{array}$} \\
\hline & & & & JSESD & $\begin{array}{l}\text { PTIP } \quad \text { off } \\
\text { NSESD }\end{array}$ & $\begin{array}{l}\text { Total } \\
\text { PTIP }\end{array}$ & \\
\hline 2011 & 2.6 & 6.7 & 1234 & & & 718 & 1952 \\
\hline 2012 & 3.7 & 5.9 & 1282 & & & 875 & 2157 \\
\hline 2013 & 4.3 & 4.9 & 1278 & 873 & 39 & 912 & 2190 \\
\hline 2014 & 4.8 & 4.3 & 13.34 & 1026 & -.52 & 974 & 2308 \\
\hline 2015 & 5.0 & 3.9 & 1388 & 890 & 173 & 106 & 2451 \\
\hline 2016 & 51 & 37 & 1473 & 481 & 643 & 112 & 2597 \\
\hline 2017 & 5.2 & 3.5 & 1586 & 375 & 828 & 120 & 2789 \\
\hline Average & 4.9 & 4.1 & & & & & \\
\hline Total & & & 7059 & 3646 & 1631 & 5276 & 12335 \\
\hline
\end{tabular}

229. The optimistic scenario - or NSESD scenario- reflects the political choice to lay emphasis on agriculture, energy and infrastructure. It adds to the NSESD, thecapital expenditure of the trend scenario, all the funding of new major actions. In this scenario, the total amount of the NSESD action plan is 139 billion CFAF for the period, with additional investments of about1 493 billion CFAF constituting a financing gap, about half of which is expected from the State. The growth rate would reach ${ }^{28}$ an average of $6.8 \%$ per annum, while public deficit in percentage of GDP would drop from $6.1 \%$ in 2013 to $3.6 \%$ in 2017, with an average annual level of $5.0 \%$.

Table 3: Growth and the public deficit 2013-17

Figure 1: Evolution of growth rate and Deficit

\begin{tabular}{|l|l|l|l|}
\hline $\begin{array}{l}\text { Optimistic } \\
\text { scenario }\end{array}$ & Growth & $\begin{array}{c}\text { Public } \\
\text { Deficit }\end{array}$ & $\begin{array}{c}\text { Additional } \\
\text { Expenditure }\end{array}$ \\
\hline & in \% & \% of $G D P$ & Bill of $C F A F$ \\
\hline 2011 & 2.6 & 6.7 & \\
\hline 2012 & 3.7 & 5.9 & \\
\hline $\mathbf{2 0 1 3}$ & 5.6 & 6.1 & 120 \\
\hline $\mathbf{2 0 1 4}$ & 6.5 & 5.5 & 259 \\
\hline $\mathbf{2 0 1 5}$ & 7.0 & 4.8 & 322 \\
\hline $\mathbf{2 0 1 6}$ & 7.5 & 4.6 & 412 \\
\hline $\mathbf{2 0 1 7}$ & 7.2 & 3.6 & 380 \\
\hline Average & $\mathbf{6 . 8}$ & $\mathbf{5 . 0}$ & \\
\hline Total & & & $\mathbf{1 4 9 3}$ \\
\hline
\end{tabular}

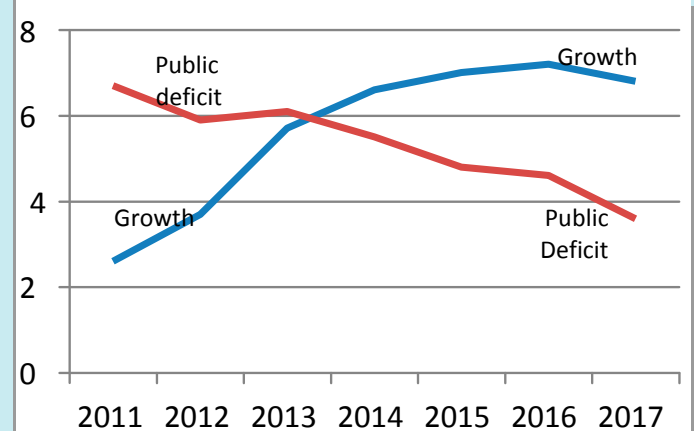

230. The breakdown of the total NSESD financing shows that the first pillar represents $61.3 \%$ of costs, against $31.9 \%$ for the second and $6.8 \%$ for the third (cf. Table-4). Likewise, regardless of whether it is from the State or foreign funding, emphasis seems to be laid on this first

\footnotetext{
${ }^{27}$ 4e PSI revenue inSeptember 2012.

${ }^{28}$ This level is attainable by Senegal which registered an average growth rate of $6.1 \%$ per annum for the 2003-2005 period
} 
pillar, with respectively $54.4 \%$ and $73.2 \%$. This relatively high level is due to the high unit costs of energy and transport infrastructure.

231. The pessimistic scenario anticipates an extreme case of weakened economic vitality that could lead the economy to a slowdown in GDP resulting in a growth of about $3.2 \%$. This scenario is based on the principal assumptions of a difficult external environment (gloomy activity and rise in oil prices and food products) and, internally, on the revival of the energy sector that is slower than expected and a delayed settlement of the Malian crisis. In such a scenario, the trend scenario expenditure would drop by 554 billion CFAF (Consolidated Investment Budget and Operating Budget), unless partners take over some projects with a direct impact on the MDG indicators. In this respect, primacy will be given to priority actions alone and the expected public deficit would be $4.2 \%$ (annual average).

232. In short, all these scenarios are constituted on the basis of the financial resources mobilization and absorption potential,strict adherence to the « sustainability » of public debt, community budget rules and international commitments.

Table 4: Distribution of NSESD financing (optimistic) based on the strategic axes (\%).

\begin{tabular}{|l|c|r|r|r|r|r|}
\hline Financing & $\mathbf{2 0 1 3}$ & $\mathbf{2 0 1 4}$ & $\mathbf{2 0 1 5}$ & $\mathbf{2 0 1 6}$ & $\mathbf{2 0 1 7}$ & Total \\
\hline \multicolumn{7}{|c|}{ PILLAR 1 : Growth, productivity and wealth creation } \\
\hline NSESD AMOUNT & 61.7 & 59.0 & 63.3 & 61.2 & 61.5 & 61.3 \\
\hline ACCOMPLISHMENT & 64.1 & 62.7 & 65.3 & 67.6 & 68.1 & 64.9 \\
\hline STATE & 55.9 & 55.9 & 55.0 & 49.1 & 51.9 & 54.4 \\
\hline TFPs & 72.1 & 68.0 & 72.6 & 80.0 & 83.0 & 73.2 \\
\hline GAP & 44.9 & 44.3 & 57.7 & 53.7 & 55.0 & 52.5 \\
\hline PILLAR 2 : Human capital, social protection and sustainable development & & \\
\hline NSESD AMOUNT & 30.0 & 34.9 & 30.4 & 32.5 & 31.1 & 31.9 \\
\hline ACCOMPLISHMENT & 26.7 & 30.1 & 26.8 & 22.5 & 19.9 & 26.5 \\
\hline STATE & 29.4 & 33.5 & 33.6 & 33.4 & 30.8 & 32.1 \\
\hline TFPs & 24.1 & 27.5 & 22.1 & 15.2 & 9.9 & 21.9 \\
\hline GAP & 53.4 & 53.9 & 40.2 & 44.2 & 42.0 & 45.2 \\
\hline PILLAR 3 : Governance, institutions, peace and security & & & \\
\hline NSESD AMOUNT & 8.3 & 6.1 & 6.3 & 6.3 & 7.4 & 6.8 \\
\hline ACCOMPLISHMENT & 9.2 & 7.2 & 7.8 & 9.9 & 12.0 & 8.7 \\
\hline STATE & 14.7 & 10.6 & 11.4 & 17.4 & 17.3 & 13.5 \\
\hline TFPs & 3.8 & 4.5 & 5.3 & 4.8 & 7.1 & 4.8 \\
\hline GAP & 1.7 & 1.8 & 2.1 & 2.1 & 3.0 & 2.3 \\
\hline
\end{tabular}




\subsection{Monitoring and evaluation of public policies}

\subsubsection{Mechanism to monitor and evaluate the Strategy}

233. The monitoring and evaluation mechanism helps actors to follow-up and analyze the results obtained throughout the implementation of the Strategy.It provides the opportunity to regularly expaln the objectives of the Strategy, ensure that they continue to be realistic and verifiable and readjust them during the implementation phase, in case the trend of the indicators is not in line with projections. Following the evaluation of the implementation of the national statistics system (SSN) and to ensure the enhanced monitoring of the economic and social policy, the action plan of theStatistics Master Plan (SDS) was reviewed and readjusted during the 2013-2017 period to be more effective and capable of producing and disseminating quality statistical data.

234. To this end, two steering levels were defined in the institutional mechanism which will be governed by regulatory texts:

235. At the political level:

- $\quad$ A Presidential Evaluation Council meets once every two years and is responsible for evaluating and deciding on the possible orientations of the Strategy based on the major results observed (in the mid-term) and international issues;

- $\quad$ A National Monitoring and Orientation Council chaired by the Prime Minister is set up. This council is composed by the Government, the representatives of technical and financial partners, the civil society, the private sector, parliament and local governments. It meets every six (6) months to evaluate the state of progress in the implementation of the strategy and issue the necessary directives for the effective implementation ofeconomic and social policy. To this end, it is in charge of periodically organizing a joint annual review of the Strategy;

- $\quad$ A Parliamentary Monitoring Committee: this committee enables parliamentarians to monitor the implementation of the national Strategy. It meets once a year. Its chairman is designated by the National Assembly.

- $\quad$ The Minister of the Economy and Finance presents a report to the meetings of these different organs.

236. At the operational level: there are two components: the coordination of the implementation of sectoral policies and steering the Strategy in each region. We therefore have:

- Ministerial Committees for monitoring-evaluation : ministries play the role of central relays in the implementation of the Strategy by assuming the operational supervision of the implementation of priority actions. The sectoral committee, chaired by the Minister in charge of the sector concerned, is responsible for monitoring the implementation of sectoral priorities and sectoral reviews on the state of progress of the sectoral policy contained in the NSESD. The committee meets at least once every quarter. The studies, planning and monitoring units provide technical secretariat services to this committee;

- Regional monitoring-evaluation committee: this committee is chaired by the Regional Governor while the Regional Development Agency (ARD) provides technical secretariat services.It regroups all categories of actors intervening in the region. Each committee meets, as needed, once every quarter to assess the state of 
progress in the implementation of the strategy, in accordance with the local vision. Every regional committee prepares an annual report on the state of progress of the Strategy in the covered region and makes recommendations to accelerate the priority actions implementation process at regional level ${ }^{29}$.

237. A technical secretariat run by the UCSPE will be responsible for applying and coordinating the global NSESD monitoring-evaluation mechanism. It ensures the effective implementation of various activities of the process and serves as secretariat to the National Monitoring and Orientation Council. It will also ensure the proper coordination of actors' interventions in the implementation of the Strategy and will prepare the report to be used in the joint annual review.

\subsubsection{Actors, appropriation and mutual responsibility}

238. The Strategy defined is the only unifying framework and reference with regard to interventions. To this end, all development actors align and harmonize their actions around these national objectives that take into account Senegal's commitments to achieve the priority objectives of the Strategy, notably the MDG. It is essential to involve all actors in the implementation of a system oriented towards development results in order to share the same understanding of the mission and especially strive togetherto achieve the results

239. The place and role of Parliament in the democratic and republican system should be put to fully played to enable elected representatives to efficiently discharge their mission of controlling government action. A single direction was thus given to for modernizing Parliament and improving its efficiency by building the parliamentarians' capacities in the control of government action.

240. The steering bodies at both national and regional or local level, mobilize all stakeholders, namely State actors, local communities, the civil society, the private sector, Parliament and technical and financial partners. To this end, the State is expected to support the functioning of these bodies (local communities, civil society, private sector). The Strategy is implemented by the various development actors working at the grassroots. The composition, structuring and functioning of all these organs will be fixed through regulatory acts. A participatory evaluation approach involving both the steering bodies and actors, will be adopted.

\footnotetext{
${ }^{29}$ There is need to make full use of and strengthen the Information and Monitoring-Evaluation System for Local Development (SISE-DL). 
The major innovation of the system was the institution and regulation of public policy monitoring. Various lessons that are globally significant are learnt from the monitoring-evaluation system. However, they unveil many constraints. They concern, among others, the fact that the meetings of the different sectoral or regional steering bodies are not systematically held, difficulties to have information on all the indicators on the restricted list and the fact that priority objectives are not fully integrated in budgetary planning.

Capitalizing on the accomplishments and in view of the results-based management requirement, the Strategy's new approach is underpinned by three conceptual foundations, which guarantee the establishment of a more effective monitoring-evaluation system:

i. $\quad$ Formative evaluation consists in critically analyzing the data collected for dynamic monitoring. It appreciates the way in which the pursued objectives are progressively attained. Within the framework of joint annual reviews of the Strategy, it explains the possible variances and proposes readjustments in the implementation of the strategy;

ii. Prognostic evaluation objectively assesses the possibilities of achieving the annual target of indicators. It provides the opportunity to review the performance projections based on the socio-economic context. The annual review should, in conclusion, give a global prognostic;

iii. . Summative or final evaluation, conducted at the end of the implementation of Strategy, makes a general assessment. It inevitably leads to a final certification of the level of achievement of objectives and the degree of overall success of the economic and social policy for the 2013-2017 period.

The application of these three foundations will distinguish two dimension for the appreciation of performances registered in each sub-sector or NSESD area: the institutional, administrative or systemic dimension, on the one hand, and the populational impact dimension, on the other. For example,in the health sub-sector, the situation of the health care system needs to be distinguished from the evaluation of thepopulation's state of health. Likewise, in the education sub-sector, the infrastructure, teaching equipment and human resources should be assessed in the same capacity as the performance obtained by the population in all cycles and types of education, relative to qualitative initial expectations. Finally, with regard to safe drinking water, the infrastructural installation should be looked into in parallelwith the effective water supply to the population.

\subsubsection{Monitoring and evaluation indicators}

241. The system providing information on the implementation of the strategy is the second component, which completes the monitoring and evaluation mechanism. It gives an overviewof the progress made and their impact on the populations' living conditions. It is linked to the steering mechanism by a well-structured and coherent information system. For that purpose, it uses indicators and a communication system. It is thus vital to institute asystem to monitor and evaluate these activities so as to measure the progress made towards the targeted objectives and the results to be attained. In this regard, the « logical framework » of the Strategy constitutes the coherence framework through which the information required to fathom and gauge the progress made in the implementation of the Strategy is defined in terms of identification, means, deadlines, sources of production and resources for the implementation of the programmes and projects.

242. A specific information system is attached to each of the three institutional levels. A global information system will be set up for the planning of the Strategy while a sectoral and regional information system will be used at the operational level. The Strategy's monitoringevaluation information system will derive from these distinct but complementary information systems

243. The NSESD information system will consist in a dashboard of indicators, dubbed restricted list of indicators, which provides information about the state of progress of the implementation of priority actions. To this end, the national statistics system, as producer of 
official statistics, is the key data source for the consolidation of the political, economic and social decision-making process It has at its disposal, since June 2007, a National Statistics Development Strategy reference framework document (SNDS, 2013-2017), the operational application of which is the Statistics Master Plan (SDS). It is scheduled for updating in 2012-2013, to take into account the fresh needs instatistical data.

244. The information system will be operated by two technical committees:

- An indicators monitoring Committee is set up within the Technical Committee of Statistics Programmes (CTPS), placed under the authority of ANSD which defines its composition and functioning. It is responsible for settingout the methodology for monitoring indicators and their target/objective for the 2013-2017 period. The committee will ensure the regular updating of monitoring indicators, in support to the institutional steering organs of the Strategy, in accordance with their schedule.It proposes mechanisms for the conduct of priority surveys to update the indicators, notably those on the restricted list.

- A Committee to monitor the Priority Action Plan formed, among others, by UCSPE, DGF, DGCPT, DPEE, AGS, APIX and DCEF which chairsit, will be responsible for the annual evaluation of the Priority Action Plan (PAP). The said committee will ensure greater visibility of the priority actions financing monitoring process and reporting during the quarterly meetings of the national council. It will also ascertain consistency in the scheduling and implementation between the MTEF and MTSEF, on the one hand, and thePAP, on the other.It will guarantee consistency between the PAP and the programming of the PTIP. It shall verify the reality of Results-Based Management (RBM), notably by analyzing the implemented budget and the results achieved and updating the macroeconomic framework.

245. The communication system hinges on the dissemination of informationon the state of progress of the implementation of theStrategy. It should involve all actors for greaterd appropriation and a coherent linkage of transversal policies in the national priorities. The progress reports should be produced on an annual basis to serve as a reference during the preparation of the State budget as well as that of local governments and partnership agreements with technical and financial partners. Communication should therefore be made through a wide dissemination of results among all actors involved to assess the quality of implementation of the Strategy. Days of review (sectoral or global) constitute an ideal framework for sharing and exchanging information on the registered results and an opportunity to make recommendations on the implementation of the economic and social policy at national, local or sectoral level. The critical participation of research and study centres will play a key role in the dissemination of these results.

\subsection{Risks linked to the implementation of the NSESD}

246. The risks of the Strategy are primarily linked to exogenous shocks that may jeopardize the macroeconomic objectives and the resource absorption capacity of the priority action plan in relation with current budget procedures and the effective control of resource use. However, these growth projections for 2013-2017 present sizeable risks in a context of gloomy world activity, rising world oil and food prices. At the domestic level, the key risks concern energy with the negative effects that would be generated by delays in the implementation of the sector's restructuring plan.In addition to this, there are-on the one hand- budget risks linked to the different social fronts, notably in the education, health and sanitation sectors 
and, on the other hand, the climate risks which make agriculture very vulnerable.

247. The key natural risk derives from the rainfall on which agricultural production still depends heavily. A situation of inadequate rainfall could significantly impede the development of the agriculture sub-sector. However, the undesirable effects of poor rainfall could be allayed if the development pace of irrigated farming in rural areas is supported and agricultural insurance mechanisms are set up. Moreover, the agricultural sector is also confronted with other natural shocks such as locust attacks, which are a serious threat to the economy, with the sole difference that public intervention could offset its effects.

248. At the economic level, the main risk relates to price changes on the world market in general and the crude oil price, in particular. The sector most exposed to risks is the energy sector which has experienced serious disruptions during the 2000-2010 decade, which were extremely unfavourable to the economy, because of its integrated and transversal nature. The persistent disruptions in electricity supply might undermine all the performance of the national economy, with disastrous consequences on the populations' well-being. At international level, the occurrence of a financial or economic crisis is a source of disturbances in the national economy, because the latter is open to the rest of the world and through a possible decline in external aid.In the same vein, remittances from Senegalese Abroad have registered a net decline.

249. The risks can also be due to developments in major companies of the processing sector. In addition to those of the energy sector, major companies of the chemical and oil mills sector are also exposed to risks. The disruptions registered in 2008 could affect growth in view of the vital role played by companies of these sub-sectors in the economy, notably in the services and industry sectors.

250. The political and institutional risks may come in various forms that directly affect the investments scheduled for the period of NSESD implementation, 2013-2017. The means required to minimize all these risks entail a firm commitment and strong solidarity from the various actors. Finally, a poor implementation of these investment expenditures could significantly affect growth and impede the achievement of objectives fixed for 2015 .

251. A way of lessening the likelihood and scope of each of these risks is to step up national competitiveness in order to further diversify sources of growth, on the one hand, and improve the flexibility of the production system and its capacity to absorb exogenous shocks with lower social costs.

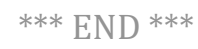




\section{ANNEXES}

Annex 1: List of monitoring and evaluation indicators .

\begin{tabular}{|c|c|c|c|c|c|c|c|c|c|c|}
\hline \multirow{2}{*}{\multicolumn{2}{|c|}{ Indicators }} & \multicolumn{3}{|c|}{ Realisation } & \multicolumn{6}{|c|}{ Targets } \\
\hline & & 2009 & 2010 & 2011 & 2012 & 2013 & 2014 & 2015 & 2016 & 2017 \\
\hline 1. Real GDP Growth Rate (in \%)(optimistic scenario) & & $2.10 \%$ & $4.10 \%$ & $2.60 \%$ & $3.70 \%$ & $5.60 \%$ & $6.50 \%$ & $7.00 \%$ & $7.50 \%$ & $7.20 \%$ \\
\hline 2. Annual average inflation rate (in \%) & & $-0.90 \%$ & $1.20 \%$ & $3.40 \%$ & $=<3 \%$ & $=<3 \%$ & $=<3 \%$ & $=<3 \%$ & $=<3 \%$ & $=<3 \%$ \\
\hline 3. Global investment rate(in \%) & & $23.00 \%$ & $22.20 \%$ & $22.40 \%$ & $24.00 \%$ & $24.00 \%$ & $24.50 \%$ & $25 \%$ & $25.50 \%$ & $26 \%$ \\
\hline 4. Global budget deficit excluding grants in percentage of GDP (optimistic) & & $4.80 \%$ & $5.20 \%$ & $6.70 \%$ & $5.90 \%$ & $6.10 \%$ & $5.50 \%$ & $4.80 \%$ & $4.60 \%$ & $3.60 \%$ \\
\hline 5. Current account deficit in percentage of GDP & & $6.70 \%$ & $6.10 \%$ & $9.20 \%$ & $8.50 \%$ & $7.70 \%$ & $7.60 \%$ & $7.30 \%$ & $6.50 \%$ & $5.30 \%$ \\
\hline \multirow{4}{*}{ 6. Percentage of Poverty } & National & & & $46.70 \%$ & $45.35 \%$ & $43.96 \%$ & $42.52 \%$ & $41.03 \%$ & $39.48 \%$ & $37.89 \%$ \\
\hline & Dakar & & & $26.20 \%$ & $25 \%$ & $24 \%$ & $23 \%$ & $22 \%$ & $21 \%$ & $20 \%$ \\
\hline & Other urban & & & $41.30 \%$ & $40 \%$ & $37.50 \%$ & $35.20 \%$ & $33.50 \%$ & $31 \%$ & $30.20 \%$ \\
\hline & Rural & & & $57.30 \%$ & $56 \%$ & $53.20 \%$ & $50 \%$ & $48 \%$ & $45 \%$ & $40 \%$ \\
\hline \multicolumn{2}{|l|}{ 7. Rural electrification rate (in \%) } & $23.80 \%$ & $23.80 \%$ & $25 \%$ & $27 \%$ & $29 \%$ & $30 \%$ & $32 \%$ & $35 \%$ & $40 \%$ \\
\hline \multirow{2}{*}{\multicolumn{2}{|c|}{$\begin{array}{|ll|}\text { 8. Non-distributed energy (GWh) } & \\
\text { 9. Number of megawatts commissioned } & \text { (Installed capacity) } \\
\end{array}$}} & 89.69 & 177.05 & 266.62 & 105 & 50 & 30 & 20 & $<20$ & $<20$ \\
\hline & & 684.55 & 686.5 & 827.5 & 1113.4 & 970.4 & 1095.4 & $\underline{1095.4}$ & & \\
\hline \multirow{2}{*}{ 10. Length of roads built (in Km) } & Paved & 688.39 & 183 & 130 & 165 & 175 & 190 & 200 & 210 & 220 \\
\hline & Unpaved & 1105.7 & 176.5 & 65 & 125 & 135 & 140 & 170 & 200 & 230 \\
\hline \multirow{2}{*}{ 11. Length ofrehabilitated roads (in Km) } & Paved & 209 & 140 & 102 & 160 & 175 & 185 & 200 & 215 & 230 \\
\hline & Unpaved & 144.5 & 60 & 30 & 125 & 150 & 160 & 180 & 200 & 220 \\
\hline \multicolumn{2}{|l|}{ 12. Number of DFS members } & 1352287 & 1470280 & 1542230 & 1614298 & 1692492 & 1756441 & 18174321 & 888504 & 1955839 \\
\hline \multicolumn{2}{|l|}{ 13. Share of irrigated areas in irrigable surface area } & $38.40 \%$ & $41.06 \%$ & $42.10 \%$ & $44.71 \%$ & $46.32 \%$ & $62.98 \%$ & $65.48 \%$ & $67.40 \%$ & $72.70 \%$ \\
\hline \multirow{2}{*}{\multicolumn{2}{|c|}{\begin{tabular}{|l|} 
14. Cereal production (in millions of tons) \\
15. Agricultural GDPgrowth rate (baseline scenario)
\end{tabular}}} & 1.869 & 1.768 & 1.099 & 2.035 & 2.117 & 2.21 & 2.289 & 2.541 & 2.795 \\
\hline & & $18.00 \%$ & $5.10 \%$ & $-21.60 \%$ & $6.20 \%$ & $8.40 \%$ & $9.50 \%$ & $10.50 \%$ & $12.50 \%$ & $14.00 \%$ \\
\hline \multicolumn{2}{|l|}{ 16. Quantity of meat and giblets per annum (in thousands oftons) } & 166 & 177 & 193 & 209 & 223 & 233 & 243 & 266 & 296 \\
\hline \multirow{2}{*}{\multicolumn{2}{|c|}{$\begin{array}{l}\text { 17. Quantity of milk produced per annum(in millions of litres) } \\
\text { 18. Level of fish biomass in mainstocks (in tons) }\end{array}$}} & 167 & 181 & 184 & 227 & 260 & 294 & 329 & 405 & 460 \\
\hline & & \multicolumn{2}{|c|}{ Not specified } & 0.6 & \multicolumn{6}{|c|}{ Targets to be set after a stock evaluation scheduled in 2011} \\
\hline \multicolumn{2}{|l|}{ 19. Volume of underground water mobilized for irrigation (in thousands of m3) } & réf.2010 & 920 & & $\underline{1200}$ & 1500 & 1800 & $\underline{2000}$ & 2000 & $\underline{2000}$ \\
\hline \multirow{2}{*}{\multicolumn{2}{|c|}{$\begin{array}{l}\text { 20. Industrialproduction index } \\
\text { 21. Number of tourist entries per annum }\end{array}$}} & 102.2 & 113.5 & 118.8 & 130.1 & 139.3 & 149.2 & 159.7 & 180 & 210 \\
\hline & & & 842400 & 1001314 & 992000 & 1041600 & 1094000 & 1149000 & 1200000 & 1200000 \\
\hline \multicolumn{2}{|l|}{ 22. Financial volume of intellectual and artistic property rights (in millions of CFAF) } & 345.77 & 420.5 & 401.5 & 580 & 725 & 906.25 & 1132.81 & & \\
\hline \multirow{2}{*}{\multicolumn{2}{|c|}{\begin{tabular}{|l|} 
23. Number ofSME under supervision \\
24. Growth rate(in $\%$ ) ofvolume of exports
\end{tabular}}} & 739 & 945 & 1339 & 1150 & 1250 & 1350 & 1450 & 2000 & 2500 \\
\hline & & $3.11 \%$ & $22.74 \%$ & $23 \%$ & $\geq 20 \%$ & $\geq 20 \%$ & $\geq 20 \%$ & $\geq 20 \%$ & $\geq 20 \%$ & $\geq 20 \%$ \\
\hline \multirow{3}{*}{ 25. GERat primary level (in \%) } & National & $78.3 \%$ & $80.3 \%$ & $79.7 \%$ & $83.7 \%$ & $85 \%$ & $88 \%$ & $90 \%$ & $92 \%$ & $95 \%$ \\
\hline & Girls & $82 \%$ & $84 \%$ & $83.3 \%$ & $84 \%$ & $86 \%$ & $89 \%$ & $91 \%$ & $92 \%$ & $95 \%$ \\
\hline & Boys & $74 \%$ & $76.4 \%$ & $80.5 \%$ & $81 \%$ & $83 \%$ & $85 \%$ & $88 \%$ & $90 \%$ & $94 \%$ \\
\hline \multirow{3}{*}{ 26. Primary completion rate (in \%) } & National & & & $59.3 \%$ & $62.5 \%$ & $66 \%$ & $71 \%$ & $77 \%$ & $84 \%$ & $90 \%$ \\
\hline & Girls & & & $58.5 \%$ & $60.5 \%$ & $65 \%$ & $70.5 \%$ & $77 \%$ & $84 \%$ & $90 \%$ \\
\hline & Boys & & & $60.2 \%$ & $63 \%$ & $67.5 \%$ & $72 \%$ & $77 \%$ & $84 \%$ & $90 \%$ \\
\hline \multirow{2}{*}{ 28. Number of registered pupilsin the classes } & National & 83529 & 77988 & 81354 & 92893 & $>100000$ & $>120000$ & $>120000$ & $>120000$ & $>120000$ \\
\hline & Women & 66208 & 66895 & 65424 & 57835 & $>60000$ & $>70000$ & $>70000$ & $>70000$ & $>70000$ \\
\hline 29. Rate of increase of students in Vocational and Technical Training (in \%) & National & $6.00 \%$ & $4 \%$ & $0.11 \%$ & $17 \%$ & $25 \%$ & $30 \%$ & $35 \%$ & $30 \%$ & $25 \%$ \\
\hline
\end{tabular}




\begin{tabular}{|c|c|c|c|c|c|c|c|c|c|c|}
\hline \multicolumn{2}{|l|}{ Indicators } & \multicolumn{3}{|c|}{ Realisation } & \multicolumn{6}{|c|}{ Targets } \\
\hline & & 2009 & 2010 & 2011 & 2012 & 2013 & 2014 & 2015 & 2016 & 2017 \\
\hline \multirow{2}{*}{ 30. Rate ofimplementation of Education budget } & TitleIII & $95.39 \%$ & $91.14 \%$ & $97 \%$ & $95.00 \%$ & $95.00 \%$ & $95.00 \%$ & $95.00 \%$ & $95.00 \%$ & $95.00 \%$ \\
\hline & Title V & $70.92 \%$ & $86.27 \%$ & $38 \%$ & $95.00 \%$ & $85.00 \%$ & $95.00 \%$ & $85.00 \%$ & $95.00 \%$ & $85.00 \%$ \\
\hline \multicolumn{2}{|l|}{ 31. Rate (in \%) of CPN4 cover } & $\mathrm{NA}$ & $75 \%$ & $50 \%$ & $53 \%$ & $55 \%$ & $60 \%$ & $63 \%$ & $70 \%$ & $75 \%$ \\
\hline \multicolumn{2}{|l|}{ 32. Rate (in \%) of deliveriesassisted by skilled attendants } & $67.00 \%$ & $65.1 \%$ (EDS-5) & $65 \%$ & $72 \%$ & $75 \%$ & $78 \%$ & $80 \%$ & $83 \%$ & $85 \%$ \\
\hline \multicolumn{2}{|l|}{ 33. Proportion (in \%) ofchildren between 0-11 months fully vaccinated } & $74 \%$ & $62.8 \%$ (EDS-5) & - & $55 \%$ & $60 \%$ & $65 \%$ & $70 \%$ & $75 \%$ & $80 \%$ \\
\hline \multicolumn{2}{|l|}{ 34. Percentageof children 0 - 5 years old benefiting from nutrition service } & & & & $55 \%$ & $60 \%$ & $65 \%$ & $70 \%$ & $75 \%$ & $80 \%$ \\
\hline \multicolumn{2}{|l|}{ 35. HIV/AIDS prevalence (in \%) among the population } & $0.70 \%$ & $0.70 \%$ & $0.70 \%$ & $<1 \%$ & $<1 \%$ & $<1 \%$ & $<1 \%$ & $<1 \%$ & $<1 \%$ \\
\hline \multicolumn{2}{|l|}{ 36. Persons living with VIH under ARV } & 12249 & 14408 & 14425 & 16444 & 18649 & 20961 & 23318 & 25649 & 28214 \\
\hline \multirow{2}{*}{ 37. Rate of execution of health budget } & Title III & $86.28 \%$ & $96.43 \%$ & $93.00 \%$ & $95.00 \%$ & $95.00 \%$ & $95.00 \%$ & $95.00 \%$ & $95.00 \%$ & $95.00 \%$ \\
\hline & Title V & $53.27 \%$ & $86.28 \%$ & $43 \%$ & $85.00 \%$ & $85.00 \%$ & $85.00 \%$ & $85.00 \%$ & $85.00 \%$ & $85.00 \%$ \\
\hline \multirow{2}{*}{ 38. Rate (in\%) of access to drinking water } & Urban & $97.00 \%$ & $98.50 \%$ & $98.70 \%$ & $99.00 \%$ & $99.00 \%$ & $99.00 \%$ & $100.00 \%$ & $100 \%$ & $100 \%$ \\
\hline & Rural & $73.60 \%$ & $77.50 \%$ & $80.10 \%$ & $79.50 \%$ & $80.00 \%$ & $85.00 \%$ & $90.00 \%$ & $95 \%$ & $98 \%$ \\
\hline \multirow[t]{2}{*}{ 39.Rate of access of households to improved sanitation system } & Urban & $63.60 \%$ & $63.10 \%$ & $63.30 \%$ & $72.20 \%$ & $74.10 \%$ & $76.10 \%$ & $78.00 \%$ & $80 \%$ & $85 \%$ \\
\hline & Rural & $28.90 \%$ & $29.60 \%$ & $34.30 \%$ & $52.00 \%$ & $57.00 \%$ & $59.00 \%$ & $63.00 \%$ & $65 \%$ & $70 \%$ \\
\hline \multicolumn{2}{|l|}{ 40. Number of serviced plots produced } & 14138 & 14138 & 14138 & 14138 & 17673 & 22091 & 27613 & 34517 & 43146 \\
\hline \multicolumn{2}{|l|}{ 41. Number of social housing units built } & 2808 & 4808 & 4808 & 4808 & 6250 & 8750 & 11800 & 17700 & 23900 \\
\hline \multicolumn{2}{|c|}{ 42. Proportion (in \%) Environment Management Plans (EMP) implemented and monitored (following EIE) } & $30.00 \%$ & $60 \%$ & $58 \%$ & $70 \%$ & $75 \%$ & $80 \%$ & $85 \%$ & $85 \%$ & $85 \%$ \\
\hline \multicolumn{2}{|l|}{ 43. Ratio reforestation / deforestation } & 0.78 & 0.96 & 0.99 & $\geq$ Ratio2011 & $\geq$ Ratio2012 & $\geq$ Ratio2013 & $\geq$ Ratio2014 & $\geq$ Ratio2015 & $\geq$ Ratio2016 \\
\hline \multicolumn{2}{|l|}{$\begin{array}{l}\text { 44. Rate (in } \%) \text { of activity } \\
\end{array}$} & $59.40 \%$ & $62.70 \%$ & $53.97 \%$ & $68.00 \%$ & $71.00 \%$ & $73.20 \%$ & $75.00 \%$ & $80.00 \%$ & $85.00 \%$ \\
\hline \multicolumn{2}{|l|}{ 45. Rate (in \%) of invisible under employment } & $22 \%$ & $21 \%$ & $16.84 \%$ & $20 \%$ & $18 \%$ & $16 \%$ & $15 \%$ & $10 \%$ & $7 \%$ \\
\hline \multirow{2}{*}{\multicolumn{2}{|c|}{$\begin{array}{l}\text { 46. Unemployment rate } \\
\text { 47. Social budget in percentage of GDP }\end{array}$}} & $10.00 \%$ & $10.00 \%$ & $10.20 \%$ & $9.40 \%$ & $8.90 \%$ & $8.40 \%$ & $7.00 \%$ & $6.00 \%$ & $6.00 \%$ \\
\hline & & & & & & & & & & \\
\hline \multicolumn{2}{|c|}{ 48. Rate of coverage by health mutual schemes (people not cared for by the formal social security systems) } & réf.2010 & $4.35 \%$ & & $13.62 \%$ & $\underline{27.70 \%}$ & $\underline{46.32 \%}$ & $50.50 \%$ & $60.30 \%$ & $65.50 \%$ \\
\hline \multirow{2}{*}{\multicolumn{2}{|c|}{\begin{tabular}{|l} 
49. Number ofvulnerable households benefiting from the Cash transfer progr \\
50. Proportion (in \%) of the budget allocated to ministries under CDSMT30
\end{tabular}}} & & 36986 & 63280 & 65000 & 75000 & 85000 & 100000 & 150000 & 200000 \\
\hline & & & & $72 \%$ & $50 \%$ & $60 \%$ & $75 \%$ & $85 \%$ & $85 \%$ & $85 \%$ \\
\hline \multicolumn{2}{|c|}{$\begin{array}{l}\text { 51. Compliance with legal deadlines for the production of the State's management accounts before } 31 \text { July of } \\
\text { current year (yes } / \mathrm{no} \text { ) }\end{array}$} & réf.2010 & Yes & Yes & Yes & Yes & Yes & Yes & Yes & Yes \\
\hline \multirow{2}{*}{ 52. Criminal records processing period } & Delinquents & 6 months & 6 months & 5months & 5 months & 5 months & 5 months & 5 months & 5 months & 5 months \\
\hline & \begin{tabular}{|l} 
Criminal \\
\end{tabular} & 2 years & 2 years & 2 years & 2 years & 2 years & 2 years & 2 years & 2 years & 2 years \\
\hline \multicolumn{2}{|l|}{ 53. Delay in making FECL and FDD available before June 30} & $\begin{array}{c}2.83 \text { (March } \\
25,2009)\end{array}$ & $<3$ months & & $<3$ months & $<3$ months & $<3$ months & $<3$ months & $<3$ months & $<3$ months \\
\hline \multicolumn{2}{|l|}{ 54. Percentage of own resources in the investment budget of local governments } & réf.2010 & $\begin{array}{l}\text { Study in } \\
\text { progress }\end{array}$ & >value 2011 & > value 2012 & > value 2013 & >value 2014 & >value 2015 & >value 2016 & > value 2017 \\
\hline
\end{tabular}

${ }^{30}$ A new proposal is expected from DGF/MEF to take into account the implementation of texts from thetransposition dof new UEMOA directives. 
Annex 2: Distribution of funding for the Priority Action Plan. 2013-2017.

\begin{tabular}{|c|c|c|c|c|c|c|}
\hline $\begin{array}{l}\text { Method of } \\
\text { Financing }\end{array}$ & 2013 & 2014 & 2015 & 2016 & 2017 & Total \\
\hline \multicolumn{7}{|c|}{ AREA 1 : Growth, productivity and wealth creation } \\
\hline NSESD & 613427 & 757275 & 766217 & 545508 & 467282 & 314908 \\
\hline OBTAINED & 559602 & 642981 & 581723 & 325366 & 255558 & 236530 \\
\hline STATE & 241328 & 250188 & 202786 & 94576 & 93039 & 881917 \\
\hline TFPs & 318275 & 392793 & 378937 & 230790 & 162519 & 148313 \\
\hline GAP & 53825 & 114294 & 184493 & 220142 & 211724 & 784478 \\
\hline \multicolumn{7}{|c|}{ AREA 2 : Human capital,social protection and sustainable development } \\
\hline NSESD & 297540 & 447930 & 367514 & 289466 & 236568 & 1639017 \\
\hline OBTAINED & 233415 & 308974 & 238832 & 108383 & 74767 & 964369 \\
\hline STATE & 126902 & 149865 & 123649 & 64387 & 55339 & 520143 \\
\hline TFPs & 106513 & 159108 & 115183 & 43996 & 19428 & 444227 \\
\hline GAP & 64125 & 138956 & 128682 & 181084 & 161802 & 674648 \\
\hline \multicolumn{7}{|c|}{ AREA 3 : Governance, institutions, peace and security } \\
\hline NSESD & 82461 & 78465 & 76485 & 56199 & 56348 & 349957 \\
\hline OBTAINED & 80411 & 73715 & 69660 & 47424 & 44873 & 316082 \\
\hline STATE & 63709 & 47672 & 42061 & 33565 & 31014 & 218019 \\
\hline TFPs & 16702 & 26043 & 27600 & 13859 & 13859 & 98063 \\
\hline GAP & 2050 & 4750 & 6825 & 8775 & 11475 & 33875 \\
\hline \multicolumn{7}{|l|}{ Overall Total } \\
\hline NSESD & 993428 & 1283669 & 1210216 & 891172 & 760197 & 5138682 \\
\hline OBTAINED & 873428 & 1025669 & 890215 & 481172 & 375197 & 3645682 \\
\hline STATE & 431939 & 447725 & 368496 & 192528 & 179392 & 1620079 \\
\hline TFPs & 441490 & 577944 & 521719 & 288645 & 195806 & 2025603 \\
\hline GAP & 120000 & 258000 & 320000 & 410000 & 385000 & 1493001 \\
\hline
\end{tabular}

TFPs = Technical and Financial Partners 
Annex 3: Distribution of financing according to the sub-sectors (in millions of CFAF), 2013-2017

\begin{tabular}{|c|c|c|c|c|c|c|c|}
\hline $\begin{array}{r}\text { Sub-sector } \\
\text { sector }\end{array}$ & $\begin{array}{l}\text { Financing } \\
\text { Method }\end{array}$ & 2013 & 2014 & 2015 & 2016 & 2017 & Total \\
\hline \multicolumn{8}{|c|}{ AREA 1 : Growth, productivity and wealth creation } \\
\hline \multirow[t]{5}{*}{ Agriculture } & NSESD AMOUNT & 82215 & 87979 & 97725 & 182570 & 167750 & 618239 \\
\hline & OBTAINED & 77117 & 74186 & 74505 & 128945 & 124112 & 478865 \\
\hline & STATE & 51624 & 47884 & 39015 & 17254 & 17104 & 172881 \\
\hline & TFPs & 25493 & 26302 & 35490 & 111691 & 107008 & 305983 \\
\hline & GAP & 5098 & 13793 & 23220 & 53625 & 43638 & 139374 \\
\hline \multirow[t]{5}{*}{ Handicrafts } & NSESD AMOUNT & 6185 & 6600 & 7220 & 7858 & 7758 & 35620 \\
\hline & OBTAINED & 1135 & 1200 & 1470 & 2608 & 2508 & 8920 \\
\hline & STATE & 920 & 1200 & 1470 & 2608 & 2508 & 8705 \\
\hline & TFPs & 215 & - & - & - & - & 215 \\
\hline & GAP & 5050 & 5400 & 5750 & 5250 & 5250 & 26700 \\
\hline \multirow[t]{5}{*}{ Trade } & NSESD AMOUNT & 5264 & 2989 & 3623 & 701 & 696 & 13273 \\
\hline & OBTAINED & 2593 & 2293 & 2917 & - & - & 7803 \\
\hline & STATE & 2353 & 2153 & 2917 & - & - & 7423 \\
\hline & TFPs & 240 & 140 & - & - & - & 380 \\
\hline & GAP & 2671 & 696 & 706 & 701 & 696 & 5470 \\
\hline \multirow{5}{*}{$\begin{array}{l}\text { Communication, telecom } \\
\text { infrastructure and services }\end{array}$} & NSESD AMOUNT & 10605 & 15053 & 18665 & 1925 & 1825 & 48073 \\
\hline & OBTAINED & 10055 & 13773 & 17490 & 825 & 525 & 42668 \\
\hline & STATE & 9055 & 8273 & 4490 & 825 & 525 & 23168 \\
\hline & TFPs & 1000 & 5500 & 13000 & - & - & 19500 \\
\hline & GAP & 550 & 1280 & 1175 & 1100 & 1300 & 5405 \\
\hline \multirow{5}{*}{$\begin{array}{l}\text { Intl coop, regional } \\
\text { integration }\end{array}$} & NSESD & 690 & 21285 & 30735 & 31775 & 10204 & 94689 \\
\hline & OBTAINED & 515 & 535 & 535 & 264 & 79 & 1927 \\
\hline & STATE & 440 & 460 & 460 & 229 & 79 & 1667 \\
\hline & TFP & 75 & 75 & 75 & 35 & - & 260 \\
\hline & GAP & 175 & 20750 & 30200 & 31512 & 10125 & 92762 \\
\hline \multirow[t]{5}{*}{ Culture } & NSESD AMOUNT & 2320 & 3020 & 3703 & 5480 & 5280 & 19803 \\
\hline & OBTAINED & 2300 & 2420 & 2453 & - & - & 7173 \\
\hline & STATE & 2300 & 2420 & 2453 & - & - & 7173 \\
\hline & TFP & - & - & - & - & - & - \\
\hline & GAP & 20 & 600 & 1250 & 5480 & 5280 & 12630 \\
\hline \multirow[t]{5}{*}{ Animal production } & NSESD AMOUNT & 14040 & 20092 & 23758 & 21827 & 16872 & 96589 \\
\hline & OBTAINED & 10487 & 13230 & 13631 & 12360 & 11710 & 61418 \\
\hline & STATE & 5570 & 7406 & 6185 & - & - & 19161 \\
\hline & TFP & 4917 & 5824 & 7446 & 12360 & 11710 & 42257 \\
\hline & GAP & 3553 & 6862 & 10127 & 9467 & 5162 & 35171 \\
\hline \multirow[t]{5}{*}{ Employment } & NSESD AMOUNT & 351 & 806 & 2666 & 2525 & 625 & 6973 \\
\hline & OBTAINED & 101 & 106 & 141 & - & - & 348 \\
\hline & STATE & 101 & 106 & 141 & - & - & 348 \\
\hline & TFP & - & - & - & - & - & - \\
\hline & GAP & 250 & 700 & 2525 & 2525 & 625 & 6625 \\
\hline Water agriculture & NSESD AMOUNT & 48642 & 77337 & 83869 & 28502 & 27422 & 265772 \\
\hline & OBTAINED & 48642 & 77337 & 83649 & 28252 & 27202 & 265082 \\
\hline & STATE & 11748 & 13223 & 12187 & 1200 & 1200 & 39558 \\
\hline & TFP & 36894 & 64114 & 71462 & 27052 & 26002 & 225524 \\
\hline & GAP & - & - & 220 & 250 & 220 & 690 \\
\hline Industry and agri-food & NSESD AMOUNT & 11455 & 15521 & 19005 & 12927 & 13400 & 72308 \\
\hline & OBTAINED & 10205 & 11021 & 11730 & 5202 & 3125 & 41283 \\
\hline & STATE & 3080 & 5130 & 5930 & 3125 & 3125 & 20390 \\
\hline & TFP & 7125 & 5891 & 5800 & 2077 & - & 20893 \\
\hline & GAP & 1250 & 4500 & 7275 & 7725 & 10275 & 31025 \\
\hline Financial Infrastructure & NSESD AMOUNT & 3368 & 2900 & 2469 & 1409 & 1102 & 11248 \\
\hline and Financial & OBTAINED & 3318 & 2900 & 2469 & 1409 & 1102 & 11198 \\
\hline Services & STATE & 831 & 822 & 270 & 1409 & 1102 & 4434 \\
\hline & TFP & 2 & 2 & 2199 & - & - & 6764 \\
\hline
\end{tabular}




\begin{tabular}{|c|c|c|c|c|c|c|c|}
\hline $\begin{array}{c}\text { Sub- } \\
\text { sectors/Areas }\end{array}$ & Financing & 2013 & 2014 & 2015 & 2016 & 2017 & Total \\
\hline & GAP & 50 & - & - & - & 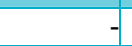 & 50 \\
\hline \multirow{5}{*}{$\begin{array}{l}\text { Infrastructure and transport } \\
\text { services }\end{array}$} & NSESD AMOUNT & 244425 & 288741 & 302407 & 164052 & 137897 & 1137522 \\
\hline & OBTAINED & 244325 & 266641 & 246447 & 98022 & 42261 & 897696 \\
\hline & STATE & 109758 & 110645 & 79500 & 40261 & 40261 & 380425 \\
\hline & TFP & 134567 & 155996 & 166947 & 57761 & 2000 & 517271 \\
\hline & GAP & 100 & 22100 & 55960 & 66030 & 95636 & 239826 \\
\hline \multirow{5}{*}{$\begin{array}{l}\text { Infrastructure and energy } \\
\text { services }\end{array}$} & NSESD AMOUNT & 146933 & 168263 & 119857 & 19126 & 18546 & 472724 \\
\hline & OBTAINED & 121138 & 148023 & 93672 & 11921 & 11391 & 386144 \\
\hline & STATE & 30598 & 37102 & 34464 & 5055 & 4525 & 111744 \\
\hline & TFP & 90540 & 110921 & 59208 & 6866 & 6866 & 274400 \\
\hline & GAP & 25795 & 20240 & 26185 & 7205 & 7155 & 86580 \\
\hline \multirow[t]{5}{*}{ Mines and quarries } & NSESD AMOUNT & 1467 & 1600 & 1800 & 2842 & 3042 & 10751 \\
\hline & OBTAINED & 417 & 200 & 200 & - & - & 817 \\
\hline & STATE & 298 & 200 & 200 & - & - & 698 \\
\hline & TFP & 119 & - & - & - & - & 119 \\
\hline & GAP & 1050 & 1400 & 1600 & 2842 & 3042 & 9934 \\
\hline \multirow{5}{*}{$\begin{array}{l}\text { Fisheries and } \\
\text { Aquaculture }\end{array}$} & NSESD AMOUNT & 11278 & 15124 & 16698 & 10693 & 5678 & 59471 \\
\hline & OBTAINED & 11028 & 12924 & 14148 & 7893 & 3878 & 49871 \\
\hline & STATE & 3698 & 3324 & 3111 & 2378 & 2378 & 14889 \\
\hline & TFP & 7330 & 9600 & 11037 & 5515 & 1500 & 34982 \\
\hline & GAP & 250 & 2200 & 2550 & 2800 & 1800 & 9600 \\
\hline \multirow{5}{*}{$\begin{array}{l}\text { Research, } \\
\text { Development and } \\
\text { Innovation }\end{array}$} & NSESD AMOUNT & 2598 & 2210 & 3287 & 1415 & 2862 & 12372 \\
\hline & OBTAINED & 565 & 845 & 805 & - & - & 2215 \\
\hline & STATE & 565 & 845 & 805 & - & - & 2215 \\
\hline & TFP & - & - & - & - & - & - \\
\hline & GAP & 2033 & 1365 & 2482 & 1415 & 2862 & 10157 \\
\hline \multirow[t]{5}{*}{ Private sector } & NSESD AMOUNT & 11436 & 13099 & 13986 & 26965 & 26308 & 91794 \\
\hline & OBTAINED & 6836 & 7649 & 8026 & 18558 & 18558 & 59627 \\
\hline & STATE & 5490 & 5253 & 5253 & 17500 & 17500 & 50996 \\
\hline & TFP & 1346 & 2396 & 2773 & 1058 & 1058 & 8631 \\
\hline & GAP & 4600 & 5450 & 5960 & 8407 & 7750 & 32167 \\
\hline \multirow[t]{5}{*}{ Food security } & NSESD AMOUNT & 1050 & 2400 & 2400 & 2900 & - & 8750 \\
\hline & OBTAINED & - & - & - & - & - & - \\
\hline & STATE & - & - & - & - & - & - \\
\hline & TFP & - & - & - & - & - & - \\
\hline & GAP & 1050 & 2400 & 2400 & 2900 & - & 8750 \\
\hline \multirow[t]{5}{*}{ Sports } & NSESD AMOUNT & 6572 & 5050 & 5300 & 500 & 500 & 17922 \\
\hline & OBTAINED & 6522 & 4800 & 4800 & - & - & 16122 \\
\hline & STATE & 2250 & 2800 & 2800 & - & - & 7850 \\
\hline & TFP & 4272 & 2000 & 2000 & - & - & 8272 \\
\hline & GAP & 50 & 250 & 500 & 500 & 500 & 1800 \\
\hline \multirow[t]{5}{*}{ Tourism } & NSESD AMOUNT & 2534 & 7205 & 7043 & 19517 & 19517 & 55816 \\
\hline & OBTAINED & 2304 & 2897 & 2635 & 9109 & 9109 & 26054 \\
\hline & STATE & 649 & 942 & 1135 & 2733 & 2733 & 8192 \\
\hline & TFP & 1655 & 1955 & 1500 & 6376 & 6376 & 17862 \\
\hline & GAP & 230 & 4308 & 4408 & 10408 & 10408 & 29762 \\
\hline \multicolumn{8}{|c|}{ AXE 2 : Human capital, social protection and sustainable development } \\
\hline \multirow{5}{*}{$\begin{array}{l}\text { Safe drinking water and sanitation } \\
\text { (EPA) }\end{array}$} & NSESD AMOUNT & 47893 & 81283 & 57405 & 91068 & 79747 & 357395 \\
\hline & OBTAINED & 42023 & 68933 & 44655 & 13711 & 12491 & 181812 \\
\hline & STATE & 12419 & 14544 & 14405 & 1220 & - & 42588 \\
\hline & TFP & 29604 & 54389 & 30250 & 12491 & 12491 & 139224 \\
\hline & GAP & 5870 & 12350 & 12750 & 77357 & 67256 & 175583 \\
\hline \multirow[t]{4}{*}{ Education and training } & NSESD AMOUNT & 73562 & 92398 & 71998 & 57614 & 45164 & 340735 \\
\hline & OBTAINED & 70124 & 82391 & 61357 & 47858 & 34689 & 296418 \\
\hline & STATE & 42190 & 57595 & 50686 & 41879 & 34645 & 226994 \\
\hline & TFP & 27934 & 24796 & 10671 & 5979 & 44 & 69424 \\
\hline
\end{tabular}




\begin{tabular}{|c|c|c|c|c|c|c|c|}
\hline $\begin{array}{c}\text { Sub- } \\
\text { sectors/areas }\end{array}$ & Financing methods & 2013 & 2014 & 2015 & 2016 & 2017 & Total \\
\hline & GAP & 3438 & 10007 & 10641 & 9756 & 10475 & 44317 \\
\hline \multirow[t]{5}{*}{ Environment } & NSESD AMOUNT & 12644 & 19935 & 19656 & 3700 & 3700 & 59635 \\
\hline & OBTAINED & 11404 & 16335 & 16131 & 200 & 200 & 44270 \\
\hline & STATE & 4896 & 6465 & 6709 & 200 & 200 & 18470 \\
\hline & TFP & 6508 & 9870 & 9422 & - & - & 25800 \\
\hline & GAP & 1240 & 3600 & 3525 & 3500 & 3500 & 15365 \\
\hline \multirow{5}{*}{$\begin{array}{l}\text { Habitat and Living } \\
\text { environment }\end{array}$} & NSESD AMOUNT & 59273 & 116650 & 106031 & 48537 & 23237 & 353727 \\
\hline & OBTAINED & 25101 & 36363 & 45845 & 13937 & 6437 & 127682 \\
\hline & STATE & 22101 & 20163 & 19345 & 3808 & 3808 & 69225 \\
\hline & TFP & 3000 & 16200 & 26500 & 10129 & 2629 & 58457 \\
\hline & GAP & 34172 & 80287 & 60186 & 34600 & 16800 & 226045 \\
\hline \multirow{5}{*}{$\begin{array}{l}\text { Population and sustainable } \\
\text { human development }\end{array}$} & NSESD AMOUNT & 125 & 350 & 450 & 450 & 300 & 1675 \\
\hline & OBTAINED & - & - & - & - & - & - \\
\hline & STATE & - & - & - & - & - & - \\
\hline & TFP & - & - & - & - & - & - \\
\hline & GAP & 125 & 350 & 450 & 450 & 300 & 1675 \\
\hline \multirow[t]{5}{*}{ Social protection } & NSESD AMOUNT & 35023 & 49078 & 49378 & 26900 & 23798 & 184176 \\
\hline & OBTAINED & 28373 & 33566 & 30466 & 9529 & 5927 & 107861 \\
\hline & STATE & 16033 & 16671 & 16039 & 5432 & 4913 & 59087 \\
\hline & TFP & 12340 & 16895 & 14427 & 4098 & 1015 & 48774 \\
\hline & GAP & 6650 & 15512 & 18912 & 17371 & 17871 & 76315 \\
\hline \multirow{5}{*}{ Risks and Disasters } & NSESD AMOUNT & 5522 & 12054 & 11586 & 12457 & 12057 & 53676 \\
\hline & OBTAINED & 5342 & 9754 & 9236 & 9857 & 9857 & 44046 \\
\hline & STATE & 5342 & 9754 & 9236 & 9857 & 9857 & 44046 \\
\hline & TFP & - & - & - & - & - & - \\
\hline & GAP & 180 & 2300 & 2350 & 2600 & 2200 & 9630 \\
\hline \multirow[t]{5}{*}{ Health Nutrition } & NSESD AMOUNT & 63499 & 76181 & 51010 & 48742 & 48567 & 287999 \\
\hline & OBTAINED & 51049 & 61631 & 31142 & 13292 & 5167 & 162281 \\
\hline & STATE & 23922 & 24673 & 7229 & 1992 & 1917 & 59733 \\
\hline & TFP & 27127 & 36958 & 23913 & 11300 & 3250 & 102548 \\
\hline & GAP & 12450 & 14550 & 19868 & 35450 & 43400 & 125718 \\
\hline \multicolumn{8}{|c|}{ AXE 3 : Gouvernance, institutions, paix et sécurité } \\
\hline \multirow{5}{*}{$\begin{array}{l}\text { Public Administration } \\
\text { And State } \\
\text { Reform }\end{array}$} & NSESD AMOUNT & 4592 & 3818 & 3459 & 3835 & 3835 & 19538 \\
\hline & OBTAINED & 4542 & 3718 & 3434 & 3835 & 3835 & 19363 \\
\hline & STATE & 4542 & 3718 & 3434 & 3835 & 3835 & 19363 \\
\hline & TFP & - & - & - & - & - & - \\
\hline & GAP & 50 & 100 & 25 & - & - & 175 \\
\hline \multirow{5}{*}{$\begin{array}{l}\text { Land-use planning, } \\
\text { Local development } \\
\text { andTerritorialisation }\end{array}$} & NSESD AMOUNT & 16320 & 18200 & 20094 & 9790 & 12790 & 77194 \\
\hline & OBTAINED & 15545 & 16950 & 17444 & 5290 & 5290 & 60519 \\
\hline & STATE & 14040 & 14040 & 14040 & - & - & 42120 \\
\hline & TFP & 1505 & 2910 & 3404 & 5290 & 5290 & 18399 \\
\hline & GAP & 775 & 1250 & 2650 & 4500 & 7500 & 16675 \\
\hline \multirow[t]{5}{*}{ Gender andEquity } & NSESD AMOUNT & 3845 & 7327 & 8150 & 6884 & 5809 & 32015 \\
\hline & OBTAINED & 3820 & 7277 & 8150 & 6884 & 5809 & 31940 \\
\hline & STATE & 2770 & 2827 & 2800 & 4065 & 2990 & 15452 \\
\hline & TFP & 1050 & 4450 & 5350 & 2819 & 2819 & 16488 \\
\hline & GAP & 25 & 50 & - & - & - & 75 \\
\hline \multirow{5}{*}{$\begin{array}{l}\text { Strategic, economic and } \\
\text { financial governance }\end{array}$} & NSESD AMOUNT & 7504 & 7263 & 8427 & 1758 & 1758 & 26709 \\
\hline & OBTAINED & 7254 & 6063 & 6727 & 58 & 58 & 20159 \\
\hline & STATE & 5814 & 2370 & 2370 & 58 & 58 & 10669 \\
\hline & TFP & 1440 & 3693 & 4357 & - & - & 9490 \\
\hline & GAP & 250 & 1200 & 1700 & 1700 & 1700 & 6550 \\
\hline \multirow{4}{*}{$\begin{array}{l}\text { Justice, Human rights and } \\
\text { Rule of law }\end{array}$} & NSESD AMOUNT & 6309 & 4978 & 4700 & 2497 & 1762 & 20245 \\
\hline & OBTAINED & 5659 & 4153 & 3600 & 1397 & 662 & 15470 \\
\hline & STATE & 4533 & 2953 & 2203 & 1397 & 662 & 11747 \\
\hline & TFP & 1126 & 1200 & 1397 & - & - & 3723 \\
\hline
\end{tabular}




\begin{tabular}{|l|l|r|r|r|r|r|r|}
\hline $\begin{array}{l}\text { Sub- } \\
\text { sectors/areas }\end{array}$ & $\begin{array}{l}\text { Method of } \\
\text { Financing } \mathrm{t}\end{array}$ & 2013 & 2014 & 2015 & 2016 & 2017 \\
\hline & GAP & 650 & 825 & 1100 & 1100 & 1100 \\
\hline Peace and security & NSESD AMOUNT & 43891 & 36879 & 31656 & 31436 & 30395 & 174257 \\
\hline & OBTAINED & 43591 & 35554 & 30306 & 29961 & 29220 & 168632 \\
\hline & STATE & 32010 & 21764 & 17214 & 24211 & 23470 & 118669 \\
\hline & TFP & 11581 & 13790 & 13092 & 5750 & 5750 & 49963 \\
\hline
\end{tabular}




\section{$1^{\text {st }}$ prioritization phase Grading the actions}

To determine NSESD priorities, the actions of strategic objectives are subjected to an evaluationgrid comprising dichotomic variations which ask whether the action has a

\section{direct impact on:}

$>$ Criterion 1 : economic growth;

$>$ Criterion 2 : Improving the business climate.

$>$ Criterion 3 : improving public financemanagement

$>$ Criterion 4 : job creation

$>$ Criterion 5 : reduction of inequalities

$>$ Criterion 6 : local development ;

$>$ Criterion 7 : significant improvement of the population's living conditions

$>$ Criterion 8 : good sectoral governance

Every time an action meets a given criterion, the modality of the concerned variabletakes value 1.

The reverse corresponds to 0 . Each criterion is weighted according to the table below:

\begin{tabular}{|c|c|c|c|c|c|c|c|c|}
\hline Criteria & Criterion 1 & Criterion2 & Criterion 3 & Criterion 4 & Criterion 5 & Criterion 6 & Criterion 7 & Criterion 8 \\
\hline Weighting & $20 \%$ & $7 \%$ & $5 \%$ & $8 \%$ & $10 \%$ & $12 \%$ & $30 \%$ & $8 \%$
\end{tabular}

This weighting reflects the political vision and helps mitigate the effect of transversality of less urgent actions. The criteria are not mutually exclusive.

Each action is given a total score $\left(\mathrm{S}_{\mathrm{a}}\right)$ by adding up the product of modalities of each criterion through the corresponding weighting. This overall score is therefore a weighted average. Thus, the higher the score $\left(\mathrm{S}_{\mathrm{a}}\right)$, the more the action in question earns in terms of priority. A type of automatic rankingis used to classify the actions according to total scores and in classes :It is specifically about the dynamic clouds method.

The number of classes required is three (3). i.e.kthis number.The first stage of the algorithm consists in choosing the kcentres of departure. The centres were imposed. A conventional allocation algorithm is then applied. It is reiterated until convergence is reached i.e. (persistence of subsets of observations which are formed each time.) The iteration process determined the three final stable centres of classes.

\section{$2^{\text {nd }}$ prioritization phase selection of action plans}

Ideally, when the economic context is difficult, the actions of the top priority class should be maintained and implemented. They represent the nucleus of the fundamental action plan that should necessarily be prioritized within the framework of a pessimistic scenario. The combinations of priority 1 actions with those of priority 2 form the core of intermediary action plans. The global action plan corresponds to the integration of all scheduled actions, moving theoretically from top priority actions to low priority actions.

The first two stages helped draw up a classification based on a grid for the evaluation of actions

It was mentioned that their results form the nucleus of action plans. The latter are to be materialized by projects, programmes or measures. The third stage should integrate the indications of the macroeconomic framework fixing the budget that should comply with the consolidated scenarios. After a series of sectoral consultations, consensus was reached on the different scenarios of the framework with the sectoral entities, notably the technical services, by organizing projects and programmes according to the desired rank.

\section{$3^{\text {rd }}$ prioritization phase: application of action plans and reasoned selection of scenarios}

An improved planning logic would require the constitution of scenarios on the basis of action plans set forth in the second prioritization phase. Then, through an iterative process, the macroeconomic framework would examine the balance between the budget earmarked by the second phase, on the one hand, and the growth objectives and the respect of commitments, on the other. On the basis of this principle, the approach proclaimed by the current budget programming establishes the three scenarios namely trend, pessimistic and optimistic scenarios. 
Annex 5: Matrix of measures, 2013-2017.

NB: Top priority actions are in bold characters. Average priority actions are in normal characters. Minor priorityactions are in italics.

The strategic objectives begin with verbs in the infinitive. They contain the lines of action or measures. The subsectors or fields are underlined in yellow.

\begin{tabular}{|c|c|}
\hline Code & AREA 1: Growth, productivity and wealth creation \\
\hline SS-1 & Agriculture \\
\hline OS-1 & Improve the steering system of the agricultural sub-sector \\
\hline LA-1 & $\begin{array}{l}\text { Adoption of a new land reform taking into account the rural registry and the equitable access ofactors } \\
\text { to land ownership }\end{array}$ \\
\hline LA-2 & $\begin{array}{l}\begin{array}{l}\text { Preparation and implementation of an } \\
\text { plan//schémadirecteurdesstatistiques agricoles }\end{array}\end{array}$ \\
\hline LA-3 & Establishment of a harmonized gender-sensitive monitoring-evaluation system \\
\hline LA-4 & Strengthening the intervention capacities of supportstructures \\
\hline LA-5 & $\begin{array}{l}\text { Strengthening dialogue between the State, professional organizations and other actors ( NG0, } \\
\text { Local Governments, etc.) }\end{array}$ \\
\hline OS-2 & Increase production and improve agricultural productivity \\
\hline LA-6 & Improve risk and disaster management to reduce the vulnerability of agricultural activities \\
\hline LA-7 & Support to the marketing of agricultural and market gardening products \\
\hline LA-8 & Support and development of agricultural research \\
\hline LA-9 & $\begin{array}{l}\text { Development of production support infrastructure (roads, feeder roads, stores, } \\
\text { electrification. etc.) }\end{array}$ \\
\hline LA-10 & Sustainable land management \\
\hline LA-11 & Modernization of equipment used by farmers \\
\hline LA-12 & Promotion of emergence poles and Common Agricultural Areas (DAP) \\
\hline LA-13 & Lay out and development of agricultural fields \\
\hline LA-14 & Improving producers' access to agricultural credit adapted to their needs \\
\hline LA-15 & Improving equitable access to seeds and other inputs of quality at profitable price \\
\hline LA-16 & $\begin{array}{l}\text { Strengthening the capacities of male and female producers (support-advice in certification, } \\
\text { information, training,agricultural advice }\end{array}$ \\
\hline LA-17 & Restoring deteriorated land \\
\hline LA-18 & Organizing agricultural sub-sectors \\
\hline SS-2 & Handicrafts \\
\hline OS-3 & Modernize handicrafts and make its products competitive \\
\hline LA-19 & Facilitating access to financingof handicraft projects \\
\hline LA-20 & $\begin{array}{l}\text { Promoting and encouraging the creation of specialized and subsidized art galleries for exhibitions and } \\
\text { exports }\end{array}$ \\
\hline LA-21 & Control and consolidation of distribution circuits \\
\hline LA-22 & Strengthening the productive base and input and handicrafts equipment supply system \\
\hline LA-23 & Strengthening the capacity of craftsmen including their professionalization \\
\hline LA-24 & $\begin{array}{l}\text { Strengthening State and non-State mechanisms and instruments for the steering of the handicraft } \\
\text { develooment policv }\end{array}$ \\
\hline LA-25 & $\begin{array}{l}\text { Repositioning handicrafts on high-value-added production niches with the development } \\
\text { of a "brand" strategv }\end{array}$ \\
\hline SS-3 & Trade \\
\hline OS-4 & Strengthening the institutional framework and implementation of sectoral policies \\
\hline LA-26 & Establishing a sectoral steering mechanism \\
\hline
\end{tabular}




\begin{tabular}{|c|c|}
\hline Code & AREA 1: Growth, productivity and wealth creation \\
\hline LA-27 & Professionalization of marketing actors and businesses \\
\hline OS-5 & Strengthen the capacities to supply goods and services \\
\hline LA-28 & Restructure the distribution channels \\
\hline LA-29 & Construction of modern marketing infrastructure geographically well distributed \\
\hline LA-30 & Import control \\
\hline LA-31 & Promoting access to local and international markets \\
\hline LA-32 & Promoting exports and e-commerce \\
\hline SS-4 & Communication, telecommunication infrastructure and services \\
\hline OS-6 & Democratize the access and use of ICT \\
\hline LA-33 & Training and sensitizing the population about the opportunities offered by the sector; \\
\hline OS-7 & Develop the digital economy \\
\hline LA-34 & Support to the emergence ofthe ICT industry \\
\hline LA-35 & Creation of technological poles and consolidation of ICT business incubators \\
\hline LA-36 & Preparation and implementation of a national strategy for the development of the digital economy \\
\hline LA-37 & Extension towards a globallicence for all providers \\
\hline LA-38 & Implementation of incentives within the framework of the law on the information society \\
\hline OS-8 & Promoting good audiovisual governance \\
\hline LA-39 & Adoption of a new Press Code, and appropriate legislative and regulatory texts and instruments \\
\hline LA-40 & Support capacity building among journalists and other Communication actors \\
\hline LA-41 & Upgrade the national radio broadcasting system to meet international standards \\
\hline LA-42 & Promotion of education, cultural, economic, and medical content in audiovisual production \\
\hline OS-9 & Promote good digital governance \\
\hline LA-43 & Improving the functioning of the administration with on-line services \\
\hline LA-44 & Preparation of a National Geomatics Plan (PNG) \\
\hline $\mathrm{LA}-45$ & Extension and consolidation of regulatory and observation missions \\
\hline OS-10 & Reduce the digital divide \\
\hline LA-46 & Creation and consolidation of spaces for access to information and knowledge \\
\hline LA-47 & Development of the universal telecommunications service \\
\hline LA-48 & Setting up ICT access facilities \\
\hline LA-49 & Completing the passage from analogue to digital audiovisual \\
\hline LA-50 & Promoting very high-speed Internet connection \\
\hline SS-5 & International cooperation, regional integration and Senegalese Abroad (SE) \\
\hline OS-11 & Foster regional integration \\
\hline LA-51 & Development and intensification of intra-community trade \\
\hline LA-52 & Encourage specialization based on the comparative advantages of States for a coherent integration \\
\hline LA-53 & Pursuing the implementation of regional economic programmes \\
\hline LA-54 & Rehabilitation and development of the infrastructure network \\
\hline LA-55 & Removing obstacles to the free movement of persons, goods and services \\
\hline OS-12 & Develop a proactive economic diplomacy \\
\hline LA-56 & Reform and rationalizethe diplomatic map including the improvement of the quality of services \\
\hline OS-13 & Develop a proactive sub-regional diplomacy \\
\hline LA-57 & Participatory and all-inclusive preparation and implementation of development policies \\
\hline LA-58 & Set up community monitoring system \\
\hline
\end{tabular}




\begin{tabular}{|c|c|}
\hline Code & AREA 1: Growth, productivity and wealth creation \\
\hline LA-59 & Joint negotiations at WTO for more equitable trade rules \\
\hline LA-60 & $\begin{array}{l}\text { Strengthening consultations on migration issues between neighbouring countries, in particular Mali, } \\
\text { and Europe }\end{array}$ \\
\hline OS-14 & Involve Senegalese Abroad in national development efforts \\
\hline LA-61 & Improving the management of migration statistics on Senegalese Abroad \\
\hline LA-62 & Promoting the transfer of knowledge and know-how of Senegalese Abroad \\
\hline LA-63 & Propagating productive investment opportunities among Senegalese Abroad \\
\hline SS-6 & Culture \\
\hline OS-15 & Increase the volume and quality of culturalproduction \\
\hline LA-64 & Reactivate cultural activities at the grassroots, notably among Sports and Cultural Associations (ASC) \\
\hline LA-65 & Improving access to credit for proponents of cultural projects \\
\hline LA-66 & Support the organization of major cultural events \\
\hline LA-67 & Construction and rehabilitation of developmental cultural facilities \\
\hline LA-68 & Creating conditions favourable to a creative economy \\
\hline LA-69 & Promoting thefilm, audiovisual and printing industry \\
\hline LA-70 & Promote intellectual property and artistic rights and fight against piracy \\
\hline LA-71 & Reactivating cultural poles at local level(cultural decentralization) \\
\hline LA-72 & Strengthen the involvement of private parties in cultural promotion \\
\hline LA-73 & Enhancement ofthe cultural diversity of our country \\
\hline OS-16 & Strengthen the steering of the cultural sub-sector \\
\hline LA-74 & Decentralization of cultural services \\
\hline LA-75 & Organization and regular upgrading of cultural statistics \\
\hline LA-76 & Professionalization of cultural actors \\
\hline LA-77 & Reform of the Senegalese Copyright Office \\
\hline OS-17 & Develop the cultural potential and natural assets \\
\hline LA-78 & Creation of a solidarity fund for retired artists \\
\hline SS-7 & Livestock production \\
\hline OS-18 & Step up the production, productivity and competitiveness of livestock production \\
\hline LA-79 & Improving livestock production \\
\hline LA-80 & Improve agriculture-livestock production integration and promote forage crops and pasture land \\
\hline LA-81 & Improving the marketing conditions of livestock by-products \\
\hline LA-82 & Improving and preserve animal health \\
\hline LA-83 & Developing pastoral boreholes, retention basins and ponds \\
\hline LA-84 & Intensifying and developing poultry production \\
\hline LA-85 & Fight against livestock theft to secure the livestock \\
\hline LA-86 & Seting up a pastoral insurance system \\
\hline LA-87 & Preservation and management of agro-pastoral ressources \\
\hline LA-88 & Promotion of modern animal production units \\
\hline LA-89 & Improving the access of livestock producers to suitable credit \\
\hline LA-90 & Strengthening pastoral infrastructure and equipment \\
\hline LA-91 & Strengthening the genetic potential of local breeds \\
\hline OS-19 & Improve sectoral steering of livestock production \\
\hline LA-92 & Improving the legislative and regulatoryframework \\
\hline
\end{tabular}




\begin{tabular}{|c|c|}
\hline Code & AREA 1: Growth, productivity and wealth creation \\
\hline LA-93 & Improving the monitoring-evaluation system of the livestock production sub-sector \\
\hline LA-94 & Support to professional organizations \\
\hline LA-95 & Strengthening the intervention c a pacities of competent technical services \\
\hline SS-8 & Employment \\
\hline OS-20 & Improve the monitoring and management of the labour market \\
\hline LA-96 & $\begin{array}{l}\text { Setting up the national employment and professional qualifications observatory and operationalize the } \\
\text { trades and occupations directory }\end{array}$ \\
\hline LA-97 & Setting up an employment information system \\
\hline LA-98 & $\begin{array}{l}\text { Setting up a national Setting up a national system to evaluate technical and vocational training and } \\
\text { validate professional experience }\end{array}$ \\
\hline LA-99 & Organizing and upgrading the informal sector \\
\hline LA-100 & Regulating the labour market and rationalizing project funding structures \\
\hline OS-21 & Promote massive job creation \\
\hline LA-101 & Supporting the creation of jobs for youths in growth sectors \\
\hline LA-102 & Supportingthe reintegration of workers who lose their jobs \\
\hline LA-103 & $\begin{array}{l}\text { Supporting the integration and reintegration of military and paramilitary personnel released from active } \\
\text { service }\end{array}$ \\
\hline LA-104 & Supporting integration/reintegration initiatives of Senegalese emigrants \\
\hline LA-105 & Supporting and facilitating access to funding of young project proponents \\
\hline LA-106 & $\begin{array}{l}\text { Facilitating the integration of youths in the employment market and reactivate the national } \\
\text { State-Employer convention }\end{array}$ \\
\hline LA-107 & Implementing incentive measures to encourage investments and job creation in the private sector \\
\hline LA-108 & Promoting the employment of vulnerable groups particularly in the Public Service \\
\hline LA-109 & Promoting self-employment among youths by capitalizing on their skills \\
\hline LA-110 & Promoting labour-intensive public investments (HIMO) \\
\hline SS-9 & Agricultural water \\
\hline OS-22 & Harness surface and underground water for primary sector activities \\
\hline LA-111 & $\begin{array}{l}\text { Construction of developmental hydro-agricultural infrastructure (dams, retention basisn, hill } \\
\text { reservoirs, feeders and emissaries) }\end{array}$ \\
\hline LA-112 & Water control and improving hydro-agricultural facilities \\
\hline LA-113 & Protecting fresh surface and underground water from marine salt and pollution \\
\hline LA-114 & Transferring excess water to dry areas \\
\hline LA-115 & Using excess flows from rural boreholes for small irrigation \\
\hline SS-10 & Industry and agro-food processing \\
\hline OS-23 & Improve the competitiveness of food processing industry \\
\hline LA-116 & Supporting agro-industrial and agro-food research \\
\hline LA-117 & $\begin{array}{l}\text { Supporting the development of units and industries active in the processing of productions of } \\
\text { the primary sector }\end{array}$ \\
\hline LA-118 & Promoting agro-business in the processing of local products to create asub-regional champion \\
\hline LA-119 & Strengthening the technial and managerial capacities of agri-food processing professionals \\
\hline OS-24 & Boost endogenous industrial development \\
\hline LA-120 & Improving the industrial policy monitoring-evaluation system \\
\hline LA-121 & Supporting the creation of SMI for the fabrication of equipment and tools \\
\hline LA-122 & Establishing multi-purpose community production workshops in the rural and periurban areas \\
\hline LA-123 & Spatial polarization of industrial development \\
\hline
\end{tabular}




\begin{tabular}{|c|c|}
\hline Code & AREA 1: Growth, productivity and wealth creation \\
\hline OS-25 & Strengthen the competitiveness of industries \\
\hline LA-124 & Improving service offer to investors \\
\hline LA-125 & Supporting the upgrading of industries \\
\hline LA-126 & Supporting SMI's access to financing \\
\hline LA-127 & Setting up a technological watch system \\
\hline LA-128 & Strengthening standardisation and the culture of performance \\
\hline LA-129 & Strengthening SMI capacities on industrial property \\
\hline SS-11 & Financial Infrastructure and Services \\
\hline OS-26 & Improve microfinance environment \\
\hline LA-130 & Improving the information and management systems of Decentralized Financial Systems (DFS) \\
\hline LA-131 & Setting up a Risk Division for DFS \\
\hline LA-132 & Promoting appropriate guarantee systems for DFS \\
\hline LA-133 & Strengthening the financial structure of DFS \\
\hline LA-134 & Strengthening the regional legal and regulatory microfinance framework \\
\hline OS-27 & Diversify and adapt the offer of financial products and services \\
\hline LA-135 & Improving access of DFS to non-financialservices and technical support \\
\hline LA-136 & Development of new payment methods (Money transfer,e-payment) \\
\hline LA-137 & Facilitating the access of youths and women to credit \\
\hline LA-138 & Promoting the savings culture \\
\hline LA-139 & Promoting Islamic finance \\
\hline LA-140 & Strengthening the presence of microfinance institutions in the rural ares \\
\hline SS-12 & Transport Infrastructure and Services \\
\hline OS-28 & Developing and modernizing transport services \\
\hline LA-141 & Stepping up risk prevention linked to all forms of pollution \\
\hline LA-142 & Improving and ensuring the security of inland waterways \\
\hline LA-143 & Developing a modern public transport system in majorcities \\
\hline LA-144 & Facilitating transportation in the corridors \\
\hline LA-145 & Strengthening the competitiveness of Dakar Port \\
\hline LA-146 & Renewing and consolidating public transport vehicle parks \\
\hline OS-29 & Developing road, rail, airport and port infrastructure \\
\hline LA-147 & Improving the security and safety of air transport and monitoringh the activities of SA \\
\hline LA-148 & Construction of airports \\
\hline LA-149 & Construction and rehabilitation of rail infrastructure \\
\hline LA-150 & Construction and rehabilitation of roadsand structures \\
\hline LA-151 & Construction, rehabilitation and maintenance of feeder roads in production zones \\
\hline LA-152 & Modernizing bus stations \\
\hline LA-153 & Modernizing airport infrastructure \\
\hline LA-154 & Conducting technical studies for all transport infrastructure projects/programmes \\
\hline LA-155 & Reactivating river and sea transport \\
\hline LA-156 & Strengthening port platform infrastructure \\
\hline OS-30 & Promote good governance in the transport sector \\
\hline LA-157 & Preparation of a Ports Code \\
\hline LA-158 & Reinforcing road security \\
\hline
\end{tabular}




\begin{tabular}{|c|c|}
\hline Code & AREA1: Growth, productivity and wealth creation \\
\hline LA-159 & Strengthening des capacités des acteurs et du pilotage du sub-sector \\
\hline SS-13 & Energy Infrastructure and services \\
\hline OS-31 & Improving the management framework of the energy sub-sector \\
\hline LA-160 & Improving the regulation \\
\hline LA-161 & Pursuing the institutional reform of SENELEC \\
\hline LA-162 & Strengthening the energy information system(SIE) \\
\hline OS-32 & Facilitateaccess to energy services \\
\hline LA-163 & Accelerating rural electrification \\
\hline LA-164 & Increasing renewable energy offer \\
\hline LA-165 & Improving access to hydrocarbons and domestic energy \\
\hline LA-166 & Increasing electricityproduction capacities \\
\hline LA-167 & integrating photovoltaic solar energy in structures and public buildings \\
\hline LA-168 & Intensifying the promotion and exploration of the sedimentary basin \\
\hline LA-169 & Promoting sub-regional and regional cooperation in energy through interconnection \\
\hline LA-170 & Promotinf Public-Private Partnership in energy \\
\hline LA-171 & Rehabilitation and modernization of transport anddistribution infrastructure \\
\hline LA-172 & Securing storage capacities and conditions \\
\hline OS-33 & Promote energy control and saving \\
\hline LA-173 & Promoting the use of energy-saving household appliances \\
\hline LA-174 & Promoting energy saving and substitution equipment \\
\hline SS-14 & Mines and quarries \\
\hline OS-34 & Increase productiona $\mathrm{nd}$ i $\mathrm{mprove}$ the productivityo f mines and quarries \\
\hline LA-175 & Strengthening of infrastructure supporting geological and mining activities \\
\hline LA-176 & Simplifying mining rights and permit processing procedures \\
\hline LA-177 & Supportingquarry operators \\
\hline LA-178 & Reinforcing national private sector involvement in the exploitation of mines and quarries \\
\hline OS-35 & Promote the participatory and all-inclusive management extractive activities \\
\hline LA-179 & Improving transparency in the management of contracts \\
\hline LA-180 & Increasing the spin-offs of extractive activitiesfor the local communities and surrounding populations \\
\hline LA-181 & Creation of clusters, in regions with a strong mining orientation, to polarize miningactivities \\
\hline LA-182 & Supervising the local populations involved in mining activities \\
\hline LA-183 & Promoting mining exploration \\
\hline LA-184 & $\begin{array}{l}\text { Reducing the effects of mining and quarryexploitation on the environment and health of the } \\
\text { localpopulations }\end{array}$ \\
\hline OS-36 & Step up the competitiveness of the Senegalese mining sector \\
\hline LA-185 & Strengthening actors of the mining sub-sector \\
\hline SS-15 & Fisheries and aquaculture \\
\hline OS-37 & Improve the production et la productivity of fisheries and aquaculture \\
\hline LA-186 & Facilitating access to credit for actors \\
\hline LA-187 & Facilitating the creation of fish feedproduction units \\
\hline LA-188 & Establishing basic infrastructure for the development of continental fisheries and aqua culture \\
\hline LA-189 & Promoting sustainable fisheries for consumption and commercial purposes \\
\hline LA-190 & Promoting applied research in fisheries and aqua culture \\
\hline
\end{tabular}




\begin{tabular}{|c|c|}
\hline Code & AREA 1: Growth, productivity and wealth creation \\
\hline LA-191 & Reduction of post-catch losses in small-scale fishing \\
\hline LA-192 & Strengthening the technical and organizational capacities of local professionals and institutions \\
\hline OS-38 & Sustainably manage the fishery resource \\
\hline LA-193 & Keeping the catching capacity under control \\
\hline LA-194 & Implementing the fisheries development plans \\
\hline LA-195 & Promoting joint management in the small-scale fishery sector \\
\hline LA-196 & Promoting a policy for the restoration and restocking of degraded ecosystems \\
\hline LA-197 & $\begin{array}{l}\text { Regulating access to fisheries resources (biological recovery, renegotiating fisheries agreements, } \\
\text { regulating fishing methods) }\end{array}$ \\
\hline OS-39 & Boost the fisheries and fish farming production \\
\hline LA-198 & $\begin{array}{l}\text { Improving the conditions of market access and competitiveness of the industrial processing sub- } \\
\text { sector }\end{array}$ \\
\hline LA-199 & Creating incubation platforms for the processing of fishery products \\
\hline LA-200 & installation of biotechnological laboratories in the fish farming zones \\
\hline LA-201 & Stepping up the technical level of non-industrial processing \\
\hline LA-202 & Restructuring the \\
\hline SS-17 & Research, Development and Innovation \\
\hline OS-41 & Promote Research \& Development \\
\hline LA-204 & Progressive increase in the Research \& Development budget \\
\hline LA-205 & Strengthening south-south and north-north scientific cooperation in R\&D \\
\hline OS-42 & Make full use of research results \\
\hline LA-206 & Establishing a national scientific and technical information system \\
\hline LA-207 & Transferring knowledge and strengthening public-private partnership in R\&D \\
\hline LA-208 & transferring technology to the rural areas including the development of op e rational units \\
\hline SS-18 & Private sector \\
\hline OS-43 & Improve the business environment \\
\hline LA-209 & Implementing decisions of the Presidential Investors' Council \\
\hline LA-210 & Promoting the creation and development of businesses by women \\
\hline LA-211 & Promoting youth entrepreneurship \\
\hline LA-212 & Strengthening the share of national private capital in the economy \\
\hline OS-44 & Consolidate the technical support and steering mechanism \\
\hline LA-213 & Improving Public-Private Dialogue (DPP) \\
\hline LA-214 & Supporting the creation of service providing companies in each integrated economic pole \\
\hline LA-215 & Supporting the creation of modern companies for the development of wood and metal \\
\hline LA-216 & Consolidation of the information system on investments notably on female entrepreneurship \\
\hline LA-217 & $\begin{array}{l}\text { Creation of a« Small Businesses and SME-SMI Pact »integrating and strengthening business support } \\
\text { mechanisms }\end{array}$ \\
\hline LA-218 & Reactivation of industrial parks \\
\hline LA-219 & Setting up an observatory of SME \\
\hline LA-220 & Promoting the quality process in businesses through stardardization and certification \\
\hline LA-221 & Promoting business incubators in all departements \\
\hline LA-222 & Rationalizing the private sector support mechanism \\
\hline LA-223 & Revising the investors' code \\
\hline LA-224 & Monitoring the"Business demography" \\
\hline
\end{tabular}




\begin{tabular}{|c|c|}
\hline Code & AXES 1: Growth, productivity and wealth creation \\
\hline OS-45 & Facilitate access to financial and non-financial services \\
\hline LA-225 & Creating the Priority Investments Guarantee Fund (FONGIP) \\
\hline LA-226 & Creating a Sovereign Stratregic Investment Fund (FONSIS) \\
\hline LA-227 & Supporting businesses in difficulty \\
\hline LA-228 & Finalising the consultations on credit \\
\hline LA-229 & Strengthening the capacities of private sector actors \\
\hline LA-230 & Increasing funds dedicated to women entrepreneurs \\
\hline SS-19 & Food security \\
\hline OS-46 & Strengthen the food crisis prevention and management system \\
\hline LA-231 & Support to the reinforcement of food security \\
\hline LA-232 & Strengthening the Eraly warning System (SAP) \\
\hline LA-233 & $\begin{array}{l}\text { Strengthening the agricultural market information system including the use of the Improved Harmonized } \\
\text { Framework }\end{array}$ \\
\hline OS-87 & Improve access to a healthy and nutritious food \\
\hline LA-453 & Promoting food diversity \\
\hline LA-454 & Strengthening the resilience of vulnerable segments \\
\hline SS-20 & Sports \\
\hline OS-47 & Promote sports and related activities \\
\hline LA-234 & $\begin{array}{l}\text { Construction of modern sports complexes, sports facilities and rehabilitation of regional } \\
\text { stadiums }\end{array}$ \\
\hline LA-235 & Developing sports in schools and fostering the sports culture \\
\hline LA-236 & Promoting sports companies and related activities \\
\hline LA-237 & Improving sports management mechanisms \\
\hline SS-21 & Tourism \\
\hline OS-48 & Promote an enhanced structuring and improve the tourism product quality \\
\hline LA-238 & Stepping up knowledge of and control over the national tourist potential or wealth \\
\hline LA-239 & Improving the conditions of reception and security of tourists at Dakar Airport and in tourist sites \\
\hline LA-240 & Development of the Pointe Sarène, Mbodiène, Joal Finio, Grande Côte,Saloum Islands sites \\
\hline LA-241 & Creating conditions conducive to private investment (judicial, fiscal, financial facilities and tourism regulation) \\
\hline LA-242 & Construction of developmental infrastructure and leisure facilities in tourist sites \\
\hline LA-243 & $\begin{array}{l}\text { Diversification of the quality tourist product using regional potentials and the multisectoral initiatives } \\
\text { For sustainable communitv develonment }\end{array}$ \\
\hline LA-244 & $\begin{array}{l}\text { Preparation and implementation of instruments for the orientation, monitoring and evaluation of the } \\
\text { policy touristique }\end{array}$ \\
\hline LA-245 & Ensuring that tourist accomodation facilities comply with the required standards \\
\hline LA-246 & Promoting a communication and marketing system \\
\hline LA-247 & Regulating the tourist offer \\
\hline LA-248 & Redesignating the Saly, Saint-Louis and Cap-Skiring holiday resorts \\
\hline
\end{tabular}

\begin{tabular}{|l|l|}
\hline \multicolumn{1}{|c|}{ Code } & AREA 2: Human capital, social protection and sustainable development \\
\hline SS-22 & Safe drinking water and sanitation(EPA) \\
\hline OS-49 & Improve the populations' access to safe drinking water in urbain and rural areas \\
\hline LA-249 & Improving the water quality in the Central regions \\
\hline
\end{tabular}


National Strategy for Economic and Social Developme

\begin{tabular}{|c|c|}
\hline Code & AREA 2: Human capital, social protection and sustainable development \\
\hline LA-250 & $\begin{array}{l}\text { Construction and rehabilitation of boreholes and storage and water supply structures in the } \\
\text { rural and periurban areas by making use ofmilitary engineering }\end{array}$ \\
\hline LA-251 & $\begin{array}{l}\text { Generalizing access (inparticular, subsidized connections and improving safe drinking water } \\
\text { supply in the urban areas }\end{array}$ \\
\hline OS-50 & Develop sanitation in the urban and rural areas \\
\hline LA-252 & Construction and rehabilitation of sewage systems in the urban and periurban areas \\
\hline LA-253 & Construction and rehabilitation of sewage systems in urban and periurban areas \\
\hline LA-254 & Construction and strengthening ofwaste water treatment and depollution system in major cities \\
\hline LA-255 & Extension of rainwater drainage system in urbancentres \\
\hline LA-256 & Implementing the reform of the water and sanitation sub-sector \\
\hline LA-257 & Constructing collective excreta disposal facilities in the rural areas \\
\hline OS-51 & Promoting good governance in the safe drinking water and sanitation sub-sector \\
\hline LA-258 & Promoting ecocitizenship at community level \\
\hline LA-259 & Rationalizing water consumption \\
\hline LA-260 & Conducting identification studies for the implementation of the PEP2025 \\
\hline LA-261 & Strengthening the logistics and human means of the health squad \\
\hline LA-262 & Revising the pricing system in the urban areas \\
\hline OS-52 & Promote the integrated and sustainable management of water resources \\
\hline LA-263 & Improving the participatory and all-inclusive management of water resources and structures \\
\hline LA-264 & Evaluation of the water potential in the Maestrichtien geological layer \\
\hline LA-265 & Protection and conservation of strategic water reserves, in particular,'lac de Guiers' \\
\hline SS-23 & Education and training \\
\hline OS-53 & Improve the quality of teaching and apprenticeship \\
\hline LA-266 & Improving the training environment \\
\hline LA-267 & Construction/equipment and rehabilitation of colleges, high schools, institutes and universities \\
\hline LA-268 & Reformingthe teachers' initial and continuing training system and curricula \\
\hline OS-54 & Develop efficient, effective and all-inclusivegovernance of the educationsystem \\
\hline LA-269 & Improving public expenditure efficiency \\
\hline LA-270 & Supporting private education structures \\
\hline LA-271 & Construction and equipment of school and departmental Inspectorates in the new regions \\
\hline LA-272 & Création d'un système d'information pour le pilotage du sector \\
\hline LA-273 & Décentralisation et déconcentration de la gestion des programmes éducatifs \\
\hline LA-274 & Evaluation permanente de la qualité des enseignements à tous les niveaux \\
\hline LA-275 & $\begin{array}{l}\text { Setting up an all-inclusive framework for dialogue to ensure better participation of actors (public, } \\
\text { private) of the education system in educational policies and programmes }\end{array}$ \\
\hline LA-276 & Management of those excluded from the education system \\
\hline LA-277 & Strengthening the capacities of the administrative staff \\
\hline OS-55 & Eradicating illiteracy and promoting national languages \\
\hline LA-278 & Codification of national languages and promotion of terminological research \\
\hline LA-279 & Construction and equipment of Non-Formal Education (ENF) structures \\
\hline LA-280 & Diversification of Non-Formal Education(ENF) offer \\
\hline LA-281 & Promoting national languages in basic education and literacy programmes \\
\hline OS-56 & Integrate apprenticeship in the vocational and technical training system \\
\hline LA-282 & Training trainers and trainees \\
\hline
\end{tabular}




\begin{tabular}{|c|c|}
\hline Code & AREA 2: Human capital, social protection and sustainable development \\
\hline LA-283 & Training through apprenticeship in Daaras \\
\hline LA-284 & Strengthening the vocational training of women \\
\hline OS-57 & Establish a 10-year basic education cycle \\
\hline LA-285 & Improving the teaching environment in the CDIPE training \\
\hline LA-286 & Improving the environment in schools and Daraas \\
\hline LA-287 & Supporting alternative DIPE structures (community centres,franco-arabedaaras...) \\
\hline LA-288 & Rigorous targeting of education offer \\
\hline LA-289 & Consolidating the basics in the fundamental subjects (Reading,Mathematics, Science, Civic Education) \\
\hline LA-290 & $\begin{array}{l}\text { Construction, rehabilitation and equipment of DIPE structures with a suitable environment for } \\
\text { persons with motor disability, notably the promotion of miltary engineering interventions }\end{array}$ \\
\hline LA-291 & Supplying the required textbooks to students \\
\hline LA-292 & Training of primary school teachers \\
\hline LA-293 & Maintaining girls and boys beyond the basic cycle \\
\hline LA-294 & Reforming the existing flow chart \\
\hline OS-58 & Promote vocational training oriented towards the job market \\
\hline LA-295 & $\begin{array}{l}\text { Adaptating the vocational training offer to the demand for emplyment in partnership with the } \\
\text { private sector }\end{array}$ \\
\hline LA-296 & $\begin{array}{l}\text { Construction, rehabilitation and equipment of high schools and vocational and technical } \\
\text { training centres }\end{array}$ \\
\hline LA-297 & Setting up aprofessional university in each development pole \\
\hline LA-298 & Developing and decentralizing vocational and continuing training \\
\hline LA-299 & Diversification of training courses \\
\hline LA-300 & Orientation, registration and maintenance of children, notably girls, in science courses \\
\hline LA-301 & Promoting girls' access to industrial and technological filières industrielles et technologiques \\
\hline LA-302 & Regulating the number of applications \\
\hline SS-24 & Environment \\
\hline OS-59 & Mitigating the effects of climate change on the ecosystems \\
\hline LA-303 & Development of community forests and rational management offorest resources \\
\hline LA-304 & Biodiversity conservation and management of humid areas //zones humides \\
\hline LA-305 & Formulating national policiesresilient to climate change \\
\hline LA-306 & Ecological management of chemical products and waste \\
\hline LA-307 & Coastal erosion control \\
\hline LA-308 & $\begin{array}{l}\text { Fight against bush fire, deforestation and degradation of land,notably the installation of fire breaks by } \\
\text { the military engineering elements }\end{array}$ \\
\hline LA-309 & Promoting the preservation and management of natural resources by local communities \\
\hline LA-310 & Systematizing prior environmental evaluation \\
\hline OS-60 & Promote green economy \\
\hline LA-311 & Promoting green economy and creating green jobs \\
\hline OS-61 & Make the rural ecosystem less vulnerable to the effects of climate change \\
\hline LA-312 & Developing agro-sylvo-pastoral activities and promoting private investments \\
\hline LA-313 & Fight against air and water pollution \\
\hline OS-62 & Strengthen capacitiesto manage the Environment and NaturalResources \\
\hline LA-314 & Productionand dissemination of information on the state of the environment and naturalresources \\
\hline LA-315 & Promoting environmental education \\
\hline
\end{tabular}




\begin{tabular}{|c|c|}
\hline Code & AREA 2: Human capital, social protection and sustainable development \\
\hline LA-316 & Strengthening the capacities of environmental actors \\
\hline SS-26 & Habitat and Living Environment \\
\hline OS-64 & Improve the quality of the living environment in the urbain and rural areas \\
\hline LA-319 & Improving the management of solid and liquid waste \\
\hline LA-320 & Developing leisure facilities and sites \\
\hline LA-321 & Laying out lakes \\
\hline LA-322 & Participation of military engineering elements in works of public interest \\
\hline OS-65 & Ensure better planning and management ofspace in cities and other towns \\
\hline LA-323 & Creation systematic lay out of green spaces/parks and farming areas inurban areas \\
\hline LA-324 & Promoting social housing and concerted development \\
\hline LA-325 & Updating and generalizing SRAT, SDAU, PDU, POS \\
\hline LA-326 & Gradual reduction of shanty towns and fight against illegal occupation and congestion \\
\hline LA-327 & Systematizing building permits and stepping upsecurity in application of the BuildingCode \\
\hline os-66 & Flood control \\
\hline LA-328 & Evacuation of rainwater \\
\hline LA-329 & Involving the military engineering in flood mangement \\
\hline LA-330 & Ban on land plotting in non-habitable areas \\
\hline LA-331 & Flood prevention and resettling persons living inlow and non aedificandi zones \\
\hline OS-67 & Promote good governance and monitoring evaluation tools of the sectoral policy \\
\hline LA-332 & Strengthening the capacities of technical services and other actors \\
\hline LA-333 & $\begin{array}{l}\text { Strengthening the system set up to minitor, assist and advice the local authorities in the exercise of transferred } \\
\text { competence }\end{array}$ \\
\hline SS-27 & Population and sustainable humandevelopment \\
\hline OS-68 & Reinforce the implementation and monitoring of population policies \\
\hline LA-334 & Supporting organs coordinating and monitoring the implementation of the nationa lpopulation policy \\
\hline LA-335 & Developing IEC/advocacy strategies for voluntary birth control \\
\hline LA-336 & Developing technical tools (methodological models andguides) \\
\hline LA-337 & Modernizing registration and the use of birth registry data \\
\hline SS-16 & Social protection \\
\hline OS-69 & Improve the socio-economic conditions of vulnerablegroups \\
\hline LA-338 & Improving access of the disabled to wheel chairs \\
\hline LA-339 & Support to the elderly \\
\hline LA-340 & Consolidation and extension of social transfer mechanisms \\
\hline LA-341 & Facilitating the access of vulnerable groups to resources and production factors \\
\hline LA-342 & Caring for invalids and disabled soldiers \\
\hline LA-343 & Caring for war orphans \\
\hline LA-344 & Strengthening the system for the social reintegration of vulnerable groups \\
\hline os-70 & Extend the social protection to the informal sector and vulnerable groups \\
\hline LA-345 & $\begin{array}{l}\text { Improving targeting mechanisms and setting up an information and monitoring- } \\
\text { Evaluation system }\end{array}$ \\
\hline LA-346 & Creating a 'Caisse Autonome de Social protection Universelle (CAPSU) \\
\hline LA-347 & Extendingfree health care to vulnerable groups (plan sésame, caesarean section, hemodialysis, etc.) \\
\hline LA-348 & Enforcing the social orientation law for the protection of the disabled \\
\hline
\end{tabular}




\begin{tabular}{|c|c|}
\hline Code & AREA 2: Human capital, social protection and sustainable development \\
\hline LA-349 & $\begin{array}{l}\text { Instituting social protection schemes adapted to each profession ( cultural actors, craftsmen, } \\
\text { Farmers, livestock producers, etc.) }\end{array}$ \\
\hline LA-350 & Setting up a health solidarity fund \\
\hline LA-351 & Instituting a basic universal health cover through the health mutual \\
\hline OS-40 & Strengthen the social security of Workers and Pensioners \\
\hline LA-352 & Improving social security benefits \\
\hline LA-353 & Fighta aganst social evasion \\
\hline LA-203 & Readjusting the income level of some categories of workers \\
\hline LA-354 & Reform of the institutional and judicial framework ofsocial security \\
\hline LA-355 & Popularization of the Social DialogueCharter \\
\hline SS-28 & Risks and Disasters \\
\hline OS-71 & Improve natural disaster management \\
\hline LA-356 & Preparation and implementation of specific intervention Plans \\
\hline LA-357 & Instituting a emergency intervention fund \\
\hline LA-358 & Setting up a mechanism for assistance and compensation of disastervictims \\
\hline LA-359 & Setting up a multisectoriel crisis management body \\
\hline LA-360 & Strengthening the capacity of civil protection actors \\
\hline OS-72 & Prevent and reduce major disaster risks \\
\hline LA-361 & Stepping up security for the transport of hazardous materials \\
\hline LA-362 & Construction and equipment in infrastructure for Civil Protection actors \\
\hline LA-363 & Displacement of populations installed in high-risk areas \\
\hline LA-364 & Development of contingency plans at national and regional level \\
\hline LA-365 & Curbing major industrial accidents \\
\hline LA-366 & Setting up an early warning system for natural diasters \\
\hline LA-367 & Operationalizing the multisectoral platform for disaster risk reduction \\
\hline LA-368 & Promoting the culture of disaster risk prevention and management \\
\hline SS-29 & Health andNutrition \\
\hline OS-73 & Improve health governance \\
\hline LA-369 & Improving the efficiency and efficacy of public expenditure on health \\
\hline LA-370 & Improving the health policies monitoring-evaluation system \\
\hline LA-371 & Improving the health policies monitoring-evaluation system \\
\hline LA-372 & Strengthening the medical surveillance system \\
\hline OS-74 & Improve mother and child health \\
\hline LA-373 & Improving the child's vaccina coverage \\
\hline LA-374 & Improving rural women's access to health care \\
\hline LA-375 & Providing health care to the newly born infant \\
\hline LA-376 & Providing free pre and post-natal consultations \\
\hline LA-377 & Promoting family planning \\
\hline LA-378 & $\begin{array}{l}\text { Promoting delivery in approved health facilities in particular assistance during delivery by } \\
\text { aualified attendants }\end{array}$ \\
\hline OS-75 & Improve performance in the prevention and fight against disease \\
\hline LA-379 & Improving the accessibility of drugs (ARV)to Persons Living with HIV(PLWHIV) \\
\hline LA-380 & Preventing the transmission of HIV and other transmissible diseases \\
\hline LA-381 & Prevention and management of chronic diseases \\
\hline
\end{tabular}




\begin{tabular}{|c|c|}
\hline Code & AREA 2: Human capital, social protection and sustainable development \\
\hline LA-382 & Strengthening the capacities of the staff to diagnose and properly monitor cases of tuberculosis \\
\hline OS-76 & Improve the nutritional state of mother and child \\
\hline LA-383 & Increasing the coverage of children benefiting from nutrition services \\
\hline LA-384 & Promoting the diversity of the diet \\
\hline LA-385 & Promoting the nutrition of vulnerable groups(children under 05 years old and pregnant women ) \\
\hline OS-77 & Improve the health offer and service quality \\
\hline LA-386 & Adoption of a national plan for the supply of basic drugs \\
\hline LA-387 & Improvingthe quality of health services \\
\hline LA-388 & Supporting the development of the pharmaceutical industry \\
\hline LA-389 & Construction and rehabilitation of health infrastructure \\
\hline LA-390 & Developing the community approch in the promotion of health \\
\hline LA-391 & Promoting generic drugs \\
\hline LA-392 & Recruiting qualified health personnel distributed equitably throughout the country \\
\hline LA-393 & $\begin{array}{l}\text { Upgrading the technical wherewithals of hospitals, healthcentres and health posts, including } \\
\text { equipment in cold chains for the Extended Immunization Programme(PEV) and generators }\end{array}$ \\
\hline LA-394 & Strengthening the involvement of the local authorities in health funding \\
\hline LA-395 & Strengthening garnison medical centres \\
\hline LA-396 & Strengthening garnison medical centres \\
\hline LA-397 & Strengthening means of evacuation \\
\hline LA-398 & Strengthening the geriatrics service \\
\hline
\end{tabular}

\begin{tabular}{|c|c|}
\hline Code & AREA 3: Governance, institutions, peace and security \\
\hline SS-30 & Public Administration and State Reform \\
\hline OS-78 & Improve public service quality \\
\hline LA-399 & Improving users' access to public service \\
\hline LA-400 & Modernizing human resource management \\
\hline LA-401 & Promoting a recruitment system based on merit \\
\hline LA-402 & Rationalizing recruitments in the public administration \\
\hline LA-403 & Rationalizing and reinforcing the decentralization of State structures \\
\hline LA-404 & Strengthening capacities to formulate, implement, evaluate and control public policies \\
\hline SS-31 & Land-Use Development, Local Development and Territorialization \\
\hline OS-79 & Promoting the viability of territories and development poles \\
\hline LA-405 & Updating and implementing the general land-use plan (PGAT) \\
\hline LA-406 & Development of integretd economic poles \\
\hline LA-407 & Reconfiguration of the territorial division plan in a participatory and consensual manner \\
\hline LA-408 & Territorialization of public policies \\
\hline LA-409 & Developing the potentials of eco-geographicentities \\
\hline OS-80 & Strengthen thecapacities of local governments \\
\hline LA-410 & Improving the financial, economicand fiscal framework of local authorities \\
\hline LA-411 & Full communalization intégrale \\
\hline LA-412 & Evaluation of the decentralization policy \\
\hline LA-413 & Promoting decentralized cooperation, notably exchanges between local authorities of theNorth \\
\hline
\end{tabular}




\begin{tabular}{|c|c|}
\hline Code & AXE 3: Gouvernance, institutions, peace and security \\
\hline & And the South- \\
\hline LA-414 & Promoting gender -sensitive budgets at the level of local community \\
\hline LA-415 & Strengthening transparency and efficiency in the management of local matters \\
\hline LA-416 & Strengthening the capacities of local authorities \\
\hline LA-417 & Substantial transfer of financial resources to local governments \\
\hline SS-25 & Gender andEquity \\
\hline OS-63 & Empower and promote women \\
\hline LA-418 & Strengthening of the capacities of institutions and local governments to mainstream gender in \\
\hline LA-317 & Strengthening the legal arrangements for theprotection of women and young girls \\
\hline LA-419 & Strengthening women's leadership and entrepreneurial capacities \\
\hline LA-318 & Strengthening partnership with internationalassociations andbodies \\
\hline SS-32 & Strategic, economic and financial governance \\
\hline OS-81 & Improve the management of public finance \\
\hline LA-420 & Improving public expenditure control \\
\hline LA-421 & Controlling and « rearranging » the public debt \\
\hline LA-422 & Modernizing and rationalizing the national tax system \\
\hline LA-423 & Poursuing the transposition and implementation of UEMOA directives on public finance \\
\hline LA-424 & Rationalizing the operating expenditure of the administration \\
\hline LA-425 & Strengthening the capacities of parliamentarians in the control of Government action \\
\hline LA-426 & Strengthening citizen control in the management of public affairs \\
\hline LA-427 & Strengthening the monitoring of external aid management \\
\hline LA-428 & implementation \\
\hline OS-82 & Improve economic governance \\
\hline LA-429 & Improving the quality of statistics production \\
\hline LA-430 & Fight against money laundering, corruption and non-transparency \\
\hline LA-431 & Strengthening public policy planning,monitoring and evaluation capacities \\
\hline OS-83 & Fight against corruption and non-transparency \\
\hline LA-432 & Preparationand implementation of a natonalstrategy on the prevention of corruption \\
\hline LA-433 & Harmonizing the internal legislation with the United Nations Convention against corruption \\
\hline LA-434 & Strengthening control organs, particularly OFNAC and the Audit Court \\
\hline SS-33 & Justice, Human Rights and Rule of Law \\
\hline OS-84 & Improve access to and the quality and efficiency of thejustice system \\
\hline LA-435 & Improving the minors management conditions \\
\hline LA-436 & Improving the conditions of stay in the prisons \\
\hline LA-437 & Reducing the duration of remanded custody \\
\hline LA-438 & Improving accessibility to community-based courts \\
\hline LA-439 & $\begin{array}{l}\text { Strengthening the institutional and human capacities of juridictions and central and decentralized } \\
\text { services }\end{array}$ \\
\hline LA-440 & Strengthening penalties for violation of the rights of women, children and minorities \\
\hline SS-34 & Peace and security \\
\hline OS-85 & Build lasting peace and social cohesion \\
\hline LA-441 & Fight against gender-based violence \\
\hline LA-442 & Organizing a national consultation on Casamance \\
\hline
\end{tabular}




\begin{tabular}{|c|c|}
\hline Code & AREA 3: Governance, institutions, peace and security \\
\hline LA-443 & Integrating thespecificities of the south in the public policies \\
\hline LA-444 & Promoting the culture of peace, concord and national solidarity \\
\hline LA-445 & Strengthening social dialogue \\
\hline OS-86 & Increasing the means of the security forces \\
\hline LA-446 & Extension of the community-based police \\
\hline LA-447 & Extension of the national identification system \\
\hline LA-448 & Fight against the proliferation and movement of small arms \\
\hline LA-449 & Strengthening the equipment and means of intervention ofsecurity forces \\
\hline LA-450 & Strengthening the means to fight against trafficking in drugs, narcotics and cybercrime and terrorism \\
\hline LA-451 & Strengthening the means to fight against trafficking in drugs, narcotics and cybercrime and terrorism \\
\hline LA-452 & Strengthening the staff and improving the continuing training of the military and paramilitary \\
\hline
\end{tabular}

